University of Louisville

ThinkIR: The University of Louisville's Institutional Repository

Electronic Theses and Dissertations

$5-2017$

\title{
Uncovering exceptional predictions using exploratory analysis of second stage machine learning.
}

Aneseh Alvanpour

University of Louisville

Follow this and additional works at: https://ir.library.louisville.edu/etd

Part of the Other Computer Engineering Commons

\section{Recommended Citation}

Alvanpour, Aneseh, "Uncovering exceptional predictions using exploratory analysis of second stage machine learning." (2017). Electronic Theses and Dissertations. Paper 2651.

https://doi.org/10.18297/etd/2651

This Master's Thesis is brought to you for free and open access by ThinkIR: The University of Louisville's Institutional Repository. It has been accepted for inclusion in Electronic Theses and Dissertations by an authorized administrator of ThinkIR: The University of Louisville's Institutional Repository. This title appears here courtesy of the author, who has retained all other copyrights. For more information, please contact thinkir@louisville.edu. 


\title{
UNCOVERING EXCEPTIONAL PREDICTIONS USING EXPLORATORY ANALYSIS OF SECOND STAGE MACHINE LEARNING
}

\author{
By \\ Aneseh Alvanpour \\ A Thesis \\ Submitted to the Faculty of the \\ J.B. Speed School of Engineering of the University of Louisville \\ in Partial Fulfillment of the Requirements \\ for the Degree of \\ Master of Science \\ in Computer Science \\ Department of Computer Engineering and Computer Science \\ University of Louisville \\ Louisville, Kentucky
}

May 2017 
Copyright 2017 by Aneseh Alvanpour

All rights reserved 



\title{
UNCOVERING EXCEPTIONAL PREDICTIONS USING EXPLORATORY ANALYSIS OF SECOND STAGE MACHINE LEARNING
}

\author{
By \\ Aneseh Alvanpour \\ A Thesis Approved on
}

April 25, 2017

by the following Thesis Committee:

Dr. Olfa Nasraoui, Thesis director

Dr. Hichem Frigui

Dr. Amir A. Amini 


\section{DEDICATION}

This thesis is dedicated to my parents,

Moones and Cyruse,

for their love, endless support and encouragement. 


\section{ACKNOWLEDGMENTS}

First and foremost, I want to thank my advisor Dr. Olfa Nasraoui for all her valuable guidance and support. This thesis would not have been possible without her time, ideas and encouragement. Also, I would like to thank other members of my committee Dr. Hichem Frigui and Dr. Amir A. Amini for their knowledge and contribution. My sincere thanks also go to the CECS department, especially Dr. Adel S. Elmaghraby., Dr. Mehmed Kantardzic and Dr. Ibrahim Imam for all their supports during my M.S. degree.

Last but not the least, I would like to thank my family and friends for their love and attentions. Special thanks to my parents, Moones and Cyruse, my lovely sister and brother-in-law, Anahita and Kamran and my little princess Artemis, and my beloved brothers, Arash and Arman, who gave me their unconditional support, love and encouragement through all this process. I will be grateful forever for their love. 


\title{
ABSTRACT \\ UNCOVERING EXCEPTIONAL PREDICTIONS USING EXPLORATORY ANALYSIS OF SECOND STAGE MACHINE LEARNING
}

\author{
Aneseh Alvanpour
}

April 25, 2017

Nowadays, algorithmic systems for making decisions are widely used to facilitate decisions in a variety of fields such as medicine, banking, applying for universities or network security. However, many machine learning algorithms are well-known for their complex mathematical internal workings which turn them into black boxes and makes their decision-making process usually difficult to understand even for experts.

In this thesis, we try to develop a methodology to explain why a certain exceptional machine learned decision was made incorrectly by using the interpretability of the decision tree classifier. Our approach can provide insights about potential flaws in feature definition or completeness, as well as potential incorrect training data and outliers. It also promises to help find the stereotypes learned by machine learning algorithms which lead to incorrect predictions and especially, to prevent discrimination in making socially sensitive decisions, such as credit decisions as well as crime-related and policing predictions. 


\section{TABLE OF CONTENTS}

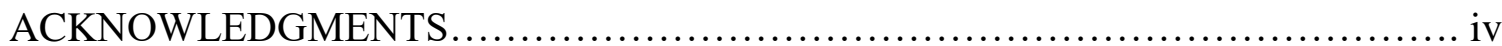

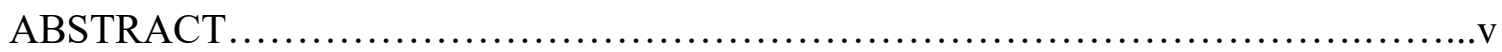

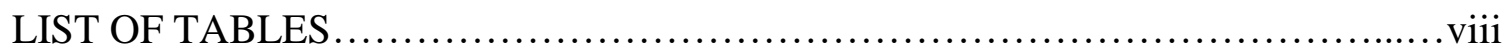

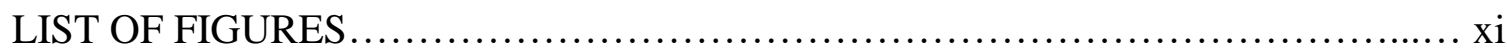

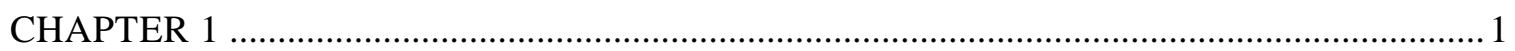

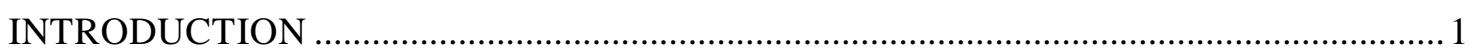

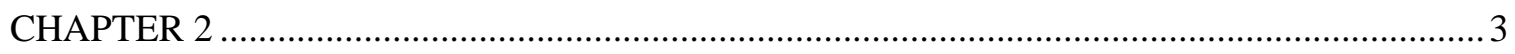

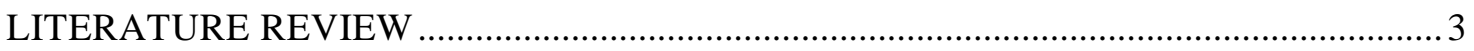

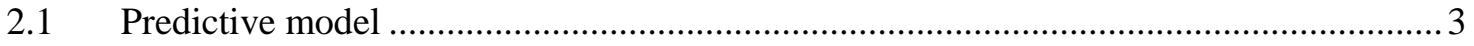

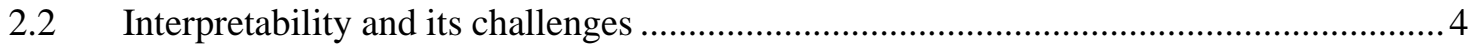

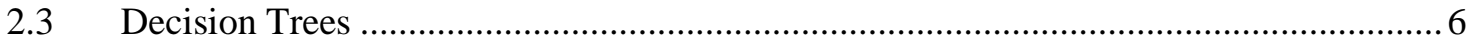

2.3.1 Decision Tree Learning Algorithms ….................................................................. 7

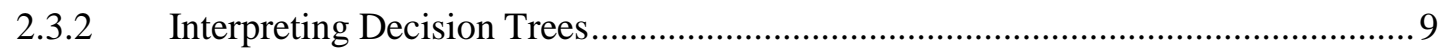

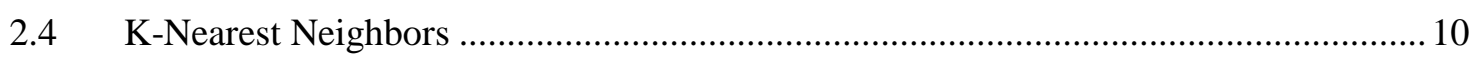

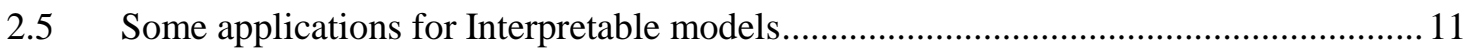

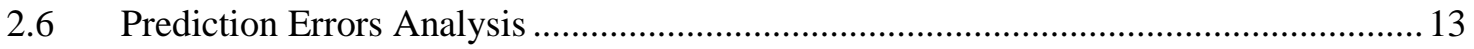

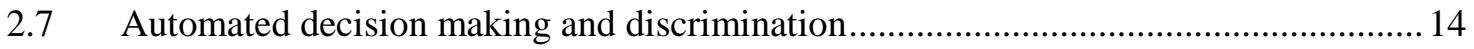

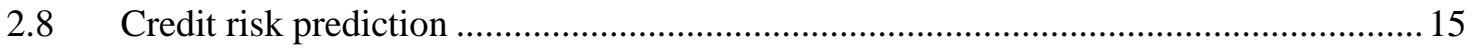

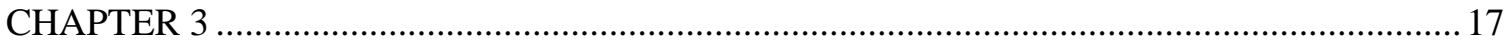

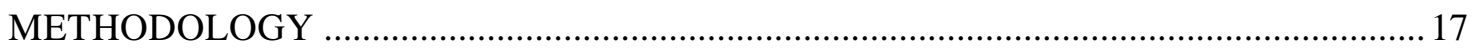

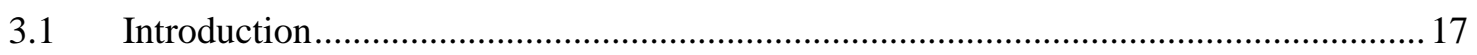

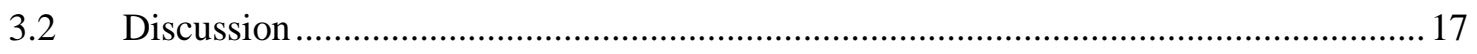

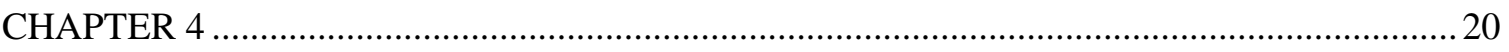

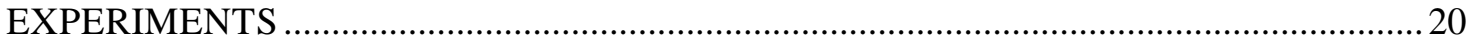

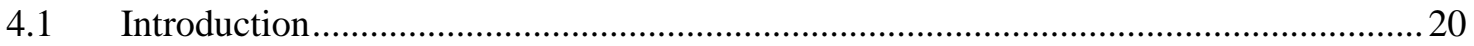

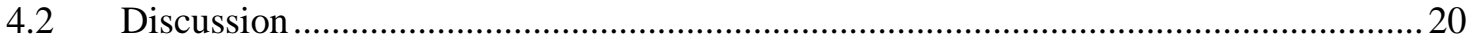

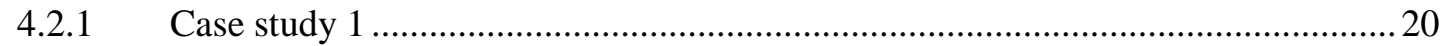

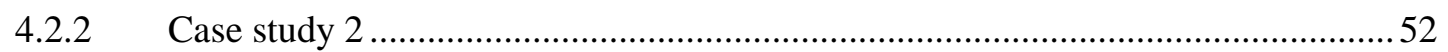




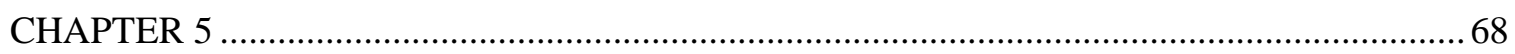

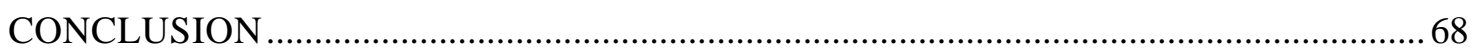

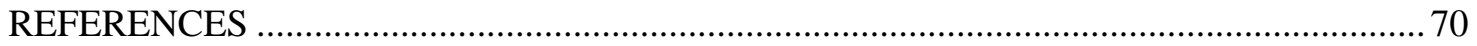

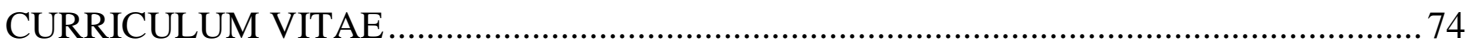




\section{LIST OF TABLES}

Table 2. 1 Pseudocode for C4.5 algorithm. 9

Table 4. 1 Summary of the Student Alcohol Consumption Data Set information[55]................. 21

Table 4. 2 Student Alcohol Consumption Data Set's Attribute Definition....................................21

Table 4. 3 Phase 1's D.T. Classifier, Finding the Optimal Depth and Best Accuracy Score ........ 23

Table 4. 4 Phase 1's D.T. Classifier, Comparing Classification Results with different Depths .... 24

Table 4. 5 Phase 1's D.T. Classifier's Classification results with Max_depth=2 ........................ 24

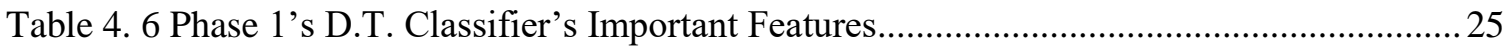

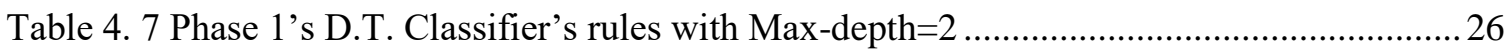

Table 4. 8 Number of misclassified data for testing data set in Phase 1 ......................................2

Table 4. 9 Number of test records that go through each node $*$ in the model. ...............................2 27

Table 4. 10 Phase 1's D.T. Classifier's paths and rules that lead to misclassification. .................28

Table 4. 11 Misclassified records which end at node 2 ("goout" $<=3.5$ and "absences" $<=26.5$ )

Table 4. 12 Misclassified records which end at node 5("goout" > 3.5 and "sex_M" $<=0.5$ ) .......29

Table 4. 13 Misclassified records which end at node 6("goout" > 3.5 and "sex_M" > 0.5) .........30

Table 4. 14 Phase 1's Prediction results for Testing data set....................................................... 31

Table 4. 15 Phase 1's Prediction results as "drinker" for Testing data set. ................................... 31

Table 4. 16 Phase 1's Prediction results as "nondrinker" for Testing data set .............................. 31

Table 4. 17 Splitting the Subset of data that was Predicted as "nondrinker" to training and testing

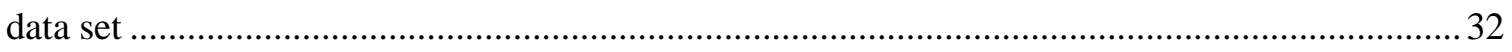

Table 4. 18 Phase 2's D.T. Classifier, Finding the Optimal Depth and Best Accuracy Score for the subset of data that was predicted as "nondrinker" in Phase 1........................................................ 32

Table 4. 19 Phase 2's D.T. Classifier, Comparing Classification Results with different Depths for

the subset that was predicted as "nondrinker" in Phase 1 ............................................................. 33

Table 4. 20 Phase 2's D.T. Classifier's Important features for the subset of data that was predicted

as "nondrinker" in Phase 1 with max_depth=2 2...................................................................... 34

Table 4. 21 Phase 2's D.T. Classifier's rules with Max_depth=2 for the subset of data that was

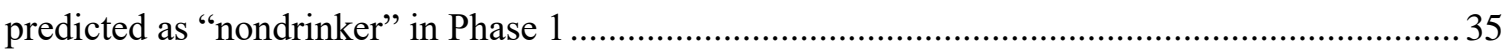

Table 4. 22 The record of data that predicted as "nondrinker" with class label "incorrect" from

Phase 1, which has been predicted to class label "incorrect" in Phase 2 ...................................... 36

Table 4. 23 Phase 2's D.T. Classifier's paths and rules that lead to misclassification for the subset

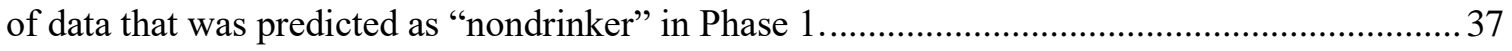

Table 4. 24 Splitting the Subset of data that was Predicted as "drinker" to training and testing data set 
Table 4. 25 Phase 2's D.T. Classifier, Finding the Optimal Depth and Best Accuracy Score for the

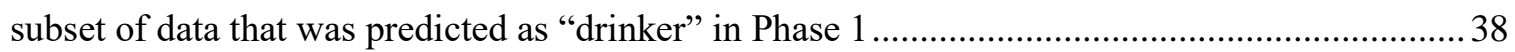
Table 4. 26 Phase 2's D.T. Classifier, Comparing Classification Results with different Depths for

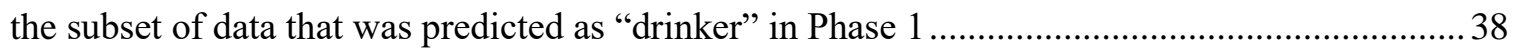
Table 4. 27 Phase 2's D.T. Classifier's Important features for the subset of data that was predicted as "drinker" in Phase 1 with max depth $=2$. 39

Table 4. 28 Phase 2's D.T. Classifier's rules with Max_depth=2 for the subset of data that was

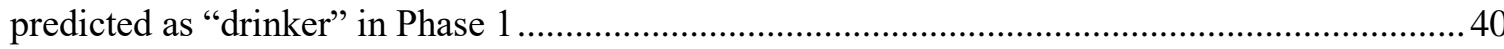

Table 4. 29 The records of data that predicted as "drinker" with class label "incorrect" from Phase 1, which has been predicted to class label "incorrect" in Phase 2 ............................................... 42 Table 4. 30 Nearest Neighbors of data record A, in training data set, from true class "nondrinker"

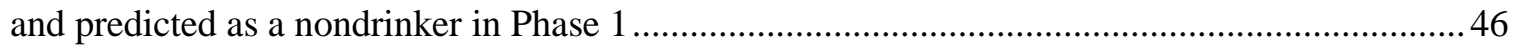
Table 4. 31 Nearest Neighbors of data record A, in training data set, from true class "drinker" and

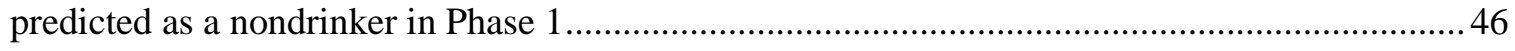

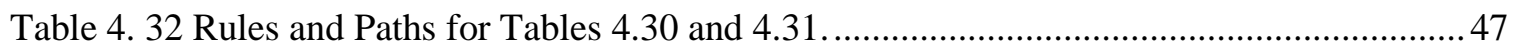

Table 4. 33 Nearest Neighbors of data record B, in training data set, from true class "drinker" and

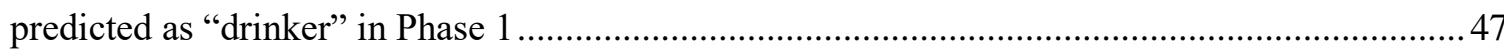

Table 4. 34 Nearest Neighbors of data record B, in training data set, from true class "nondrinker"

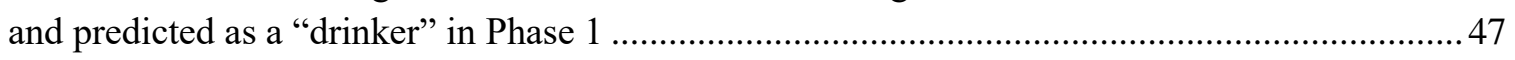

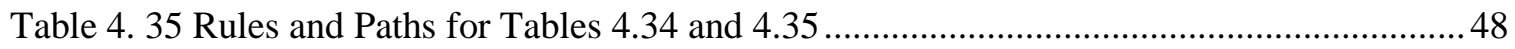

Table 4. 36 Summary of the results for Student Alcohol dataset................................................. 48

Table 4. 37 Phase 1's D.T. Classifier's Important features. .......................................................50

Table 4. 38 Phase 2's D.T. Classifier's Important features for the subset of data that was predicted

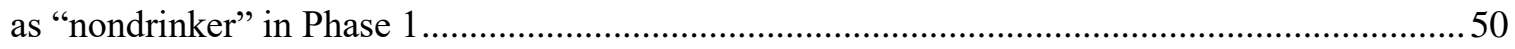

Table 4. 39 Phase 2's D.T. Classifier's Important features for the subset of data that was predicted

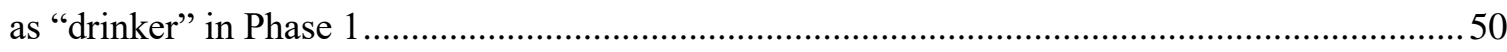

Table 4. 40 Comparing Classification results before Decision Tree tuning parameter for Phase 1

Table 4. 41 Comparing Classification results after Decision Tree tuning parameter for Phase 1.51

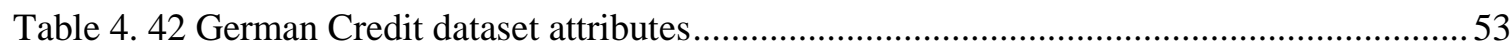

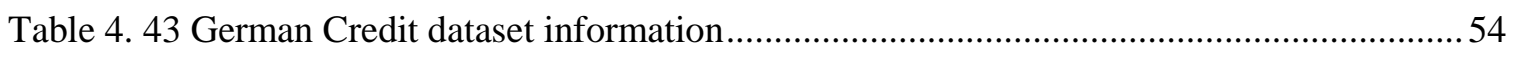

Table 4. 44 Phase 1's D.T. for German credit data, Finding the Optimal Depth and Best Accuracy

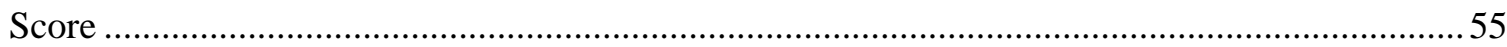

Table 4. 45 Phase 1's D.T. Classifier's Confusion matrix with max_depth=5 for German credit

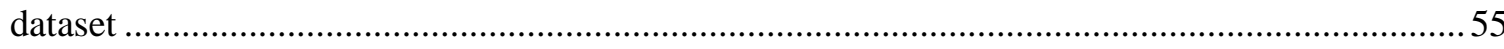

Table 4. 46 Phase 1's D.T's top important features for German credit dataset ............................56

Table 4. 47 Phase 2's D.T. Classifier, Finding the Optimal Depth and Best Accuracy Score for the subset of data that was predicted as "bad" in Phase 1 for German credit data ..............................58

Table 4. 48 Phase 2's D.T. Confusion matrix report for the subset of data that was predicted as "bad" in Phase 1 for German Credit data.....................................................................................58

Table 4. 49 Important features for the subset of data that was predicted as "bad" in Phase 1 for

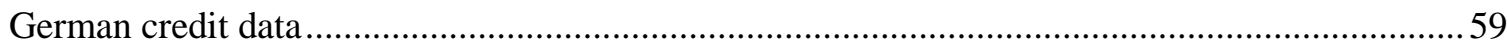

Table 4. 50 Phase 2's D.T. Classifier, Finding the Optimal Depth and Best Accuracy Score for the subset of data that was predicted as "good" in Phase 1 for German credit data 60 
Table 4. 51 Phase 2's D.T. Confusion matrix report for the subset of data that was predicted as

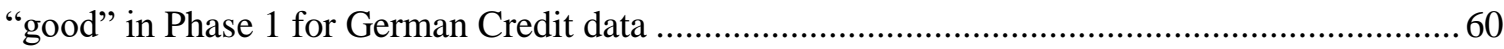

Table 4. 52 Important features for the subset of data that was predicted as "good" in Phase 1 for

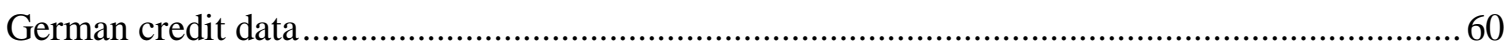

Table 4. 53 Summary of the results for German Credit dataset.................................................. 63

Table 4. 54 Nearest Neighbors of data record D, in training data set, from true class "bad" and

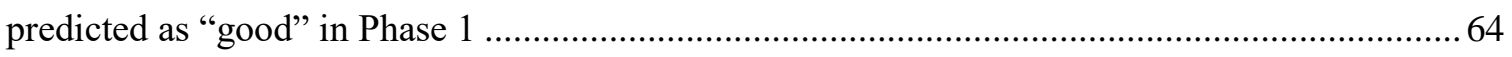

Table 4. 55 Nearest Neighbors of data record D, in training data set, from true class "good" and

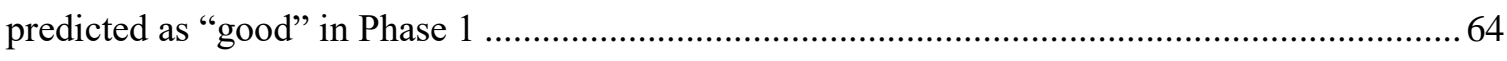

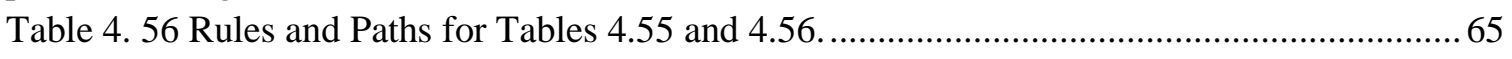

Table 4. 57 Nearest Neighbors of data record H, in training data set, from true class "bad" and predicted as "bad" in Phase 1

Table 4. 58 Nearest Neighbors of data record H, in training data set, from true class "good" and

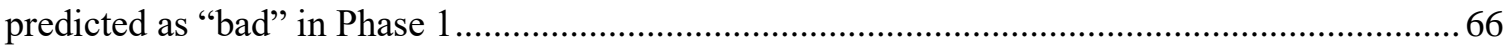

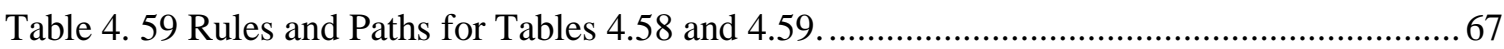




\section{LIST OF FIGURES}

Figure 2. 1 The process of making decision by applying LIME algorithm [3] ............................. 4

Figure 2. 2 Relation between different terms of interpretability. [2] ............................................. 5

Figure 2. 3 The graphical structure of a decision tree classifier. .............................................. 7

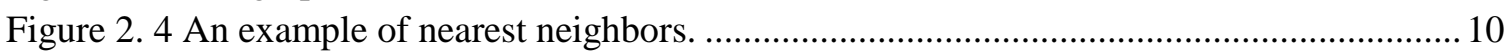

Figure 2. 5 unrestricted Bayesian network classifier learned using Markov Chain Monte for credit

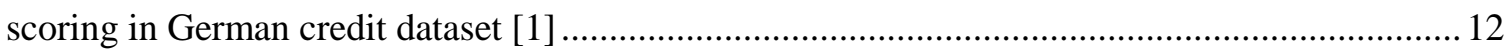

Figure 2. 6 Rules Extracted by Neurorule for German Credit dataset [1] .................................. 13

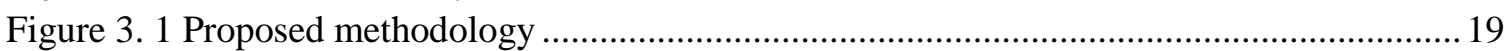

Figure 4. 1 Phase 1's D.T. Classifier, Finding the Optimal Depth and Best Accuracy Score .......23

Figure 4. 2 Phase 1's D.T. Classifier's confusion matrix with max_depth=2 .............................25

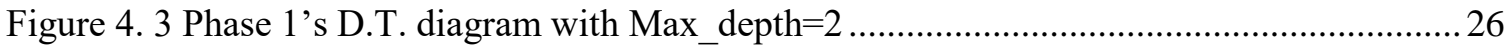

Figure 4. 4 Phase 2's D.T. Classifier, Finding the Optimal Depth and Best Accuracy Score for the

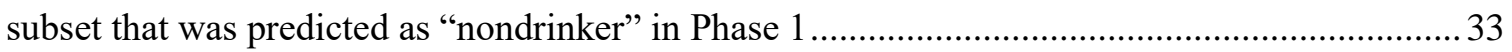

Figure 4. 5 Phase 2's D.T. Classifier, Confusion_matrix with max_depth=2 for the subset of data

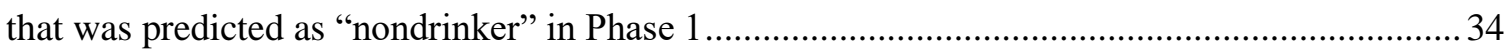

Figure 4. 6 Phase 2's D.T. diagram with Max_depth=2 for the subset of data that was predicted as

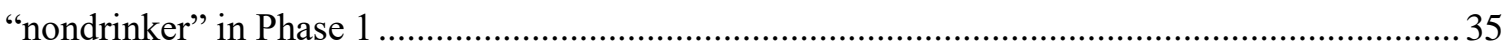

Figure 4. 7 Phase 2's D.T. Classifier, Finding the Optimal Depth and Best Accuracy Score for the

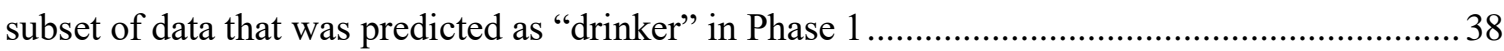

Figure 4. 8 Phase 2's D.T. Classifier's Confusion matrix with max_depth=2 for the subset of data

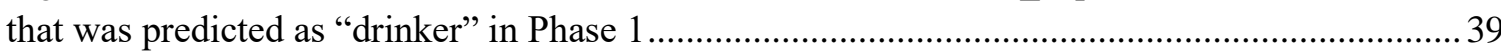

Figure 4. 9 Phase 2's D.T. diagram with max depth=2 for the subset of data that was predicted as

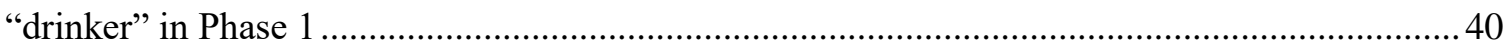

Figure 4. 10 Phase 1's D.T. Classifier's Confusion matrix with max_depth=5 for German credit

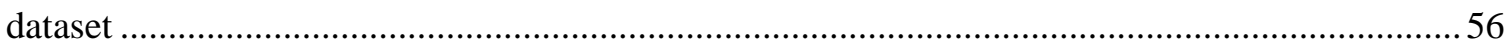

Figure 4. 11 Phase 1's D.T's diagram for German credit dataset with max depth $=5$....................57 Figure 4. 12 Phase 2's D.T. Confusion matrix report for the subset that was predicted as "bad" in

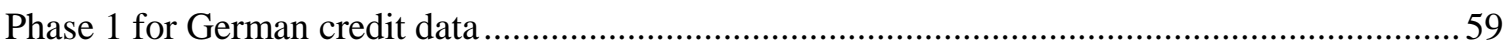

Figure 4. 13 Phase 2's D.T. Confusion matrix report for the subset of data that was predicted as

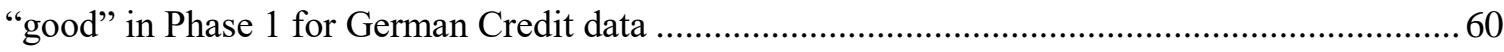

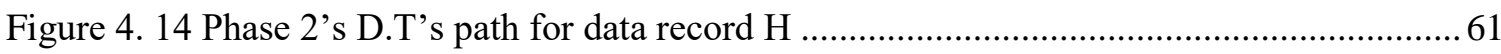

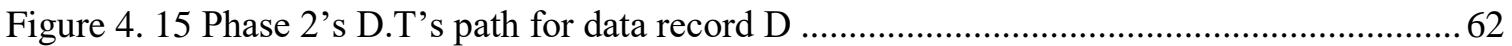




\section{CHAPTER 1}

\section{INTRODUCTION}

Most of the work in evaluating the performance of predictive models has focused on improving the accuracy of the model rather than interpretability [4]. This led to building more complex classifiers such as ensembles [5], support vector machines [6] and kernel-based learning methods [7], known as black-box models, which tend to have high predictive accuracy, but less interpretability for the users $[8][9,10]$. On the other hand, white-box classifiers, such as decision trees, Naïve Bayes, k-nearest neighbors, and logistic regression, help the users more in understanding the decisions that made by the classifiers. The decision tree classifier is one of the most popular machine learning algorithms that can be displayed in the form of if-then rules and visualized as a graphical tree in which improve human readability, by reading paths from the root to each leaf. This characteristic of decision trees can help the user to trace and explore the classification process especially when the classifier makes an incorrect prediction.

Interpretable models play an important role in explaining predictions [11]. However, little work has paid attention to using interpretability to explain incorrect predictions. Yet explaining errors in prediction, can provide insights about potential flaws in feature definition or completeness, as well as potential incorrect training data and 
outliers. It will also help to find the stereotypes learned by machine learning algorithms which lead to incorrect predictions.

Finding the incorrect stereotypical predictions prevent unfair decisions especially when the training data sets are biased regarding the discriminative attributes such as race, gender, and religion. This becomes more serious in making socially sensitive decisions [12] such as credit decisions, insurance premium computations [13] and predictive policing [14]. For instance, several researches show that whites are more likely to use and sell drugs but it is the black people who are mostly arrested for drugs. Also although, only $13 \%$ of people in the US are black, more than $60 \%$ of individuals in prisons are black [15]. Therefore, we need to be careful about the automated discriminations that can be learned by algorithms while learning rules from data.

In this work, we try to develop a methodology to explain the prediction errors by using the interpretability of the decision tree classifier. After the introduction in Chapter 1, we review the important concepts that have been applied in our methodology and related works in Chapter 2, then continue by presenting the methodology in Chapter 3. Experimental results are presented in Chapter 4. Finally, Chapter 5 summarizes the results. 


\section{CHAPTER 2}

\section{LITERATURE REVIEW}

\subsection{Predictive model}

Despite many adoptions, most of the machine learning models are black boxes which make understanding the reasons behind their predictions more challenging. Such understanding provides insight into the model, which makes the model and the prediction more trustable. Considering the important role of humans in using the machine learning tools, there is always a big concern: if the users do not trust a model or a prediction, they will not use it [3]. Regarding this concern, we need to distinguish between two concepts of the trust: (1) trusting a prediction and (2) trusting a model, which both stem from how much the humans are able to understand the prediction model's behavior.

Paying attention to the trust in prediction is important when the model is used to make decisions. In some machine learning applications such as medical diagnosis [16] or terrorist detection, incorrect predictions cost too much and may cause a disaster. In addition to considering trust in prediction, we need to examine the model before applying it to real-world problems. In this case, the model should convince the users that it is reliable and will perform well in real datasets.

Figure 2.1 explains how we can trust a predictive model by understanding the reason behind it and provides the process of making decision by LIME. The authors in 
[3] propose LIME, an algorithm that explains the predictions of any classifier in an interpretable and faithful manner, by learning an interpretable model locally around the prediction. The model has predicted that a patient has the flu and then LIME highlights

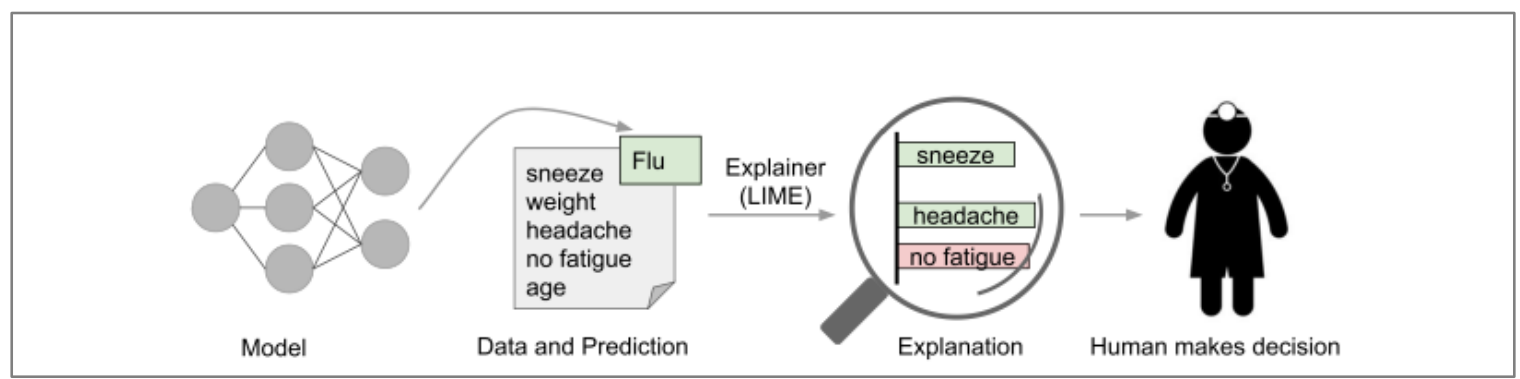

Figure 2. 1 The process of making decision by applying LIME algorithm [3]

the list of symptoms that led to this prediction by the model either contribute to the flu (headache and sneeze) or not (no fatigue). Then a doctor, by using previous knowledge, can trust and accept the prediction or refuse it.

\subsection{Interpretability and its challenges}

Traditional evaluation of the performance of predictive machine learning algorithms has focused on model accuracy. There are other factors such as complexity, performance, extendibility and interpretability which can be used in analyzing and comparing different types of machine learning algorithms [17]. According to [3], an explanation model represents textual or visual concepts to provide the interpretability: a qualitative understanding of the relationship between instances and the prediction results. 
Several works has been made to underline the need to consider interpretability alongside accuracy [18]. For instance, the authors in $[19,20]$ discuss other factors rather than accuracy when two models show a similar accuracy.

Looking at the literature indicates that due to the subjective nature of the interpretability, there is no general agreement about its definition [2]. Many discussions have been made about the relation between different terms of interpretability as shown in Figure 2.2.

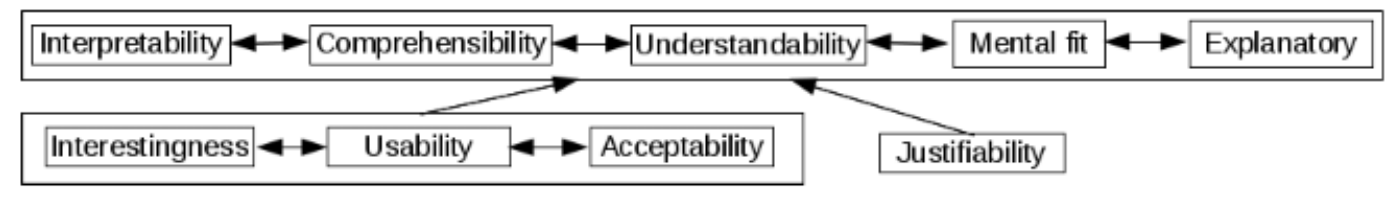

Figure 2. 2 Relation between different terms of interpretability [2]

Rüping in [21] argues that an interpretable model should be understandable and suggests that interpretability can be correlated to accuracy, understandability and efficiency. Other authors use the interpretability as synonym of "understandability" [22, 23] or "comprehensibility" [19, 24]. The "Mental fit" is another term has been added to the interpretability by Feng and Michie [25], which is related to human's ability to understand and test the model. "Explanatory," "sparsity," and "transparency" are the other terms linked to the interpretability [26].

For measuring the interpretability, Bibal and Frénay in [2] suggest that the interpretability can be measured by either models or representation. Then, they introduce two approaches in comparing the interpretability and representation of the models. First 
one is comparing by mathematical entities which is called mathematical heuristic. This approach can compare models with the same type, such as two decision trees. Another technique is user-based surveys which users try to estimate the interpretability of models by comparing their representations. In [17], the authors conduct a quantitative survey to analyze understandability of models from user's point of view which shows decision tree models are more understandable than decision rule models. Then they find a negative correlation between the complexity and understandability of the classification models.

\subsection{Decision Trees}

Decision tree learning is a method for approximating discrete-valued target functions, in which the learned function is represented by a decision tree [27]. This supervised machine learning method, classifies the instances by sorting them down the tree, from the root to some leaf nodes. It consists of two type of nodes:

1. Decision Nodes(leaves): Assign class labels to each instance.

2. Internal Nodes: Split the instance space into two or more sub-spaces based on a certain discrete function of the input attributes values or ranges for numeric ones.

An instance is classified by starting from the root node, moving down the tree branch according to the outcomes of the tests at the internal nodes, until reaching a leaf node and assigning a class label. Figure 2.3 presents an example of decision tree taken from our experimental results in Chapter 4. The tree classifies high school students as drinker or not. 


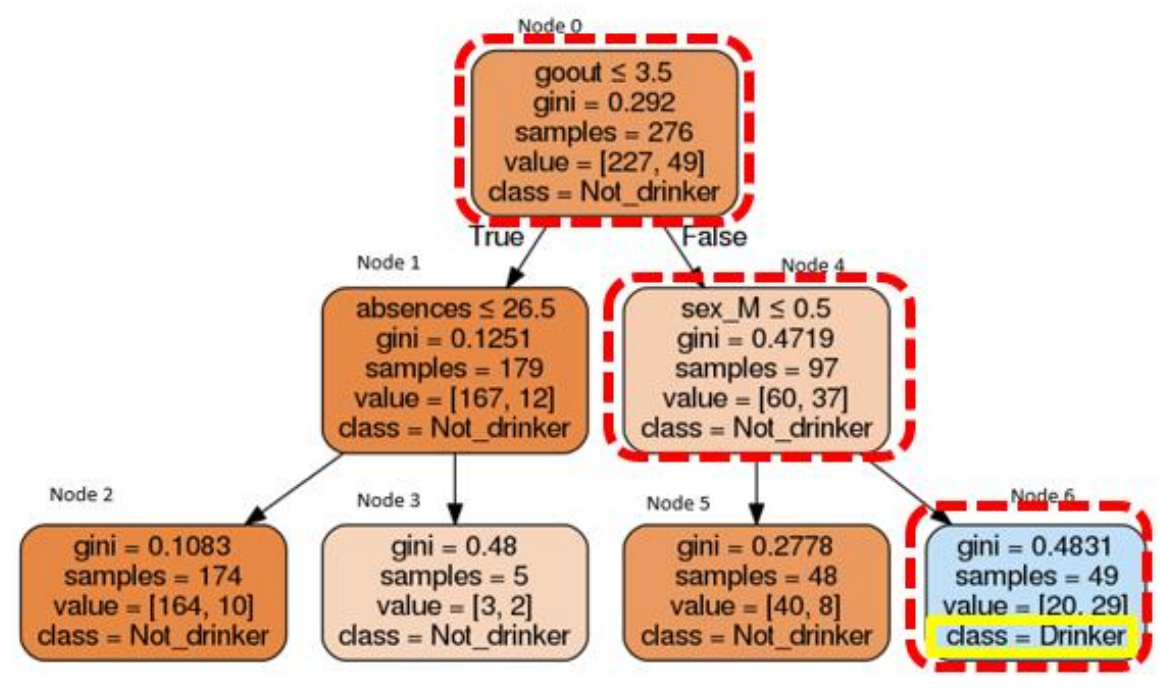

Figure 2. 3 The graphical structure of a decision tree classifier

\subsubsection{Decision Tree Learning Algorithms}

Most algorithms that have been developed for learning decision trees are variations on a core algorithm that employs a top-down, greedy search through the space of possible decision trees. This approach is exemplified by the ID3 algorithm which was developed in 1986 by Ross Quinlan and its successors C4.5 [28]and CART [29]. Some consist of two conceptual phases: growing and pruning (C4.5 and CART). Other inducers perform only the growing phase [30].

The C4.5 which is the successor to ID3, has removed the limitation that features must be categorical by dynamically defining a discrete attribute (based on numerical variables) that partitions the continuous attribute value into a discrete set of intervals. Also, it can deal with missing values, when some training data records have unknown values. 
To select the attribute that is most informative in classifying our data we should define information gain which measures how well an attribute is in splitting the data. Then we need to introduce the Entropy that defines the (im)purity of an arbitrary collection of instances. If we put $\mathrm{p}_{1}\left(\mathrm{p}_{0}\right)$ the proportion of examples of class $1(0)$ in the given collection of $\mathrm{S}$, then the Entropy is:

$$
\operatorname{Entropy}(S)=-p_{1} \log _{2}\left(p_{1}\right)-p_{0} \log _{2}\left(p_{0}\right)
$$

where $p_{0}=1-p_{1}$.

Therefore, the $\operatorname{Gain}\left(S, x_{j}\right)$ will be the expected reduction in entropy because of splitting on attribute $x_{j}$.

$$
\operatorname{Gain}\left(S, x_{j}\right)=\operatorname{Entropy}(S)-\sum_{v \in \text { values }\left(x_{j}\right)} \frac{\left|S_{v}\right|}{|S|} \operatorname{Entropy}\left(S_{v}\right)
$$

where values $\left(x_{j}\right)$ is the set of all possible values of attribute $x_{j}, S_{v}$ is a subset of $S$ where attribute $x_{j}$ has the value $v$, and $\left|S_{v}\right|$ is the number of observation in $S_{v}$. The Gain criterion was used in ID3 in order to choose an attribute to split at a specific node, while C4.5 normalizes the Gain and uses a Gainratio criterion:

$$
\begin{gathered}
\operatorname{Gainratio}\left(S, x_{j}\right)=\frac{\operatorname{Gain}\left(S, x_{j}\right)}{\operatorname{SplitInfromation}\left(S, x_{j}\right)} \\
\operatorname{SplitInfromation}\left(\boldsymbol{S}, \boldsymbol{x}_{\boldsymbol{j}}\right)=-\sum_{\boldsymbol{v} \in \text { values }\left(x_{j}\right)} \frac{\left|S_{\boldsymbol{k}}\right|}{|S|} \log _{2} \frac{\left|S_{\boldsymbol{k}}\right|}{|\boldsymbol{S}|}
\end{gathered}
$$

SplitInformation is the entropy of $\mathrm{S}$ with respect to the values of $x_{j}$.

Pseudocode for C4.5 algorithm for building decision trees [31]: 
Table 2. 1 Pseudocode for C4.5 algorithm

\section{Algorithm C4.5}

1. Check for any base cases*

2. For each attribute $A$

3. Find the normalized information gain from splitting on A

4. Let A_best be the attribute with the highest normalized information gain

5. Create a decision node that splits on A_best

6. Recur on the sub-lists obtained by splitting on A_best, and add those nodes as children of node.

*The base cases are the following:

- All the examples from the training set belong to the same class (a tree leaf labeled with that class is returned).

- The training set is empty (returns a tree leaf called failure).

- The attribute list is empty (returns a leaf labeled with the most frequent class or the disjunction of all the classes).

CART [29] is very similar to C4.5, but it supports numerical target variables (regression) and does not compute rule sets. CART constructs binary trees using the feature and threshold that yield the largest information gain at each node.

\subsubsection{Interpreting Decision Trees}

Decision trees are one of the most popular machine learning algorithms in the domains in which there is a need to explain the prediction results for the user [32], due to the following features: 


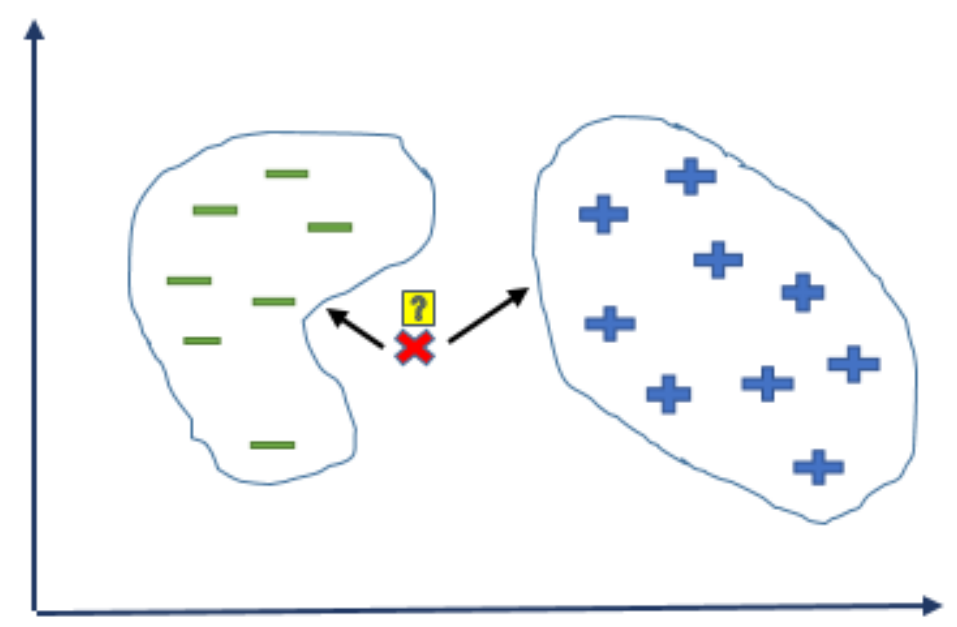

Figure 2. 4 An example of nearest neighbors

1. Having a graphical structure, which makes it easy for the users to follow the path from the root to the desired node.

2. Providing a subset of features, so the user can focus more on the relevant features, which are closer to the root of the tree.

3. Providing individual explanations for each instance of training data. [33, 34]

\subsection{K-Nearest Neighbors}

The k-nearest neighbor classifier is one of the distance-based learnings that classifies a data record based on the $\mathrm{k}$ most similar data (neighbors) in the training data set. The distance metric can be Euclidean distance for continues values and Hamming distance for discrete values. Although, the nearest neighbor classifier is one of the simplest machine learning algorithms, it requires a large computing power when calculating the distance of a data record to its neighbors. Also, this problem will be more challenging when the training data set is noisy [35]. In the example shown in Figure 2.4, the goal is to assign a class label to the unknown data record $\mathrm{x}$ based on the two existed classes. 


\subsection{Some applications for Interpretable models}

Despite considering the predictive accuracy metrics as the main factor while evaluating models [4], there are other domains of applications in which the interpretability of the prediction is important for the users. For these applications, we should provide a model which is acceptable for the users like credit scoring [36], medicine [37] and bioinformatics [9]. This need becomes more serious when the model provides an unexpected prediction. In that case, the user asks good explanations from the system which highlights the crucial role of the interpretability of the model.

Medical domains, because of having critical context [38], require decision making to be always supported by explanations [37, 39] [40]. The necessity of explaining and justifying the decision when diagnosing a new patient is the main goal of Lavrac in her paper [41]. Also, she talks about the decision tree classifier which is easy to understand and can be used to support diagnosis without using the computer.

Bioinformatics is another application in which interpretability of models has an important role. The authors of [42] believe that the comprehensibility of discovered knowledge is required in bioinformatics because the discovered knowledge needs to be interpreted by biologist rather than accepting it blindly as a black-box. The paper introduces a data mining approach to generate a set of comprehensible rules by applying C4.5 algorithms which predict whether a protein has post-synaptic activity. According to their results, predicting the function of proteins based on their primary sequences is one of the challenges in bioinformatics due to the complex relationship between protein sequences and their functions. The rules were analyzed based on both their accuracy and 


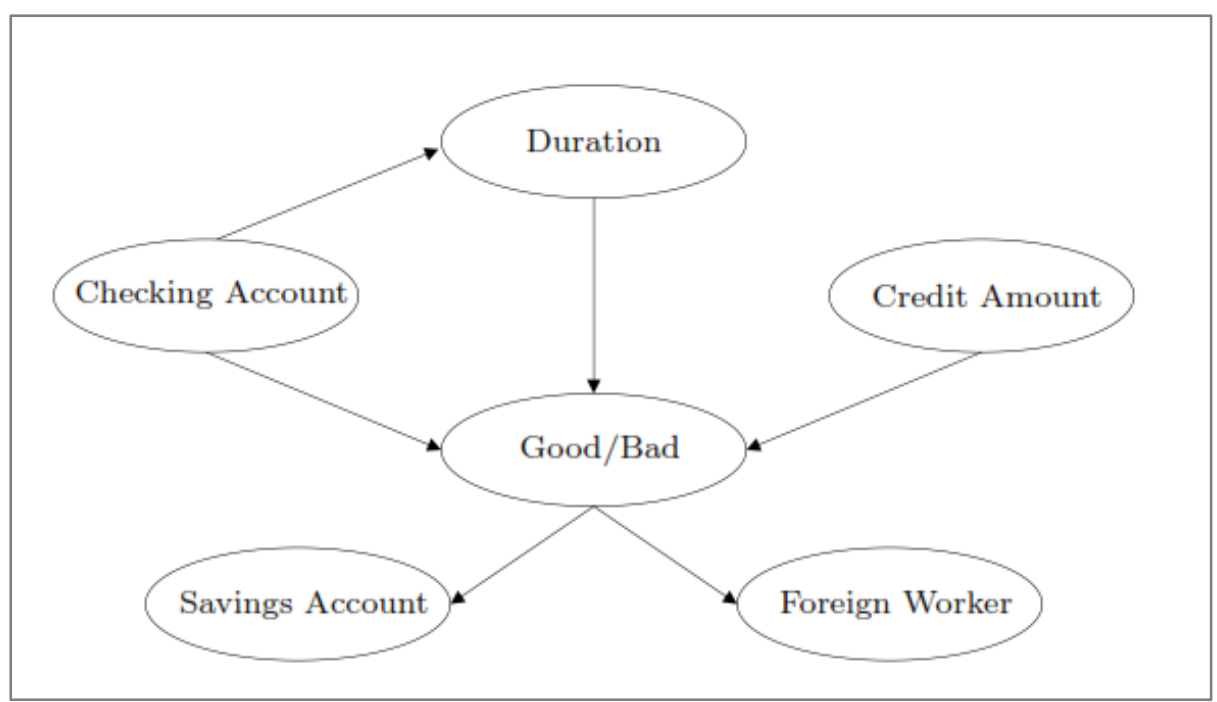

Figure 2. 5 unrestricted Bayesian network classifier learned using Markov Chain Monte for credit scoring in German credit dataset [1]

unexpectedness. The ones which are surprising could be more interesting for the biologist in determining novel insights.

Model comprehensibility and accuracy are also the key factors in building a successful credit scoring system. An expert in this field cannot trust a complex scorecard because of its low comprehensive explanation. Therefore, these black box predictive models cannot be very helpful in credit decision making. [1] investigates the performance of many classifiers in predicting and distinguishing between good and bad payers as represented in Figure 2.5 and 2.6 from [1] for German Credit dataset. Also, [43] discusses the difficulty of prediction in financial problems and tries to uncover the valuable patterns by applying Genetic Algorithms. 


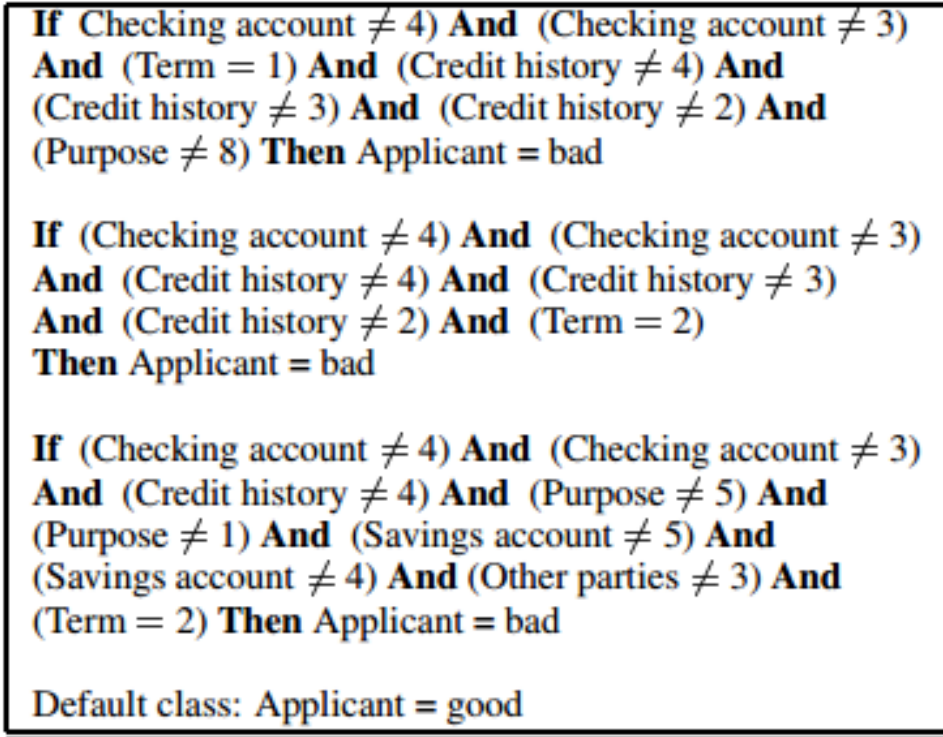

Figure 2. 6 Rules Extracted by Neurorule for German Credit dataset [1]

\subsection{Prediction Errors Analysis}

Analyzing and learning from errors in prediction, which are concerns in many works [6], mostly have been applied in detecting and predicting incorrect predictions in order to minimize its cost or in building a more accurate prediction model. Yet, less work directly focuses on how to explain the prediction errors. For this purpose, we need models which are able to explain the reasons behind the predictions.

One of the known examples in detecting misclassification is in spam classification when the classifier makes mistakes in distinguishing between spam and non-spam emails. In that case, we examine the instances in which the algorithm made errors on them to find out a systematic pattern to help us build new features and attributes to avoid these mistakes in the features. For example, usually, most of the spam emails are pharmacy emails or phishing ones. So, looking at them will help us to understand what features are useful to assign them correctly to a class [44]. 
Another work in analyzing the prediction errors is [45] which presents a generalpurpose biologically plausible computational model, called SELP (Surprise $\rightarrow$ Explain $\rightarrow$ Learn $\rightarrow$ Predict). They use predictive coding which learns from only prediction errors and surprises in streaming data, unlike the traditional algorithms which continuously analyze all the data.

Applying interpretability of classifiers in explaining the classification process, especially for understanding the misclassification, is the goal of [46]. They design and implement a Visual Data Mining system for classifying remotely sensed images (VDMRS). Their proposed system provides two views; one of them is the decision tree classifier which provides tracing and discovering of the classification steps and understanding how a sample has been classified correctly or even finding in which step it has been misclassified.

\subsection{Automated decision making and discrimination}

Nowadays, algorithmic systems for making decisions are widely used to facilitate decisions in a variety of fields such as medicine, banking, education or predictive policing [13]. However, these automated decisions can be very sensitive when applied to socially sensitive personal information such as demographics. The mining algorithms are trained from datasets which may be biased regarding a certain group such as women or minorities. Therefore, there is always a need to make sure that using data mining methods for socially sensitive decision making do not lead to discrimination and unfair treatment against a group of people due to their gender, age, religious or ethnicity [12]. 
Automated discrimination can happen as a direct result of data analytics. These unfair treatments can occur unintentionally; for instance, considering a neighborhood as a factor of ethnicity. For example, looking at demographic data related to the people who are living in certain area and frequently getting credit denial, we can find that they all related to the same ethnic minority [47]. Also, Lowry, in her paper [48], mentions another example regarding automatically discriminating decisions against female and minority applicants of St. George's Hospital Medical School in the 1980s.

The discovery and prevention of automated discrimination has been moderately discussed in the literature [49] [14, 50-52].

\subsection{Credit risk prediction}

Repayment of the loan and interest is very important for the lending institutions because late or incomplete paying off the borrowed money will reduce their profits and will affect their services for new customers. When a bank receives a loan application, based on the applicant's profile, the bank should decide whether or not to grant a loan to

a customer. In this regard, there are two types of risks associated with the bank's decision [53]:

1. Not approving the loan to a good credit risk customer, who is more likely to pay off the loan, leads to loss of business to the bank.

2. Approving the loan to a person with a bad credit risk, who is not able to repay the loan on time or in full amount, may harm the financial interests of the bank. 
Therefore, financial institutions and banks are always investigating more accurate methods to analyze their customer's credit information. Machine learning is one of the approaches in the field used for credit-risk evaluation by building an intelligent decision system to distinguish between good and bad payers based on the information provided for the applications.

An intelligence credit scoring system should be able to provide a clear insight to the experts about why and how an applicant has been chosen as good or bad [36]. One way that a bank can provide experts and customers a meaningful information about the logic for this algorithmic decision system and the consequences of such processing is applying a decision tree classifier. The graphical representation provided by this classifier makes it easy to follow the logic of decisions for the users, particularly the rejected applicants. 


\section{CHAPTER 3}

\section{METHODOLOGY}

\subsection{Introduction}

This chapter will describe a methodology to help investigate reasons for incorrect predictions. In Phase 1, we will build a predictive model to find possible stereotypes learned by the decision tree classifier. Then, Phase 2, will detect the incorrect stereotypical predictions and the possible reasons behind them.

\subsection{Discussion}

Our work is divided in two phases, Phase 1 and Phase 2. In Phase 1, we build our classification model by applying a decision tree classifier on the entire training data set to obtain the initial prediction results and the important features. We divide our dataset into training and testing with splitting ratio of 0.7 for training and 0.3 for testing.

Then, in Phase 2, based on the predicted results, we create a new training data set from the testing data in Phase 1, called "Predicted as Class 1" which consists of only records that have been predicted as "Class 1". In the same way, we extract another training data subset for those that has been predicted as "Class 2" with the class name "Predicted as Class 2". New labels are then assigned by comparing prediction results from Phase 1 with the true class labels. If the prediction and true class label are the same, the new label will be "correct". Otherwise, we will assign the new label, "incorrect". In 
Phase 2, we learn a decision tree classifier again on the newly labeled subset, separately. Hence, by following the paths within the decision trees from both phases, for the records that have been labeled incorrectly in Phase 1 (with new label "incorrect" in Phase 2) and have the same predicted label ("incorrect") in Phase 2, we try to determine which attribute is responsible for the incorrect prediction.

In each phase, we determine the optimal depth of decision trees and the minimum number of misclassified data records before learning our predictive model. Finding the optimal depth will avoid the overfitting and hence, considering irrelevant attributes in making decisions.

We continue our investigations by finding similar data records to the misclassified ones, among neighbors with the same and different actual class labels by using k nearest neighbors. Exploring shared characteristics promises to help find which features are the red flags and need to be considered when making decisions.

Moreover, the "important features" provided by the decision tree classifier are extracted to explore the possible key roles they may have in describing incorrect predictions.

In the next chapter, we present our experimental results which illustrate, in detail, how we apply this methodology to two real datasets. 


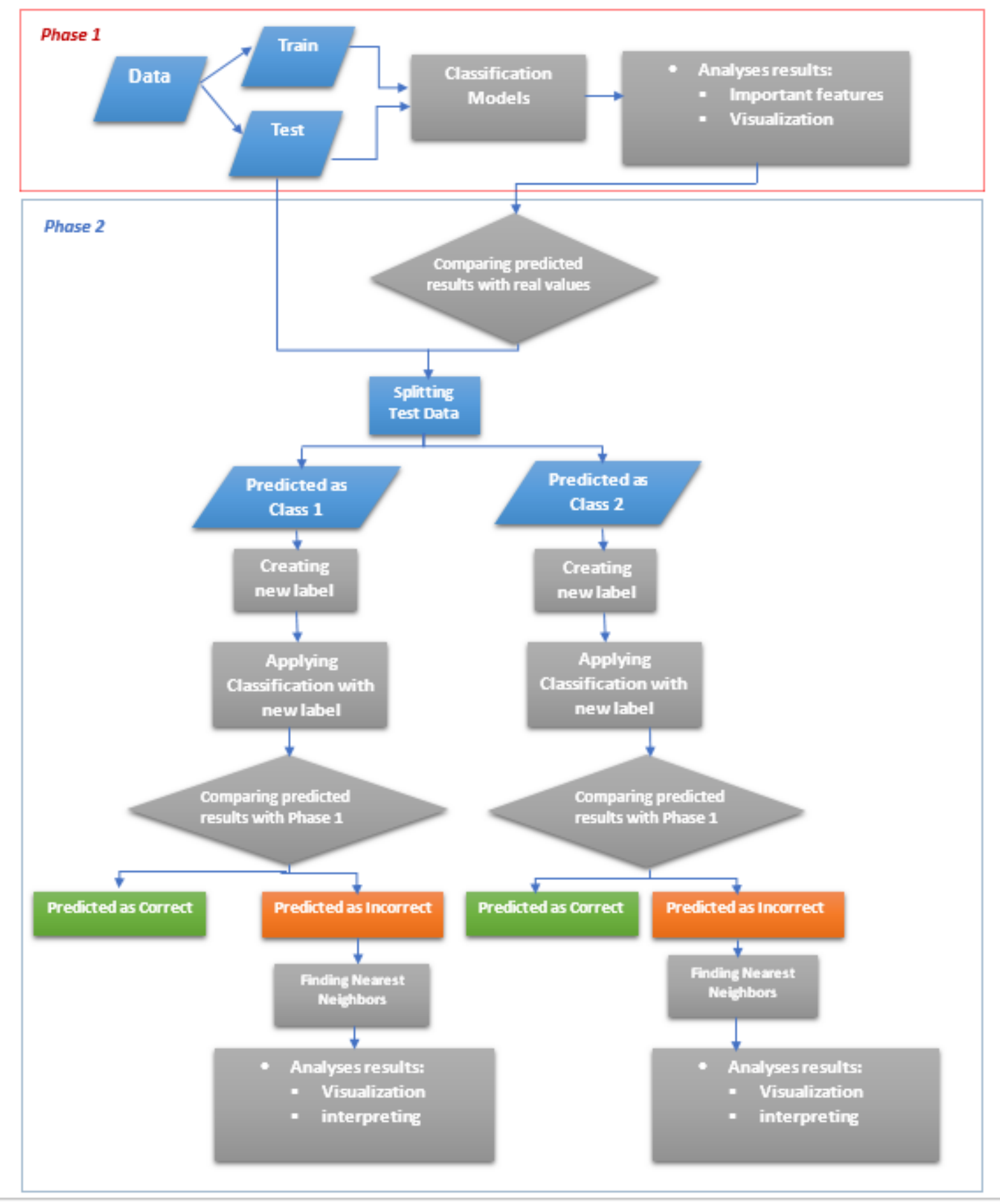

Figure 3. 1 Proposed methodology 


\section{CHAPTER 4}

\section{EXPERIMENTS}

\subsection{Introduction}

In this chapter, we apply the methodology presented in Chapter 3 to two real datasets, Student Alcohol Consumption and German Credit, to explore the predictive rules after learning the decision tree classifier and describe which attributes can explain the incorrect predictions.

\subsection{Discussion}

\subsubsection{Case study 1}

Research showed that there are high rates of using alcohol among college students and young adults. These students are more likely to experience school problems such has higher absences and failing courses, legal problems such as arrests for drinking and driving, abuse of other drugs, etc. In our work, we use a real student alcohol consumption dataset to find out what are the potential attributes in categorizing addicted students from others.

\subsubsection{Student Alcohol Consumption dataset}

\subsection{Phase 1}

The Student Alcohol Consumption dataset is provided by Fabio Pagnotta, Hossain Mohammad Amran in UCI Machine Learning Repository [54] and it related to their research about finding the correlation between alcohol usage and the socio- 
demographics, study time, and other behavioral attributes for Portuguese secondary school's students in two datasets, student-mat.csv (students who have Math course) and student-por.csv (students who have Portuguese language course). In our thesis, we only use the Math course. This data set consists of 395 instances with 32 attributes with no missing values. Tables 4.1 and 4.2 provide more details about the attributes and their definitions.

Table 4. 1 Summary of the Student Alcohol Consumption Data Set information[55]

\begin{tabular}{|l|c|c|c|}
\hline & Instances & Attributes & Missing values \\
\hline Data & 395 & 32 & 0 \\
\hline
\end{tabular}

Table 4. 2 Student Alcohol Consumption Data Set's Attribute Definition

\begin{tabular}{|c|c|c|}
\hline $\mathrm{Nr}$. & Attributes & Definition \\
\hline 1 & school & $\begin{array}{l}\text { student's school (binary: "GP" - Gabriel Pereira or "MS" - Mousinho da } \\
\text { Silveira) }\end{array}$ \\
\hline 2 & sex & student's sex (binary: "F" - female or "M" - male) \\
\hline 3 & age & student's age (numeric: from 15 to 22 ) \\
\hline 4 & address & student's home address type (binary: "U" - urban or "R" - rural) \\
\hline 5 & famsize & family size (binary: "LE3" - less or equal to 3 or "GT3" - greater than 3) \\
\hline 6 & Pstatus & parent's cohabitation status (binary: "T" - living together or "A" - apart) \\
\hline 7 & Medu & $\begin{array}{l}\text { mother's education (numeric: } 0 \text { - none, } 1 \text { - primary education (4th grade), } 2- \\
5 \text { th to } 9 \text { th grade, } 3 \text { - secondary education or } 4 \text { - higher education) }\end{array}$ \\
\hline 8 & Fedu & $\begin{array}{l}\text { father's education (numeric: } 0 \text { - none, } 1 \text { - primary education ( } 4 \text { th grade), } 2- \\
5 \text { th to } 9 \text { th grade, } 3 \text { - secondary education or } 4 \text { - higher education) }\end{array}$ \\
\hline 9 & Mjob & $\begin{array}{l}\text { mother's job (nominal: "teacher", "health" care related, civil "services" (e.g. } \\
\text { administrative or police), "at_home" or "other") }\end{array}$ \\
\hline 10 & Fjob & $\begin{array}{l}\text { father's job (nominal: "teacher", "health" care related, civil "services" (e.g. } \\
\text { administrative or police), "at_home" or "other") }\end{array}$ \\
\hline 11 & reason & $\begin{array}{l}\text { reason to choose this school (nominal: close to "home", school "reputation", } \\
\text { "course" preference or "other") }\end{array}$ \\
\hline 12 & guardian & student's guardian (nominal: "mother", "father" or "other") \\
\hline 13 & traveltime & $\begin{array}{l}\text { home to school travel time (numeric: } 1-<15 \text { min., } 2-15 \text { to } 30 \text { min., } 3-30 \\
\text { min. to } 1 \text { hour, or } 4->1 \text { hour) }\end{array}$ \\
\hline 14 & studytime & $\begin{array}{l}\text { weekly study time (numeric: } 1-<2 \text { hours, } 2-2 \text { to } 5 \text { hours, } 3-5 \text { to } 10 \text { hours, or } \\
4->10 \text { hours) }\end{array}$ \\
\hline 15 & failures & number of past class failures (numeric: $n$ if $1<=n<3$, else 4 ) \\
\hline 16 & schoolsup & extra educational support (binary: yes or no) \\
\hline 17 & famsup & family educational support (binary: yes or no) \\
\hline 18 & paid & $\begin{array}{l}\text { extra paid classes within the course subject (Math or Portuguese) (binary: yes } \\
\text { or no) }\end{array}$ \\
\hline 19 & activities & extra-curricular activities (binary: yes or no) \\
\hline
\end{tabular}




\begin{tabular}{|l|l|l|}
\hline 20 & nursery & attended nursery school (binary: yes or no) \\
\hline 21 & higher & wants to take higher education (binary: yes or no) \\
\hline 22 & internet & Internet access at home (binary: yes or no) \\
\hline 23 & romantic & with a romantic relationship (binary: yes or no) \\
\hline 24 & famre & quality of family relationships (numeric: from 1 - very bad to 5 - excellent) \\
\hline 25 & freetime & free time after school (numeric: from 1 - very low to 5 - very high) \\
\hline 26 & goout & going out with friends (numeric: from 1 - very low to 5 - very high) \\
\hline 27 & Dalc & workday alcohol consumption (numeric: from 1 - very low to 5 - very high) \\
\hline 28 & Walc & weekend alcohol consumption (numeric: from 1 - very low to 5 - very high) \\
\hline 29 & health & current health status (numeric: from 1 - very bad to 5 - very good) \\
\hline 30 & absences & number of school absences (numeric: from 0 to 93) \\
\hline 31 & G1 & first period grade (numeric: from 0 to 20) \\
\hline 32 & G2 & second period grade (numeric: from 0 to 20) \\
\hline 33 & G3 & final grade (numeric: from 0 to 20, output target) \\
\hline 34 & Alc & $\begin{array}{l}\text { Alcohol consumption between week (numeric: from 1 - very low to 5 - very } \\
\text { high) }\end{array}$ \\
\hline
\end{tabular}

Following [55] which is related to this dataset, we create a new attribute "Alc" which is a combination of two attributes "Walc," weekend alcohol consumption, and “Dal," workday alcohol consumption.

$$
A l c=(\text { Walc } * 2+\text { Dalc } * 5) / 7
$$

After rounding the value, the result will be an integer between 1 and 5. Hence, we create a new attribute (new_target) which categorizes students to "Nondrinker" if "Alc" is less than 3 (1 and 2) and "drinker" if "Alc" equals 3, 4 or 5. Then in preprocessing, we convert "Nondrinker" to 0 and "drinker" to 1.

The next step is to divide our dataset into training and testing with splitting ratio of 0.7 for training and 0.3 for testing.

Before starting the classification, we try to find the optimal depth of the decision tree classifier which has the minimum number of incorrect predictions. It will help prevent overfitting: when the accuracy of the decision tree on the training data set is 
higher than the testing data. To find efficient parameters, we use "GridSearchCv" provided by "scikit-learn" which exhaustively considers all possible combinations of parameter values and chooses the best ones. According to the Table 4.3 and 4.4, we decide to choose the Max_depth=2 which has the best accuracy and the minimum number misclassified records.

Table 4. 3 Phase 1's D.T. Classifier, Finding the Optimal Depth and Best Accuracy Score

\begin{tabular}{|l|l|}
\hline D.T depth & Accuracy score \\
\hline 1 & 0.82 \\
\hline 2 & 0.85 \\
\hline 3 & 0.85 \\
\hline 4 & 0.85 \\
\hline 5 & 0.84 \\
\hline 6 & 0.82 \\
\hline 7 & 0.81 \\
\hline 8 & 0.80 \\
\hline 9 & 0.83 \\
\hline 10 & 0.79 \\
\hline 11 & 0.80 \\
\hline
\end{tabular}

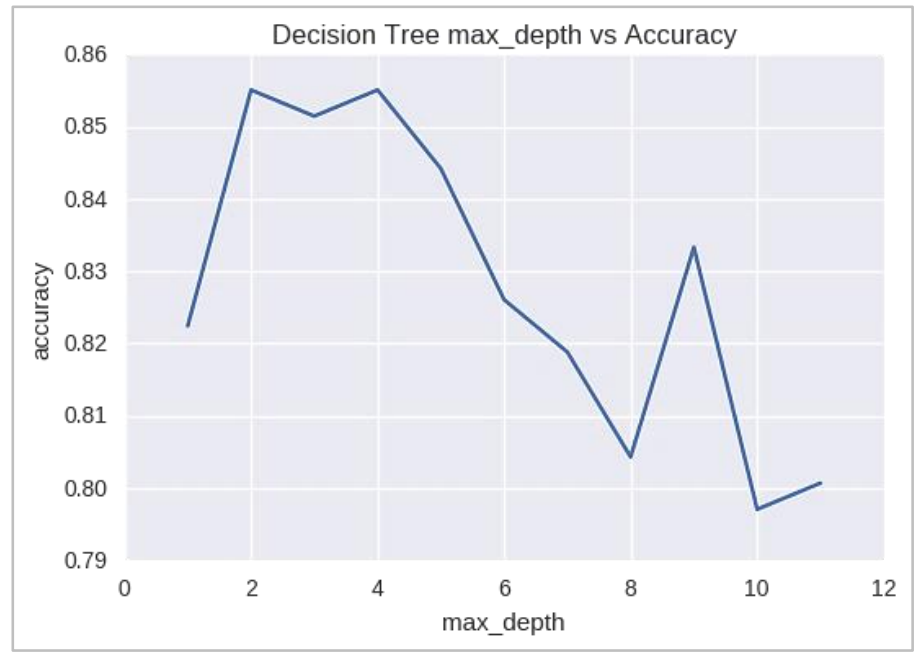

Figure 4. 1 Phase 1's D.T. Classifier, Finding the Optimal Depth and Best Accuracy Score 
Table 4. 4 Phase 1's D.T. Classifier, Comparing Classification Results with different Depths

\begin{tabular}{|l|l|l|l|l|}
\hline & accuracy_score & Roc_auc_score & $\begin{array}{l}\text { F1 } \\
\text { score }\end{array}$ & $\begin{array}{l}\text { Number of } \\
\text { Misclassified records }\end{array}$ \\
\hline $\begin{array}{l}\text { Decision Tree Classifier with } \\
\text { Max_depth=2 }\end{array}$ & 0.8319 & 0.7197 & 0.5454 & 20 \\
\hline $\begin{array}{l}\text { Decision Tree Classifier with } \\
\text { Max_depth=3 }\end{array}$ & 0.7983 & 0.7706 & 0.2941 & 24 \\
\hline $\begin{array}{l}\text { Decision Tree Classifier with } \\
\text { Max_depth=4 }\end{array}$ & 0.8067 & 0.7846 & 0.3783 & 23 \\
\hline
\end{tabular}

Now we fit the D.T. classifier with max_depth $=2$ to the training and testing data sets with splitting ratio of 0.7 for training and 0.3 for testing to predict whether a student is a drinker or not. The classification results are shown in Table 4.5. According to the confusion matrix shown in Figure 4.2, we have 20 misclassified data records: 10 "drinker" students which has been predicted as "nondrinker" and 10 "nondrinker" students that has been predicted to "drinker".

Table 4. 5 Phase 1's D.T. Classifier's Classification results with Max_depth=2

\begin{tabular}{|l|l|l|l|}
\hline & accuracy_score & Roc_auc_score & $\begin{array}{l}\text { F1 } \\
\text { score }\end{array}$ \\
\hline $\begin{array}{l}\text { D.T. Classifier with } \\
\text { Max_depth=2 }\end{array}$ & 0.8319 & 0.7197 & 0.5454 \\
\hline
\end{tabular}




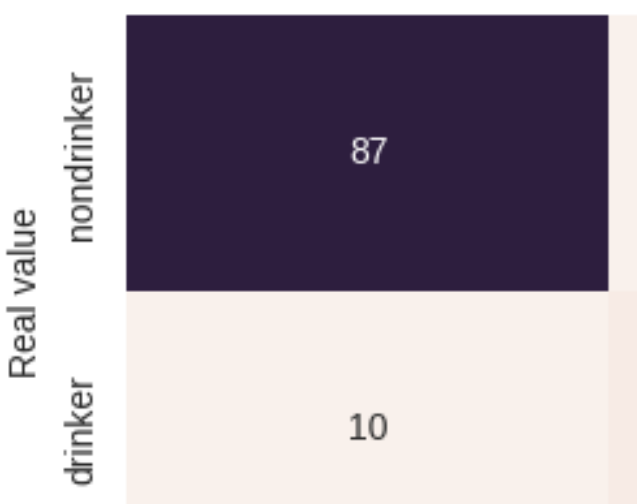

10

12

nondrinker
60

45

30

15

\section{Predicted value}

Figure 4. 2 Phase 1's D.T. Classifier's confusion matrix with max_depth=2

Also, the "important features" provided by decision tree classifier with max_depth=2 are "goout", "sex" and "absences" that have greater effects on predictions. (Table 4.6)

Table 4. 6 Phase 1's D.T. Classifier's Important Features

\begin{tabular}{|l|l|}
\hline features & Degree of importance \\
\hline goout & 0.5566 \\
\hline sex_F & 0.3923 \\
\hline absences & 0.0510 \\
\hline
\end{tabular}

As it mentioned before, the decision tree's graphical structure and if-then rules make it easy for general users to understand the prediction results. For example, in Figure 4.3 by following the path includes node 0 , node 4 , and then node 6 , the user will find that if a student goes out frequently with friends and is a male, he is more likely to be a “drinker", which is expected and does make sense. 


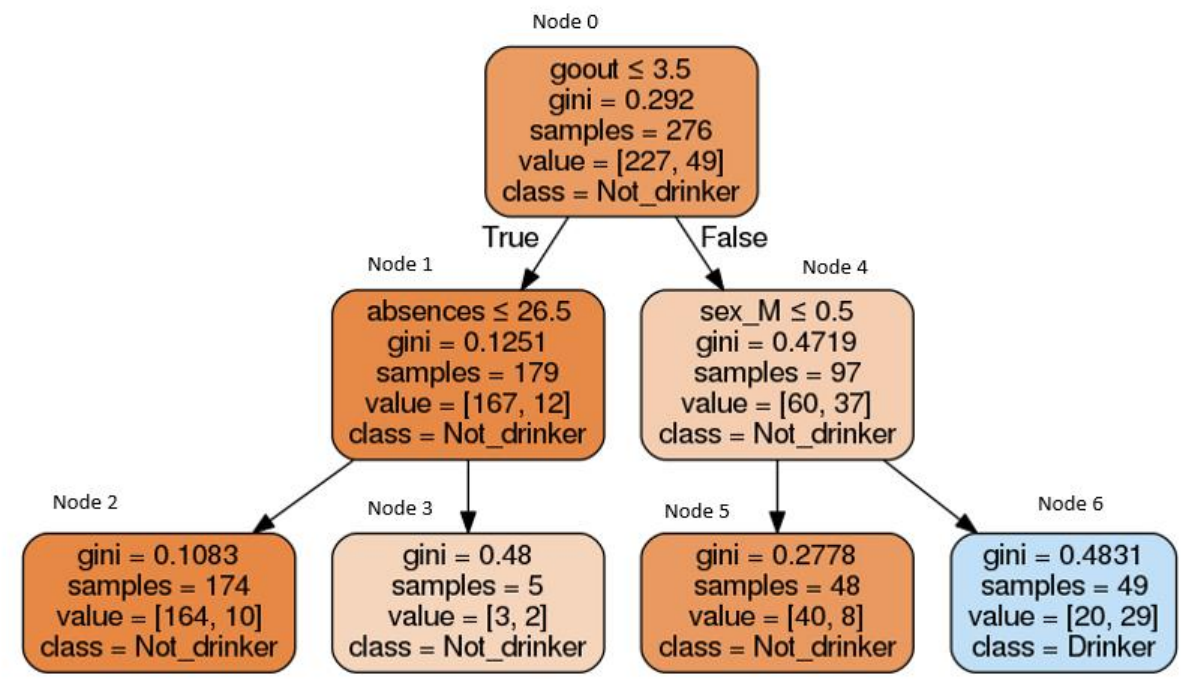

Figure 4. 3 Phase 1's D.T. diagram with Max_depth=2

Table 4. 7 Phase 1's D.T. Classifier's rules with Max-depth=2

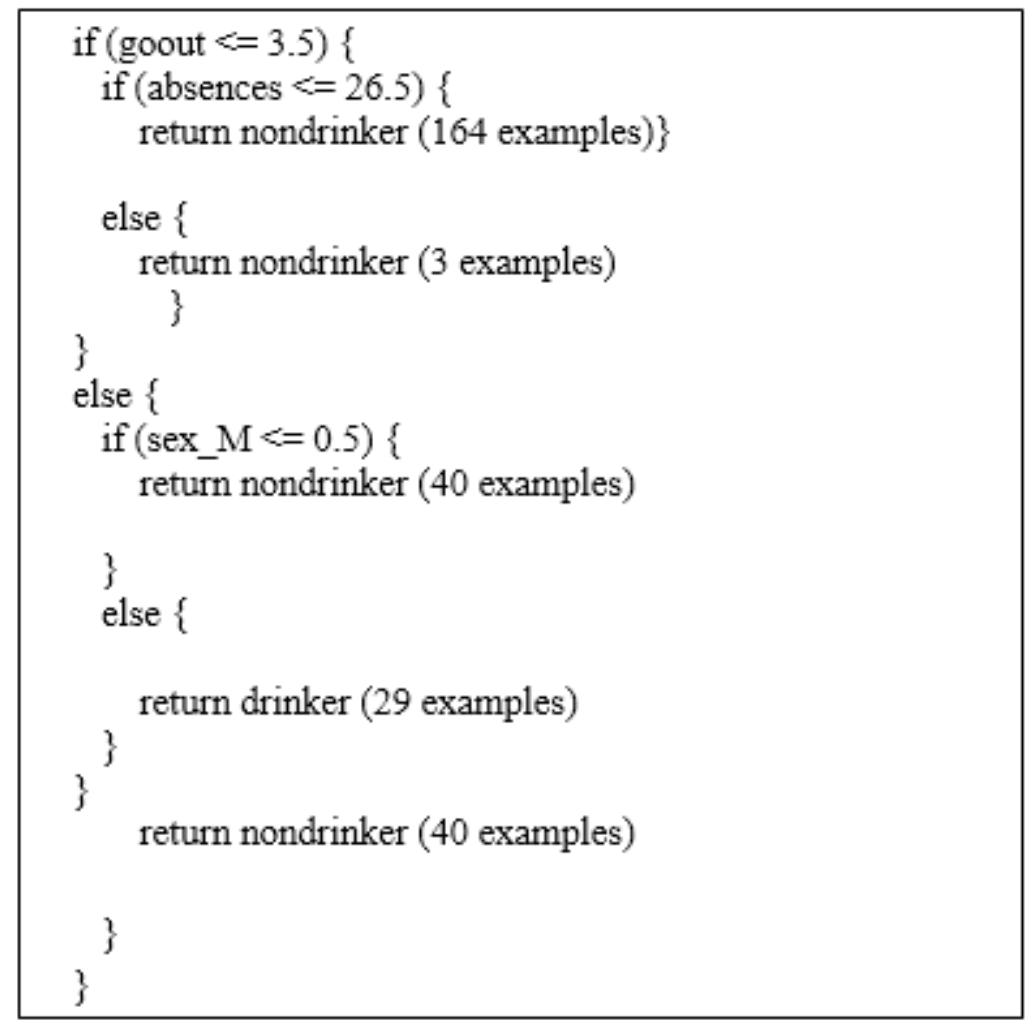




\section{Learning Decision Tree on Testing Data (unseen data) to find the paths:}

After fitting the Decision Tree Classifier to the training dataset, we can use the decision_path() function from scikit-learn to find the nodes that were reached by each record in our testing dataset on the path from the root to leaf. This method converts testing data set which has 119 rows to a matrix of $119^{*} 7$, where 7 is the total number of nodes in the classifier model. By following the path for each specific record, we can find the attributes which caused the classifier to predict a class label incorrectly.

Table 4. 8 Number of misclassified data for testing data set in Phase 1

\begin{tabular}{|l|l|}
\hline Number of misclassified data in Phase 1 & 20 \\
\hline Number of misclassified data ending in "Node 2" & 8 \\
\hline Number of misclassified data ending in "Node 6" & 10 \\
\hline Number of misclassified data ending in "Node 5" & 2 \\
\hline
\end{tabular}

Table 4.9 Number of test records that go through each node $*$ in the model

\begin{tabular}{|c|c|c|c|c|c|c|}
\hline $\begin{array}{l}\text { Node } \\
* \\
\text { indicates } \\
\text { a leaf } \\
\text { node }\end{array}$ & $\begin{array}{l}\text { Number } \\
\text { of } \\
\text { records } \\
\text { that } \\
\text { passes } \\
\text { through } \\
\text { each } \\
\text { node in } \\
\text { testing } \\
\text { data }\end{array}$ & $\begin{array}{l}\text { Number of } \\
\text { Misclassified } \\
\text { records from } \\
\text { True Class } \\
\text { "drinker", } \\
\text { which ends } \\
\text { in node } 2\end{array}$ & $\begin{array}{l}\text { Number of } \\
\text { Misclassified } \\
\text { records from } \\
\text { True Class } \\
\text { "drinker", } \\
\text { which ends } \\
\text { in node } 6\end{array}$ & $\begin{array}{l}\text { Number of } \\
\text { Misclassified } \\
\text { records from } \\
\text { True Class } \\
\text { "not } \\
\text { drinker", } \\
\text { which ends } \\
\text { in node } 5\end{array}$ & $\begin{array}{l}\text { Path } \\
\text { from } \\
\text { Phase } \\
1 \\
\text { (See } \\
\text { Table } \\
\text { 4.10 } \\
\text { for } \\
\text { each } \\
\text { path) }\end{array}$ & $\begin{array}{l}\text { Index of Misclassified } \\
\text { records }\end{array}$ \\
\hline 0 & 119 & & & & & \\
\hline 1 & 77 & & & & & \\
\hline $2 *$ & 77 & 8 & & & $0,1,2$ & $\begin{array}{l}\text { '369','384','228','392','393, } \\
\text { '41','249','89' }\end{array}$ \\
\hline $3 *$ & 0 & & & & & \\
\hline 4 & 42 & & & & & \\
\hline $5^{*}$ & 22 & & & 2 & $0,4,5$ & '318', '61' \\
\hline $6^{*}$ & 20 & & 10 & & $0,4,6$ & $\begin{array}{l}\text { '304','161','172','354','6','307', } \\
\text { '277', '242','351', '347' }\end{array}$ \\
\hline
\end{tabular}

* refers to the decision nodes (leaves) in Figure 4.3. 


\section{Analyzing and Visualizing misclassified records in Decision Tree Classifier from Phase 1:}

To learn more about the misclassified data records, we extract and display them in Tables 4.11-13. According to Table 4.9, we have eight misclassified data records that follow the Path $0,1,2$ which indicates that students who do not go out frequently with friends and do not have many absences in their courses, are more likely to be nondrinkers. Among them, three students are with actual class label "drinker" and five students are with actual class label "nondrinker" (Table 4.10). To have a better visualization, we only show some of important attributes in this part.

Table 4. 10 Phase 1's D.T. Classifier's paths and rules that lead to misclassification

\begin{tabular}{|l|l|l|l|}
\hline $\begin{array}{l}\text { Phase 1, } \\
\text { Decision Tree } \\
\text { Classifier } \\
\text { Path }\end{array}$ & $\begin{array}{l}\text { Rule that causes } \\
\text { misclassification }\end{array}$ & $\begin{array}{l}\text { Number of test data } \\
\text { records that were } \\
\text { misclassified by this } \\
\text { rule }\end{array}$ & $\begin{array}{l}\text { Number of test data } \\
\text { records that were } \\
\text { classified correctly by this } \\
\text { rule }\end{array}$ \\
\hline Path $0,1,2$ & $\begin{array}{l}\text { if (goout }<=3.5)\{ \\
\text { if }(\text { absences }<=26.5)\{ \\
\text { return nondrinker }\end{array}$ & 8 & 69 \\
\hline Path $0,4,5$ & $\begin{array}{l}\text { if (goout }>3.5)\{ \\
\text { if }(\text { sex_M }<=0.5)\{ \\
\text { return nondrinker }\end{array}$ & 2 & 12 \\
\hline Path $0,4,6$ & $\begin{array}{l}\text { if (goout }>3.5)\{ \\
\text { if }(\text { sex_M }>0.5)\{ \\
\text { return drinker }\end{array}$ & 10 & \\
\hline
\end{tabular}


Table 4. 11 Misclassified records which end at node 2 ("goout" $<=3.5$ and "absences" $<=26.5$ )

\begin{tabular}{|c|c|c|c|c|c|c|c|c|c|c|c|c|c|c|c|c|c|c|c|}
\hline \multirow[t]{6}{*}{ Nondrinker } & sex & age & Medu & Fedu & Mjob & Fjob & \multicolumn{2}{|c|}{ guardian traveltime } & \multirow{2}{*}{\begin{tabular}{|c} 
studytime \\
2 \\
\end{tabular}} & \multirow{2}{*}{\begin{tabular}{|c|} 
failures \\
0
\end{tabular}} & \multicolumn{3}{|c|}{ activities nursery freetime } & \multirow{2}{*}{\begin{tabular}{|c} 
goout \\
2
\end{tabular}} & \multirow{2}{*}{\begin{tabular}{|c|} 
absences \\
10
\end{tabular}} & \multirow{2}{*}{$\begin{array}{l}\text { G1 } \\
14\end{array}$} & \multirow{2}{*}{$\begin{array}{c}\text { G2 } \\
12\end{array}$} & \multirow{2}{*}{$\begin{array}{c}\text { G3 } \\
11\end{array}$} & \multirow{2}{*}{$\begin{array}{c}\text { Alc } \\
3\end{array}$} \\
\hline & $\mathrm{F}$ & 18 & 4 & 4 & other & teacher & father & 3 & & & no & no & 2 & & & & & & \\
\hline & M & 21 & 1 & 1 & other & other & other & 1 & 1 & 3 & no & no & 5 & 3 & 3 & 10 & 8 & 7 & 3 \\
\hline & $\mathrm{M}$ & 18 & 3 & 2 & services & other & mother & 3 & 1 & 0 & no & no & 4 & 1 & 0 & 11 & 12 & 10 & 3 \\
\hline & M & 15 & 4 & 4 & teacher & other & other & 1 & 1 & 0 & no & no & 4 & 3 & 8 & 12 & 12 & 12 & 3 \\
\hline & M & 16 & 0 & 2 & other & other & mother & 1 & 1 & 0 & no & no & 3 & 2 & 0 & 13 & 15 & 15 & 3 \\
\hline \multirow[t]{4}{*}{ Drinker } & sex & age & Medu & Fedu & Mjob & Fjob & \multicolumn{2}{|c|}{ guardian traveltime } & studytime & failures & activities & nursery & freetime & goout & absences & G1 & G2 & G3 & Alc \\
\hline & M & 18 & 4 & 2 & other & other & father & 2 & 1 & 1 & no & yes & 4 & 3 & 14 & 6 & 5 & 5 & 4 \\
\hline & M & 18 & 2 & 1 & at_home & other & mother & 4 & 2 & 0 & yes & yes & 3 & 2 & 14 & 10 & 8 & 9 & 4 \\
\hline & $M$ & 16 & 4 & 4 & teacher & health & mother & 1 & 2 & 0 & no & yes & 1 & 3 & 18 & 8 & 6 & 7 & 4 \\
\hline
\end{tabular}

Table 4. 12 Misclassified records which end at node 5("goout" $>3.5$ and "sex_M" $<=0.5$ )

\begin{tabular}{|c|c|c|c|c|c|c|c|c|c|c|c|c|c|c|c|c|c|c|c|}
\hline & sex & age & Medu & Fedu & Mjob & Fjob & guardian & traveltime & studytime & failures & activities & nursery & freetime & goout & absences & G1 & G2 & G3 & Alc \\
\hline Nondrinker & $F$ & 17 & 3 & 4 & at_home & services & father & 1 & 3 & 0 & yes & no & 3 & 4 & 0 & 11 & 11 & 10 & 3 \\
\hline Drinker & $F$ & 16 & 1 & 1 & services & services & father & 4 & 1 & 0 & yes & no & 5 & 5 & 6 & 10 & 8 & 11 & 5 \\
\hline
\end{tabular}


Table 4. 13 Misclassified records which end at node 6("goout" > 3.5 and "sex_M" > 0.5)

\begin{tabular}{|c|c|c|c|c|c|c|c|c|c|c|c|c|c|c|c|c|c|c|c|}
\hline \multirow[t]{11}{*}{ Nonrinker } & sex & age & Medu & Fedu & Mjob & Fjob & guardian & traveltime & studytime & failures & activities & nursery & freetime & goout & absences & G1 & G2 & G3 & Alc \\
\hline & M & 19 & 3 & 3 & other & other & other & 1 & 2 & 1 & yes & yes & 4 & 4 & 20 & 15 & 14 & 13 & 1 \\
\hline & $M$ & 15 & 3 & 2 & other & other & mother & 2 & 2 & 2 & no & yes & 4 & 4 & 6 & 5 & 9 & 7 & 2 \\
\hline & $M$ & 17 & 4 & 4 & teacher & other & mother & 1 & 2 & 0 & yes & yes & 4 & 4 & 0 & 13 & 11 & 10 & 2 \\
\hline & $M$ & 17 & 4 & 3 & services & other & mother & 2 & 2 & 0 & yes & no & 5 & 5 & 4 & 13 & 11 & 11 & 2 \\
\hline & $M$ & 16 & 2 & 2 & other & other & mother & 1 & 2 & 0 & no & yes & 4 & 4 & 0 & 12 & 12 & 11 & 1 \\
\hline & $M$ & 19 & 4 & 4 & teacher & services & other & 2 & 1 & 1 & no & yes & 3 & 4 & 38 & 8 & 9 & 8 & 1 \\
\hline & $M$ & 18 & 4 & 4 & teacher & services & mother & 2 & 1 & 0 & yes & yes & 2 & 4 & 22 & 9 & 9 & 9 & 2 \\
\hline & $M$ & 17 & 3 & 3 & health & other & mother & 2 & 2 & 0 & no & yes & 5 & 4 & 2 & 13 & 13 & 13 & 2 \\
\hline & $M$ & 16 & 4 & 3 & teacher & other & mother & 1 & 1 & 0 & yes & no & 4 & 5 & 0 & 6 & 0 & 0 & 1 \\
\hline & $M$ & 18 & 4 & 3 & teacher & other & mother & 1 & 3 & 0 & no & yes & 4 & 5 & 0 & 10 & 10 & 9 & 2 \\
\hline
\end{tabular}




\subsection{Phase 2}

In this Phase, we split the test data set from Phase 1 into two subsets, "Predicted as a drinker", for which the decision tree classifier from Phase 1 has predicted them as "drinker" and "Predicted as a nondrinker" for those that have been predicted as "nondrinker" by the decision tree classifier from Phase 1. Then for each subset, we create a new class label by comparing the predicted labels with the true labels. So, for the data set "Predicted as a drinker", the new label ("new_target") is "correct" if the real target (before applying the decision tree classifier) is "drinker" and the predicted value (after applying the decision tree classifier) is still a "drinker". Otherwise, it should be

"incorrect." Similarly, for the subset "Predicted as a nondrinker", if the person is really a "nondrinker" and the classifier has predicted them as a "nondrinker", the new label is "correct"; otherwise, the new label is "incorrect".

Table 4. 14 Phase 1's Prediction results for Testing data set

\begin{tabular}{|l|l|l|}
\hline Data & Instances & Attributes \\
\hline Test Dataset from Phase 1 & 119 & 58 \\
\hline Records Predicted as drinker & 22 & 58 \\
\hline Records Predicted as nondrinker & 97 & 58 \\
\hline
\end{tabular}

Table 4. 15 Phase 1's Prediction results as “drinker" for Testing data set

\begin{tabular}{|l|l|l|}
\hline Data & Instances & Attributes \\
\hline Test data Predicted as drinker & 22 & 58 \\
\hline Records Predicted as drinker correctly & 12 & 58 \\
\hline Records Predicted as drinker incorrectly & 10 & 58 \\
\hline
\end{tabular}

Table 4. 16 Phase 1's Prediction results as "nondrinker" for Testing data set

\begin{tabular}{|l|l|l|}
\hline Data & Instances & Attributes \\
\hline Test data Predicted as nondrinker & 97 & 58 \\
\hline Records Predicted as nondrinker correctly & 87 & 58 \\
\hline Records Predicted as nondrinker incorrectly & 10 & 58 \\
\hline
\end{tabular}




\section{Building the D.T. Classifier for the subset of data that was predicted as "nondrinker":}

After Splitting the subset of data that was predicted as "nondrinker", as shown in Table 4.17, we apply "GridSearchCv" to find the optimal depth for D.T. and the minimum number of misclassified records. According to Table 4.18, the confusion matrix report for both max_depth= 1 and max_depth=2 are the same. Therefore, to have a better and deeper view of the decision tree classifier, we decide to choose max_depth=2 to continue working.

Table 4. 17 Splitting the Subset of data that was Predicted as "nondrinker" to training and testing data set

\begin{tabular}{|c|c|c|c|}
\hline & Instances & Attributes & Missing values \\
\hline Predicted as nondrinker & 97 & 58 & 0 \\
\hline Training Data_3 (70\% from row 1) & 67 & 58 & 0 \\
\hline Testing Data_3 (30\% from row 1) & 30 & 58 & 0 \\
\hline
\end{tabular}

Table 4. 18 Phase 2's D.T. Classifier, Finding the Optimal Depth and Best Accuracy Score for the subset of data that was predicted as "nondrinker" in Phase 1

\begin{tabular}{|c|c|}
\hline D.T. depth & Accuracy score \\
\hline 1 & 0.8656 \\
\hline 2 & 0.8656 \\
\hline 3 & 0.8507 \\
\hline 4 & 0.8507 \\
\hline 5 & 0.8507 \\
\hline 1 & 0.8656 \\
\hline
\end{tabular}




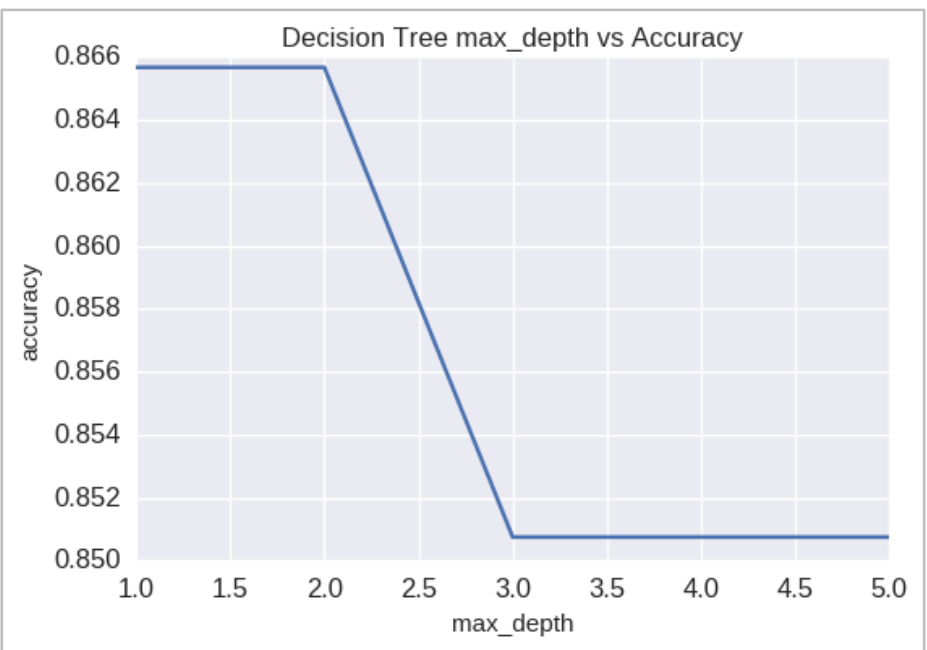

Figure 4. 4 Phase 2's D.T. Classifier, Finding the Optimal Depth and Best Accuracy Score for the subset that was predicted as "nondrinker" in Phase 1

Table 4. 19 Phase 2's D.T. Classifier, Comparing Classification Results with different Depths for the subset that was predicted as "nondrinker" in Phase 1

\begin{tabular}{|c|c|c|c|c|}
\hline & accuracy_score & Roc_Auc_score & $\begin{array}{c}\text { F1 } \\
\text { score }\end{array}$ & $\begin{array}{c}\text { Number of } \\
\text { Misclassified records }\end{array}$ \\
\hline $\begin{array}{c}\text { Decision Tree Classifier with } \\
\text { Max_depth=1 }\end{array}$ & 0.9 & 0.625 & 0.4 & 3 \\
\hline $\begin{array}{c}\text { Decision Tree Classifier with } \\
\text { Max_depth=2 }\end{array}$ & 0.9 & 0.552 & 0.4 & 3 \\
\hline $\begin{array}{c}\text { Decision Tree Classifier with } \\
\text { Max_depth=3 }\end{array}$ & 0.866 & 0.552 & 0.333 & 4 \\
\hline
\end{tabular}

Learning the D.T. on Training Data_3 (the training data of the subset that was predicted as "nondrinker") and then the prediction results are shown in Figure 4.5 as a confusion matrix. Indeed, Phase 2 predicts if Phase 1's prediction is incorrect. The data records for which their real value was "incorrect" in Phase 1 and they have been predicted to "incorrect" in Phase 2 can help us to find the rules that lead to incorrect predictions (incorrect stereotypical predictions). Here there is only one instance with this condition and we call it record "A" (Figure 4.5). For further exploration, we will go through the paths that led to predictions in Phase 1 and Phase 2 for data record " $A$ ". 


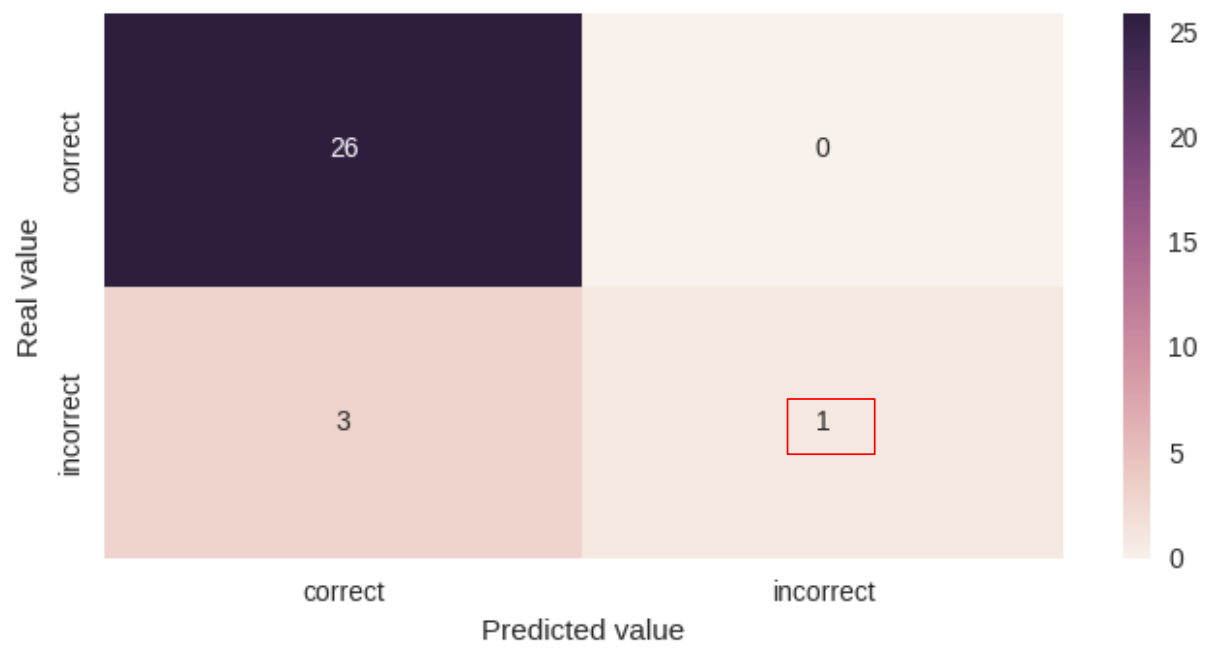

Figure 4. 5 Phase 2's D.T. Classifier, Confusion_matrix with max_depth=2 for the subset of data that was predicted as "nondrinker" in Phase 1

Phase 2's D.T. Classifier's Important features for the subset of data that was predicted as "nondrinker" in Phase 1 with max_depth=2:

Here the decision dree classifier chooses attributes "traveltime" and "Fedu" (Father education) as the important ones in making predictions. These features may hold the key to explaining and fixing incorrectly classified stereotyped data records. (Table 4.20)

Table 4. 20 Phase 2's D.T. Classifier's Important features for the subset of data that was predicted as "nondrinker" in Phase 1 with max_depth=2

\begin{tabular}{|c|c|}
\hline Features & Degree of importance \\
\hline traveltime & 0.5179 \\
\hline Fedu & 0.4820 \\
\hline Fjob_health & 0.0000 \\
\hline Medu & 0.0000 \\
\hline absences & 0.0000 \\
\hline
\end{tabular}

Decision tree extracted rules for data predicted as "nondrinker" in Phase 1, with max_depth=2:

Table 4.21 and Figure 4.6 display the graphical prediction results and decision rules generated be the decision tree classifier for this subset of data. 
Table 4. 21 Phase 2's D.T. Classifier's rules with Max_depth=2 for the subset of data that was predicted as "nondrinker" in Phase 1

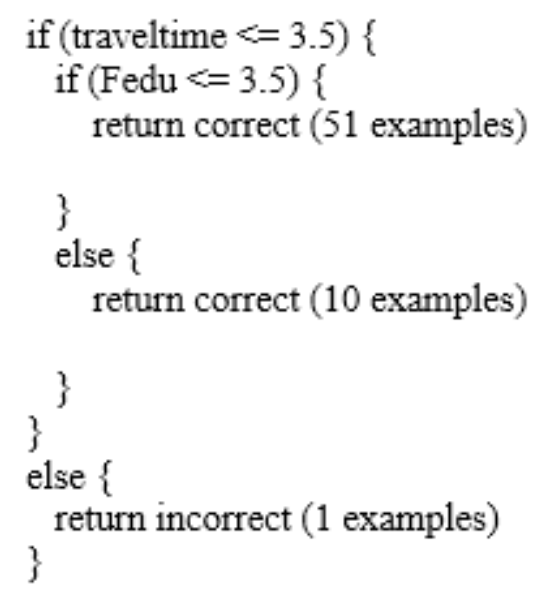

Decision Tree diagram for the subset of data was predicted as "nondrinker" in Phase 1, with max_depth=2:

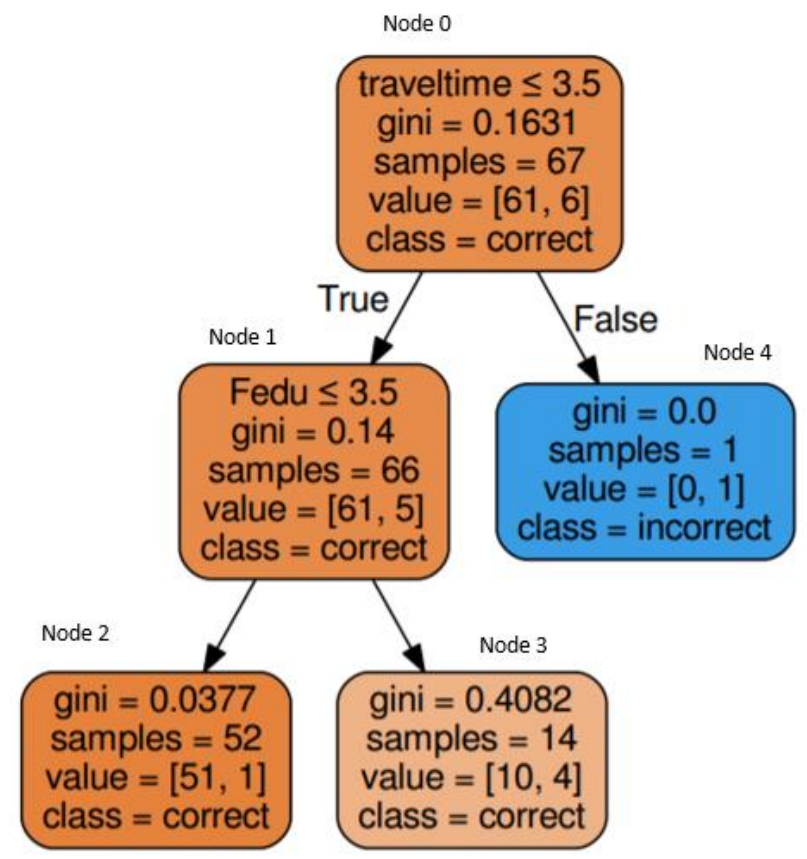

Figure 4. 6 Phase 2's D.T. diagram with Max_depth=2 for the subset of data that was predicted as "nondrinker" in Phase 1

Analyzing and Visualizing the records that have label "incorrect" in Phase 2 and have been predicted as "incorrect" by the Phase 2 Decision Tree Classifier:

Table 4.22 displays more information about data record " $\mathrm{A}$ ” and its attributes. 
Table 4. 22 The record of data that predicted as "nondrinker" with class label "incorrect" from Phase 1, which has been predicted to class label "incorrect" in Phase 2

\begin{tabular}{|c|c|c|c|c|c|c|c|c|c|c|c|c|c|c|c|c|c|c|c|}
\hline & sex & age & Medu & Fedu & Mjob & Fjob & guardian & traveltime & studytime & failures & activities & nursery & freetime & goout & absences & G1 & G2 & G3 & Alc \\
\hline & $\mathbf{F}$ & 16 & 1 & 1 & services & services & father & 4 & 1 & 0 & yes & no & 5 & - & & 0 & & & \\
\hline
\end{tabular}


Table 4. 23 Phase 2's D.T. Classifier's paths and rules that lead to misclassification for the subset of data that was predicted as "nondrinker" in Phase 1

\begin{tabular}{|l|l|l|l|}
\hline & Rules that lead to misclassification & $\begin{array}{l}\text { Number of test } \\
\text { data records } \\
\text { misclassified by } \\
\text { this rule }\end{array}$ & $\begin{array}{l}\text { Number of test } \\
\text { data records } \\
\text { classified } \\
\text { correctly by this } \\
\text { rule }\end{array}$ \\
\hline Path $0,1,2$ & $\begin{array}{l}\text { if (traveltime <=3.5 })\{ \\
\text { if }(\text { Fedu }<=3.5)\{ \\
\text { return correct }\end{array}$ & 2 & 22 \\
\hline Path 0,4 & $\begin{array}{c}\text { if (traveltime }>3.5) \\
\text { return incorrect }\end{array}$ & 1 & 0 \\
\hline
\end{tabular}

Building a Phase 2's D.T Classifier for the subset of data that was predicted as "drinker" by D.T from Phase 1 :

Table 4. 24 Splitting the Subset of data that was Predicted as "drinker" to training and testing data set

\begin{tabular}{|l|l|l|l|}
\hline & Instances & Attributes & Missing values \\
\hline Predicted as drinker & 22 & 58 & 0 \\
\hline Training Data_4 (70\% from row 1) & 15 & 58 & 0 \\
\hline Testing Data_4 (30\% from row 1) & 7 & 58 & 0 \\
\hline
\end{tabular}

Finding the optimal Depth for the subset of data that was predicted as "drinker" in Phase 1:

According to Table 4.25 which shows the results of searching the best accuracy score and minimum number of misclassified data records by applying "GridSearchCv" to Training Data_4, both max_depth= 1 and max_depth=2 generate the same accuracy scores. So, to have a better and deeper view of decision tree classifier we decide to choose max_depth=2 to continue working. 
Table 4. 25 Phase 2's D.T. Classifier, Finding the Optimal Depth and Best Accuracy Score for the subset of data that was predicted as "drinker" in Phase 1

\begin{tabular}{|l|l|}
\hline D.T depth & Accuracy score \\
\hline 1 & 0.4666 \\
\hline 2 & 0.4666 \\
\hline 3 & 0.4666 \\
\hline 4 & 0.4000 \\
\hline 5 & 0.4000 \\
\hline
\end{tabular}

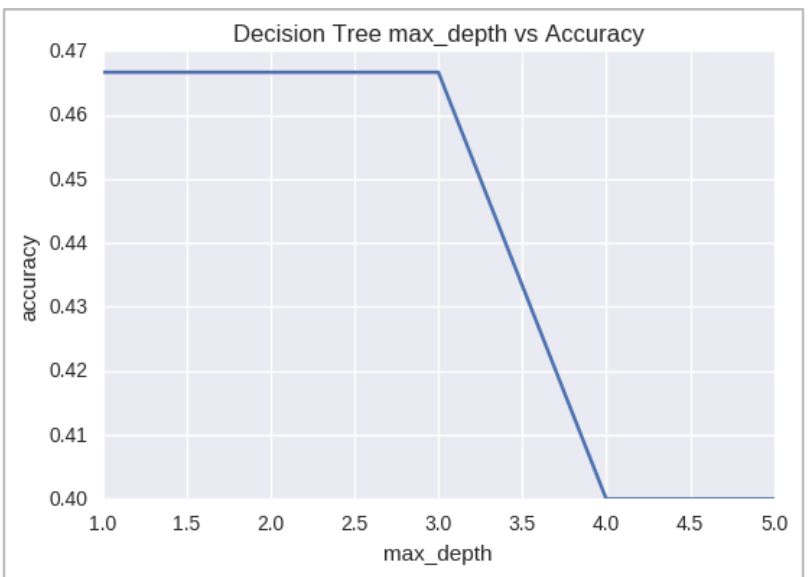

Figure 4. 7 Phase 2's D.T. Classifier, Finding the Optimal Depth and Best Accuracy Score for the subset of data that was predicted as "drinker" in Phase 1

Comparing Classification results with different depth of tree Phase2:

Table 4. 26 Phase 2's D.T. Classifier, Comparing Classification Results with different Depths for the subset of data that was predicted as "drinker" in Phase 1

\begin{tabular}{|l|l|l|l|l|}
\hline & accuracy_score & Roc_auc_score & $\begin{array}{l}\text { F1 } \\
\text { score }\end{array}$ & $\begin{array}{l}\text { Number of } \\
\text { Misclassified } \\
\text { records }\end{array}$ \\
\hline $\begin{array}{l}\text { Decision Tree } \\
\text { Classifier with } \\
\text { Max_depth=1 }\end{array}$ & 0.4285 & 0.45 & 0.5 & 4 \\
\hline $\begin{array}{l}\text { Decision Tree } \\
\text { Classifier with } \\
\text { Max_depth=2 }\end{array}$ & 0.5714 & 0.7 & 0.5714 & 3 \\
\hline $\begin{array}{l}\text { Decision Tree } \\
\text { Classifier with } \\
\text { Max_depth=3 }\end{array}$ & 0.5714 & 0.7 & 0.5714 & 3 \\
\hline
\end{tabular}


Phase 2's D.T Confusion_matrix with max_depth=2 for data predicted as "drinker" in Phase 1:

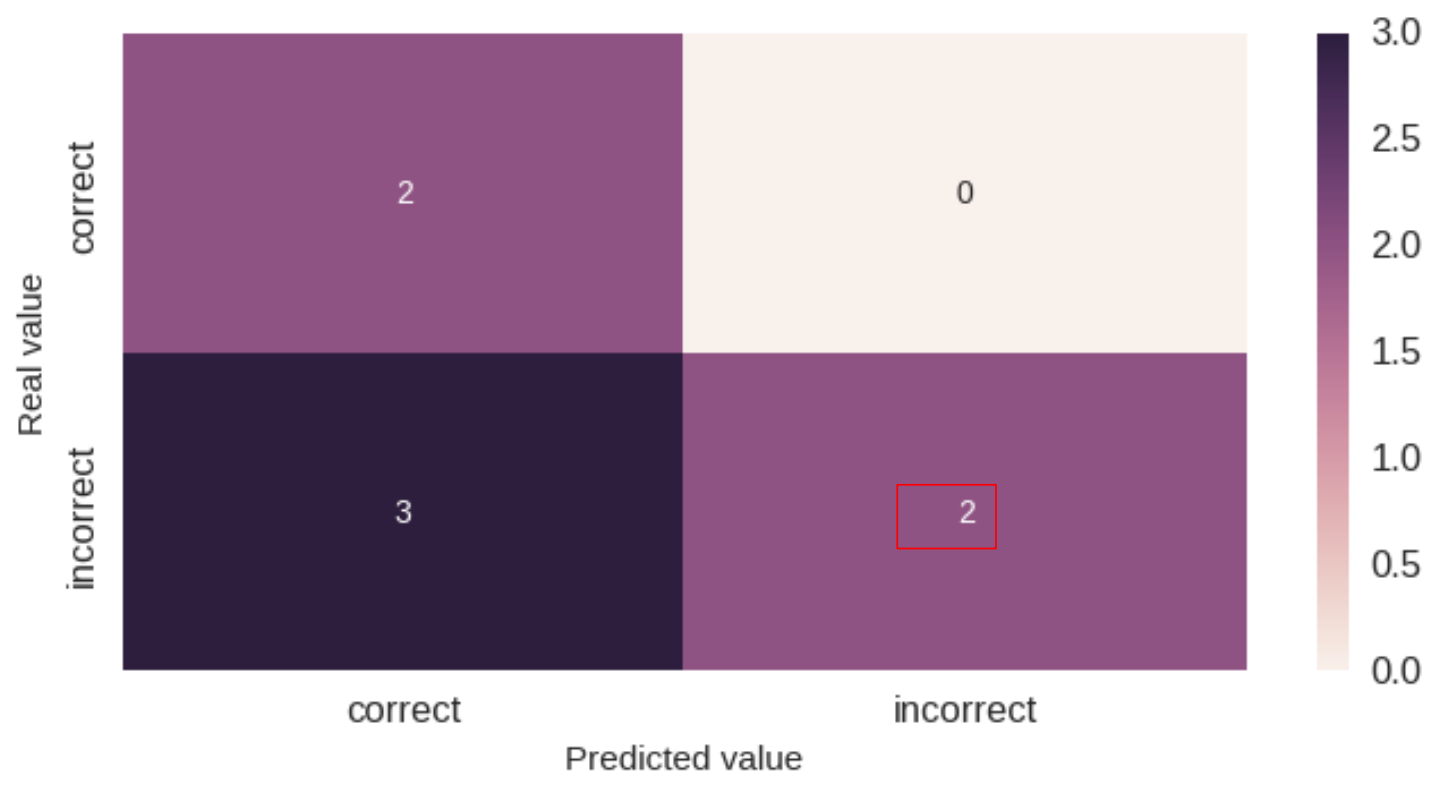

Figure 4. 8 Phase 2's D.T. Classifier's Confusion matrix with max_depth=2 for the subset of data that was predicted as "drinker" in Phase 1

Phase 2's Decision Tree Classifier's Important features for data predicted as "drinker" during Phase 1:

Table 4. 27 Phase 2's D.T. Classifier's Important features for the subset of data that was predicted as "drinker" in Phase 1 with max depth=2

\begin{tabular}{|l|l|}
\hline features & Degree of importance \\
\hline G2 & 0.4000 \\
\hline Medu & 0.3333 \\
\hline G1 & 0.2666 \\
\hline Fjob_other & 0.0000 \\
\hline absences & 0.0000 \\
\hline
\end{tabular}

These important features may hold the key to understanding the basis for the incorrect stereotypical predictions from Phase 1.

Extracting rules for Phase 2's Decision Tree Classifier trained on data predicted as "drinker" in Phase 1: 
Table 4. 28 Phase 2's D.T. Classifier's rules with Max_depth=2 for the subset of data that was predicted as "drinker" in Phase 1

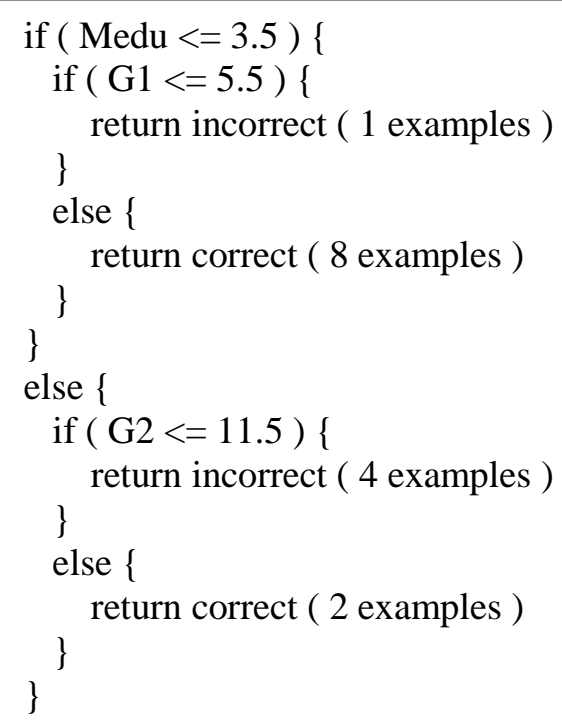

Phase 2's Tree Diagram for Decision Tree Classifier for data that was predicted as "drinker" during Phase 1:

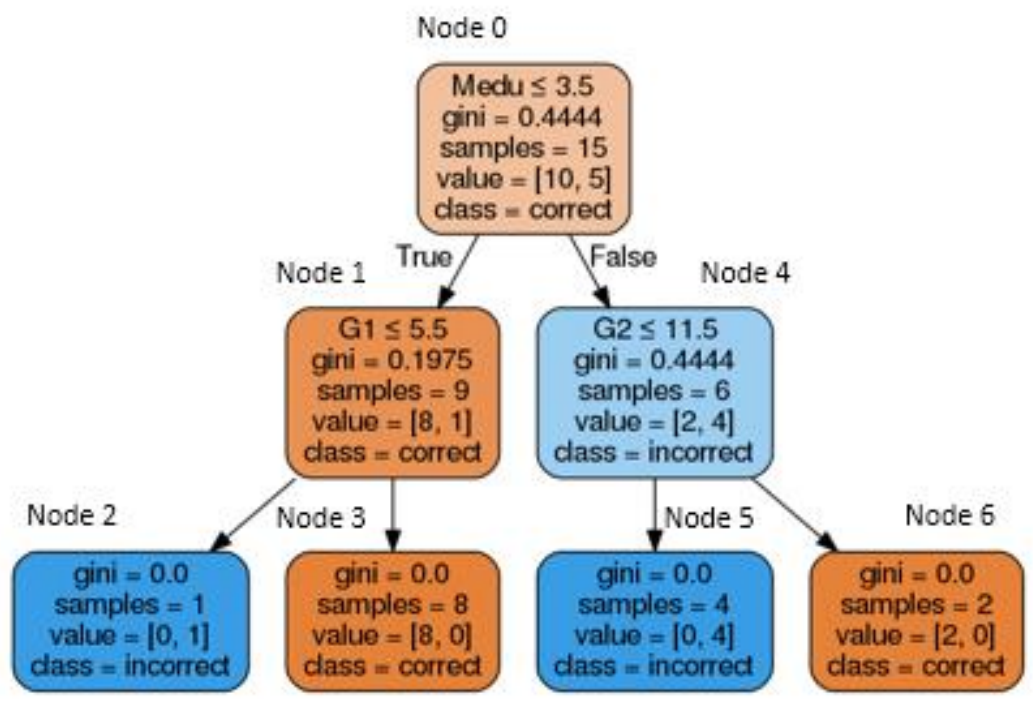

Figure 4. 9 Phase 2's D.T. diagram with max depth=2 for the subset of data that was predicted as "drinker" in Phase 1

In this step, according to the confusion matrix, we have two records for which their real value was "incorrect" and they have been predicted to "incorrect" (Figure 4.8). 
We will visualize these examples in Table 4.29. These two records have been predicted as a drinker in Phase 1 because their "goout" is greater than 3.5 and they are males ( sex_M $>0.5$ ). Then in Phase 2, because of having "Medu" $>3.5$ and G2 $<=11.5$, the model predicts them as a label of "incorrect". 
Table 4. 29 The records of data that predicted as "drinker" with class label "incorrect" from Phase 1, which has been predicted to class label "incorrect" in Phase 2.

\begin{tabular}{|c|c|c|c|c|c|c|c|c|c|c|c|c|c|c|c|c|c|c|c|}
\hline Nondrinker & sex & age & Medu & Fedu & Mjob & Fjob & guardian traveltime & studytime & failures & activities & nursery & freetime & goout & absences & G1 & G2 & G3 & Alc \\
\hline & M & 18 & 4 & 4 & teacher & services & mother & 2 & 1 & 0 & yes & yes & 2 & 4 & 22 & 9 & 9 & 9 & 2 \\
& M & 18 & 4 & $\mathbf{3}$ & teacher & other & mother & 1 & 3 & 0 & no & yes & 4 & 5 & 0 & 10 & 10 & 9 & $\mathbf{2}$ \\
\hline
\end{tabular}




\subsection{Analyzing the results}

Table 4.30 shows student "A" among her neighbors who all traverse the same path in Phase1's D.T because they go out a lot with friends and are females and, like A, have been predicted to be "nondrinker". The only difference is their real label: A was really a “drinker" but A1, A2 and A3 were really "nondrinkers". Looking at their similarity in going through the same path in Phase 1, we can understand how our model has learned to predict A, like A1, A2 and A3, as a "nondrinker". Their different decision tree paths in Phase 2 indicate how A is suspected to be a "drinker" in reality. As Table 4.30 shows, she spends a long time (more than 1 hour) getting home from school. This time may be spent with peers without parent supervision and possibly lead to drinking more alcohol.

The next table, Table 4.31, displays information related to record A and her neighbors who are all drinkers in reality but have been predicted incorrectly as "nondrinker". In Phase 1, their D.T paths followed two rules which caused the prediction "nondrinker"; one path says, if a student goes out frequently with friends but is a female, she is more likely to be a "nondrinker," and another one says having not too much hanging out with friends and not many absences in classes, counts for being a "nondrinker". Both rules make sense and are expected.

Record A and A'3 both have been predicted incorrectly as "nondrinkers" and our model in Phase 2 succeed to detect this wrong prediction. Their path in Phase 2 tells us which attributes may have misled the model in Phase 1, namely, having high "traveltime" to get back home from school, for both students, as shown in Table 4.31. 
Analyzing Table 4.33 and 4.34, provides us with the same information as we got above. Table 4.33 helps us to find B's neighbors, B1, B2 and B3, which are all "drinkers" and have been predicted correctly as "drinkers" (with probability \%60), which led our Phase 1 model to treat record B like them and forecast it as a "drinker". All nearest neighbors, B1, B2 and B3, frequently go out with their friends and are Male. So, they are more likely to be a "drinker". Moreover, the model in Phase 2 indicates that the prediction made in Phase 1 was correct to considered them as "drinker". But the path in Phase 2 explains that because they have highly educated mothers and not very weak performances in their second period grade, G2, they should be predicted as "nondrinker". This example may illustrate the importance of family (for example educated parents) on child discipline.

Other records with the same characteristic as record B, which have been classified incorrectly as "drinker" in Phase 1, are listed in Table 4.34. The rule that has incorrectly predicted students B'1, B'2 and B'3 to be "drinkers" in Phase 1 says the male students who like going out a lot with friends have characteristics of "drinkers". These students' paths in Phase 2 show the incorrect predictions for those who have an educated mother and not a very low grade in second period exam (G2) is wrong and need to be corrected.

From all these experiments, we saw how analyzing the D.T. path traversed by data that has been classified incorrectly can help explain the misclassifications based on certain features' conditions that are shared by these misclassified records. We can check the common and expected rules, for example being predicted as "nondrinker" for a student who goes out a lot with friends but is a female and being forecasted to be "drinker" for a male student who hangs out frequently with friends. These common rules that can lead to 
wrong predictions exemplify stereotypes that are learned by classifiers. Incorrect stereotypical predictions could be corrected in a second phase, in our example, by considering the parents' education for students who have been incorrectly predicted as a "drinker" and the time spent getting back home from school for students who have been predicted as a "nondrinker".

Going out more frequently with friends is one of the main concerns of parents who worry about their children becoming addicted to alcohol. Our study shows that a classification model easily learns such common stereotypical rules; however, this is not enough to predict whether a student is a drinker or not. For example, for female students, going out a lot is not enough to categorize them as "drinker", and we need to check another attribute for them. Record A'3 is the one that showed the importance of having long "traveltime" between school and home. This female student does not go out a lot with friends and does not have a lot of absences in her classes, which misleads the prediction model to judge her as a "nondrinker"; but paying attention to the long time that she spends getting home from school uncovers this incorrect prediction and corrects her label as a "drinker". The important role played by the time that a student spends after school to get home in predicting addiction to alcohol is illustrated in record A, which emphasizes that spending a long time to come back home from school is the rule condition that put her correctly in the drinker category. 
Table 4. 30 Nearest Neighbors of data record A, in training data set, from true class "nondrinker" and predicted as a nondrinker in Phase 1

\begin{tabular}{|c|c|c|c|c|c|c|c|c|c|c|}
\hline $\begin{array}{l}\text { Index } \\
\text { of } \\
\text { data } \\
\text { recor } \\
\text { ds }\end{array}$ & $\begin{array}{c}\text { Tempo } \\
\text { rary } \\
\text { name }\end{array}$ & $\begin{array}{c}\text { Distance } \\
\text { from A }\end{array}$ & $\begin{array}{c}\text { Real } \\
\text { Label in } \\
\text { Phase } 1\end{array}$ & $\begin{array}{c}\text { Predicte } \\
\text { d Label } \\
\text { in Phase } \\
1\end{array}$ & $\begin{array}{c}\text { Probabili } \\
\text { ty to be } \\
\text { in class } \\
\text { nondrink } \\
\text { er, } \\
\text { (Phase 1) }\end{array}$ & $\begin{array}{c}\text { Probabil } \\
\text { ity to be } \\
\text { in class } \\
\text { drinker, } \\
\text { (Phase } \\
1)\end{array}$ & $\begin{array}{c}\text { D.T } \\
\text { Path } \\
\text { fro } \\
\text { m } \\
\text { Pha } \\
\text { se } 1\end{array}$ & $\begin{array}{c}\text { Real } \\
\text { Label } \\
\text { in } \\
\text { Phase } \\
\quad 2\end{array}$ & $\begin{array}{c}\text { Predict } \\
\text { ed } \\
\text { Label } \\
\text { in } \\
\text { Phase 2 }\end{array}$ & $\begin{array}{c}\text { D.T } \\
\text { Path } \\
\text { in } \\
\text { Pha } \\
\text { se } 2\end{array}$ \\
\hline 61 & $\mathbf{A}$ & 0 & drinker & $\begin{array}{c}\text { Nondrin } \\
\text { ker }\end{array}$ & 0.833 & 0.166 & $0,4,5$ & $\begin{array}{c}\text { incorre } \\
\text { ct }\end{array}$ & $\begin{array}{c}\text { incorre } \\
\text { ct }\end{array}$ & 0,4 \\
\hline 284 & A1 & 5.5 & $\begin{array}{c}\text { Nondrin } \\
\text { ker }\end{array}$ & $\begin{array}{c}\text { Nondrin } \\
\text { ker }\end{array}$ & 0.833 & 0.166 & $0,4,5$ & correct & correct & $0,1,2$ \\
\hline 204 & A2 & 5.9 & $\begin{array}{c}\text { Nondrin } \\
\text { ker }\end{array}$ & $\begin{array}{c}\text { Nondrin } \\
\text { ker }\end{array}$ & 0.833 & 0.166 & $0,4,5$ & correct & correct & $0,1,2$ \\
\hline 283 & A3 & 6 & $\begin{array}{c}\text { Nondrin } \\
\text { ker }\end{array}$ & $\begin{array}{c}\text { Nondrin } \\
\text { ker }\end{array}$ & 0.833 & 0.166 & $0,4,5$ & correct & correct & $0,1,2$ \\
\hline
\end{tabular}

Table 4. 31 Nearest Neighbors of data record A, in training data set, from true class "drinker" and predicted as a nondrinker in Phase 1

\begin{tabular}{|c|c|c|c|c|c|c|c|c|c|c|}
\hline $\begin{array}{l}\text { Index } \\
\text { of } \\
\text { data } \\
\text { recor } \\
\text { ds }\end{array}$ & $\begin{array}{l}\text { Tempora } \\
\text { ry name }\end{array}$ & $\begin{array}{c}\text { Distan } \\
\text { ce } \\
\text { from } \\
\text { A }\end{array}$ & $\begin{array}{c}\text { Real } \\
\text { Label } \\
\text { in } \\
\text { phase } \\
1\end{array}$ & $\begin{array}{c}\text { Predicted } \\
\text { Label in } \\
\text { phase } 1\end{array}$ & $\begin{array}{c}\text { Probabili } \\
\text { ty to be in } \\
\text { class } \\
\text { nondrink } \\
\text { er, phase } \\
1\end{array}$ & $\begin{array}{l}\text { Probabili } \\
\text { ty to be } \\
\text { in class } \\
\text { drinker, } \\
\text { phase } 1\end{array}$ & $\begin{array}{c}\text { Path } \\
\text { fro } \\
\text { m } \\
\text { phas } \\
\text { e } 1\end{array}$ & $\begin{array}{c}\text { Real } \\
\text { Label } \\
\text { in } \\
\text { phase } 2\end{array}$ & $\begin{array}{c}\text { Predict } \\
\text { ed } \\
\text { Label } \\
\text { in } \\
\text { phase } 2\end{array}$ & $\begin{array}{c}\text { Path } \\
\text { in } \\
\text { phas } \\
\text { e } 2\end{array}$ \\
\hline 61 & $\mathbf{A}$ & 0 & $\begin{array}{c}\text { drink } \\
\text { er }\end{array}$ & $\begin{array}{c}\text { Nondrink } \\
\text { er }\end{array}$ & 0.83 & 0.17 & $0,4,5$ & $\begin{array}{c}\text { incorre } \\
\text { ct }\end{array}$ & $\begin{array}{c}\text { incorre } \\
\text { ct }\end{array}$ & 0,4 \\
\hline 41 & A'1 & 8.6 & $\begin{array}{c}\text { drink } \\
\text { er }\end{array}$ & $\begin{array}{c}\begin{array}{c}\text { Nondrink } \\
\text { er }\end{array} \\
\end{array}$ & 0.95 & 0.05 & $0,1,2$ & $\begin{array}{c}\text { incorre } \\
\text { ct }\end{array}$ & correct & $0,1,3$ \\
\hline 318 & A'2 & 9.48 & $\begin{array}{c}\text { drink } \\
\text { er }\end{array}$ & $\begin{array}{c}\text { Nondrink } \\
\text { er }\end{array}$ & 0.83 & 0.17 & $0,4,5$ & $\begin{array}{c}\text { incorre } \\
\text { ct }\end{array}$ & correct & $0,1,3$ \\
\hline 228 & A'3 & 10.29 & $\begin{array}{c}\text { drink } \\
\text { er }\end{array}$ & $\begin{array}{c}\text { Nondrink } \\
\text { er }\end{array}$ & 0.95 & 0.05 & $0,1,2$ & $\begin{array}{c}\text { incorre } \\
\text { ct }\end{array}$ & $\begin{array}{c}\text { incorre } \\
\text { ct }\end{array}$ & 0,4 \\
\hline
\end{tabular}


Table 4. 32 Rules and Paths for Tables 4.30 and 4.31

\begin{tabular}{|c|c|c|c|}
\hline Record names & Phase/predicted class & Path & Rules \\
\hline $\mathbf{A}, \mathbf{A} 1, \mathbf{A} 2, \mathbf{A} 3, \mathbf{A}^{\prime} 2$ & $1 /$ predicted as a nondrinker & $0,4,5$ & $\begin{array}{l}\text { if }(\text { goout }>3.5) \\
\text { if }(\text { sex_M }<=0.5) \\
\text { return nondrinker }\end{array}$ \\
\hline A'1, A'3 & & $0,1,2$ & $\begin{array}{l}\text { if }(\text { goout }<=3.5) \\
\text { if }(\text { absences }<=26.5) \\
\text { return nondrinker }\end{array}$ \\
\hline A, A'3 & $2 /$ predicted as a nondrinker & 0,4 & $\begin{array}{l}\text { if (traveltime > 3.5) } \\
\text { return incorrect }\end{array}$ \\
\hline $\mathbf{A 1}, \mathbf{A 2}, \mathbf{A 3}$ & & $0,1,2$ & $\begin{array}{c}\text { if } \text { (traveltime }<=3.5 \text { ) } \\
\text { if }(\text { Fedu }<=3.5) \\
\text { return correct }\end{array}$ \\
\hline A'1, A'2 & & $0,1,3$ & $\begin{array}{c}\text { if }(\text { traveltime }<=3.5) \\
\text { if }(\text { Fedu }>=3.5) \\
\text { return correct }\end{array}$ \\
\hline
\end{tabular}

Nearest Neighbors of data record $B$, in the training data set, from predicted as drinker during Phase 2.

Table 4. 33 Nearest Neighbors of data record B, in training data set, from true class "drinker" and predicted as "drinker" in Phase 1

\begin{tabular}{|c|c|c|c|c|c|c|c|c|c|c|}
\hline $\begin{array}{l}\text { Index } \\
\text { of } \\
\text { data } \\
\text { recor } \\
\text { ds }\end{array}$ & $\begin{array}{l}\text { Tempora } \\
\text { ry name }\end{array}$ & $\begin{array}{c}\text { Distan } \\
\text { ce } \\
\text { from } \\
\text { A }\end{array}$ & $\begin{array}{c}\text { Real } \\
\text { Label in } \\
\text { Phase } 1\end{array}$ & $\begin{array}{c}\text { Predict } \\
\text { ed } \\
\text { Label } \\
\text { in } \\
\text { Phase } 1\end{array}$ & $\begin{array}{c}\text { Probabili } \\
\text { ty to be } \\
\text { in class } \\
\text { nondrink } \\
\text { er, (Phase } \\
\text { 1) }\end{array}$ & $\begin{array}{l}\text { Probabil } \\
\text { ity to be } \\
\text { in class } \\
\text { drinker, } \\
\text { (Phase 1) }\end{array}$ & $\begin{array}{c}\text { D.T } \\
\text { Path } \\
\text { fro } \\
\text { m } \\
\text { phas } \\
\text { e } 1\end{array}$ & $\begin{array}{c}\text { Real } \\
\text { Label } \\
\text { in } \\
\text { Phase } \\
2\end{array}$ & $\begin{array}{c}\text { Predict } \\
\text { ed } \\
\text { Label } \\
\text { in } \\
\text { Phase } 2\end{array}$ & $\begin{array}{l}\text { D.T } \\
\text { Path } \\
\text { in } \\
\text { Pha } \\
\text { se } 2\end{array}$ \\
\hline 347 & B & 0 & $\begin{array}{c}\text { Nondrin } \\
\text { ker }\end{array}$ & drinker & 0.40 & 0.60 & $0,4,6$ & $\begin{array}{c}\text { incorre } \\
\text { ct }\end{array}$ & $\begin{array}{c}\text { incorre } \\
\text { ct }\end{array}$ & $0,4,5$ \\
\hline 330 & B1 & 5.2 & drinker & drinker & 0.40 & 0.60 & $0,4,6$ & correct & correct & $0,1,3$ \\
\hline 250 & B2 & 6.3 & drinker & drinker & 0.40 & 0.60 & $0,4,6$ & correct & correct & $0,1,3$ \\
\hline 125 & B3 & 7.8 & drinker & drinker & 0.40 & 0.60 & $0,4,6$ & correct & correct & $0,1,3$ \\
\hline
\end{tabular}

Table 4. 34 Nearest Neighbors of data record B, in training data set, from true class "nondrinker" and predicted as a "drinker" in Phase 1

\begin{tabular}{|l|l|l|l|l|l|l|l|l|l|l|}
\hline $\begin{array}{l}\text { Index } \\
\text { of } \\
\text { data } \\
\text { recor } \\
\text { ds }\end{array}$ & $\begin{array}{l}\text { Tempora } \\
\text { ry name }\end{array}$ & $\begin{array}{l}\text { Distan } \\
\text { ce } \\
\text { from } \\
\text { A }\end{array}$ & $\begin{array}{l}\text { Real } \\
\text { Label in } \\
\text { Phase 1 }\end{array}$ & $\begin{array}{l}\text { Predict } \\
\text { ed } \\
\text { Label } \\
\text { in } \\
\text { Phase 1 }\end{array}$ & $\begin{array}{l}\text { Probabili } \\
\text { ty to be } \\
\text { in class } \\
\text { nondrink } \\
\text { er, } \\
\text { (Phase 1) }\end{array}$ & $\begin{array}{l}\text { Probabil } \\
\text { ity to be } \\
\text { in class } \\
\text { drinker, } \\
\text { (Phase 1) }\end{array}$ & $\begin{array}{l}\text { D.T } \\
\text { Path } \\
\text { fro } \\
\text { m } \\
\text { Pha } \\
\text { se 1 }\end{array}$ & $\begin{array}{l}\text { Real } \\
\text { Label } \\
\text { in } \\
\text { Phase } \\
2\end{array}$ & $\begin{array}{l}\text { Predict } \\
\text { ed } \\
\text { Label } \\
\text { in } \\
\text { Phase 2 }\end{array}$ & $\begin{array}{l}\text { D.T } \\
\text { Path } \\
\text { in } \\
\text { Pha } \\
\text { se 2 }\end{array}$ \\
\hline 347 & B & 0 & $\begin{array}{l}\text { Nondrin } \\
\text { ker }\end{array}$ & drinker & $\mathbf{0 . 4 0}$ & $\mathbf{0 . 6 0}$ & $\mathbf{0 , 4 , 6}$ & $\begin{array}{l}\text { incorre } \\
\text { ct }\end{array}$ & $\begin{array}{l}\text { incorre } \\
\text { ct }\end{array}$ & \begin{tabular}{l}
$0,4,5$ \\
\hline
\end{tabular} \\
\hline
\end{tabular}




\begin{tabular}{|c|c|c|c|c|c|c|c|c|c|c|}
\hline 172 & B'1 & 4.8 & $\begin{array}{l}\text { Nondrin } \\
\text { ker }\end{array}$ & drinker & 0.40 & 0.60 & $0,4,6$ & $\begin{array}{l}\text { incorre } \\
\text { ct }\end{array}$ & $\begin{array}{l}\text { incorre } \\
\text { ct }\end{array}$ & $\overline{0,4,5}$ \\
\hline 354 & B'2 & 7.48 & $\begin{array}{l}\text { Nondrin } \\
\text { ker }\end{array}$ & drinker & 0.40 & 0.60 & $0,4,6$ & $\begin{array}{l}\text { incorre } \\
\text { ct }\end{array}$ & $\begin{array}{l}\text { incorre } \\
\text { ct }\end{array}$ & $0,4,5$ \\
\hline 161 & B'3 & 9.84 & $\begin{array}{l}\text { Nondrin } \\
\text { ker }\end{array}$ & drinker & 0.40 & 0.60 & $0,4,6$ & $\begin{array}{l}\text { incorre } \\
\text { ct }\end{array}$ & $\begin{array}{l}\text { incorre } \\
\text { ct }\end{array}$ & $0,1,2$ \\
\hline
\end{tabular}

Table 4. 35 Rules and Paths for Tables 4.33 and 4.34

\begin{tabular}{|c|c|c|c|}
\hline Records name & Phase/class & Path & Rules \\
\hline $\begin{array}{l}\text { B,B1,B2,B3, } \\
\text { B'1,B'2,B'3 }\end{array}$ & 1/predicted as drinker & $0,4,6$ & $\begin{array}{c}\text { if }(\text { goout }>3.5)\{ \\
\text { if }(\text { sex_M }>0.5)\{ \\
\text { return drinker }\end{array}$ \\
\hline B ,B'1,B'2 & \multirow[t]{2}{*}{ 2/predicted as drinker } & $0,4,5$ & $\begin{array}{l}\text { if }(\text { Medu }>3.5) \\
\text { if }(\text { G2 }<=11.5) \\
\text { return incorrect }\end{array}$ \\
\hline B1,B2,B3 & & $0,1,3$ & $\begin{array}{c}\text { if }(\text { Medu < }=3.5) \\
\text { if }(\text { G1 }>5.5) \\
\text { return correct }\end{array}$ \\
\hline B'3 & & $0,1,2$ & $\begin{array}{c}\text { if }(\text { Medu }<=3.5) \\
\text { if }(\text { G1 }<=5.5) \\
\text { return incorrect }\end{array}$ \\
\hline
\end{tabular}

Table 4. 36 Summary of the results for Student Alcohol dataset

\begin{tabular}{|c|c|c|c|c|}
\hline $\begin{array}{l}\text { Misclassified } \\
\text { data record }\end{array}$ & $\begin{array}{l}\text { Real Label } \\
\text { in phase } 1\end{array}$ & $\begin{array}{l}\text { Predicted } \\
\text { Label in } \\
\text { phase } 1\end{array}$ & $\begin{array}{l}\text { Reasons for } \\
\text { prediction in Phase } 1\end{array}$ & $\begin{array}{l}\text { Reasons which } \\
\text { can explain } \\
\text { incorrect } \\
\text { prediction in } \\
\text { Phase } 1\end{array}$ \\
\hline A & drinker & nondrinker & $\begin{array}{ll} & \text { Frequently } \\
\text { going out with } \\
\text { friends } \\
\text { - } & \text { Female }\end{array}$ & $\begin{array}{l}\text { Long travel } \\
\text { time to get } \\
\text { home }\end{array}$ \\
\hline$A^{\prime} 3$ & drinker & nondrinker & 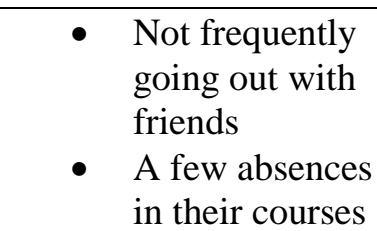 & $\begin{array}{l}\text { - Long travel } \\
\text { time to get } \\
\text { home }\end{array}$ \\
\hline $\mathrm{B}$ & nondrinker & drinker & $\begin{array}{ll} & \text { Frequently } \\
\text { going out with } \\
\text { friends } \\
\text { - } & \text { Male }\end{array}$ & $\begin{array}{ll}\text { - } & \begin{array}{l}\text { Highly } \\
\text { educated } \\
\text { mother }\end{array} \\
\text { - } & \text { Not very } \\
\text { weak } \\
\text { performanc } \\
\text { e in their } \\
\text { grades }\end{array}$ \\
\hline
\end{tabular}


Our results for male students also confirm that hanging out a lot with friends is not a sufficient factor for being a "drinker" because we have some real drinkers and real nondrinkers who all go out a lot to meet their friends. Here, the role of having educated parents in the family, particularly mothers, is more important than course grades. We can see for instance, that record $\mathrm{B}$, although has been misclassified in Phase 1 as a drinker, was correctly classified in phase 2 because of the educated mother. Another example illustrating the impact of parents' education for nondrinking children was B1, B2 and B3 who are male drinkers, go out a lot with peers, and have less educated mothers.

As discussed above, our analysis shows that an educated mother plays an important role in preventing alcohol addiction for male teenagers. According to our study, the girls who spend more than one hour in their trip from school to home are more likely to be drinkers.

\section{Validating the experimental results}

As we have mentioned before, the important features may have the key for explaining and fixing the misclassified stereotype data records. Here, we investigate this hypothesis by comparing the important features in each phase and finding their relation with the features that helped us to explain the misclassified records.

The important feature in "scikit-learn" is calculated by "Gini importance" or "mean decrease impurity" which is the (normalized) total reduction of the criterion brought by that feature. The higher, the more important the feature.

Tables 4.37-39 show the attributes which are important in making decisions by decision trees in Phase 1 and Phase 2 for each predicted class. As we can see "traveltime" and "Medu," which helped us to explain the reason behind incorrect predictions, are 
important features chosen by decision trees to make predictions. Hence, this finding supports our hypothesis about the role of important features in explaining the prediction results.

\section{Phase 1's important features}

Table 4. 37 Phase 1's D.T. Classifier's Important features

\begin{tabular}{|l|l|}
\hline attribute & importance \\
\hline goout & 0.556622 \\
\hline sex_M & 0.392336 \\
\hline absences & 0.051042 \\
\hline
\end{tabular}

Phase 2's important features for the subset of data that was predicted as "nondrinker" in Phase 1

Table 4. 38 Phase 2's D.T. Classifier's Important features for the subset of data that was predicted as "nondrinker" in Phase 1

\begin{tabular}{|l|l|}
\hline attribute & importance \\
\hline traveltime & 0.517902 \\
\hline Fedu & 0.482098 \\
\hline
\end{tabular}

\section{Phase 2's important features for the subset of data that was predicted as "drinker" in Phase 1}

Table 4. 39 Phase 2's D.T. Classifier's Important features for the subset of data that was predicted as "drinker" in Phase 1

\begin{tabular}{|l|l|}
\hline attribute & importance \\
\hline G2 & 0.400000 \\
\hline Medu & 0.333333 \\
\hline G1 & 0.266667 \\
\hline
\end{tabular}

To further investigate, we compare the performance of the decision tree classifier for each Phase, in two parts, before pruning the tree and after it, and for each part, we include all features and then important features only. According to Table 4.40, repeating the classification process only with important features has improved the classification results in Phase 1, as we expected. Also, having the same results in Table 4.41, for decision trees 
after pruning indicates our model is strong enough. Therefore, instead of considering all the features, we can apply our model only on the important features and get the same results.

Table 4. 40 Comparing Classification results before Decision Tree tuning parameter for Phase 1

\begin{tabular}{|l|l|l|}
\hline & With all features & With important features \\
\hline Accuracy score & 0.7142 & 0.7563 \\
\hline Roc_auc score & 0.5260 & 0.6220 \\
\hline F1 score & 0.2272 & 0.3829 \\
\hline
\end{tabular}

Table 4. 41 Comparing Classification results after Decision Tree tuning parameter for Phase 1

\begin{tabular}{|l|l|l|}
\hline & With all features & With important features \\
\hline Accuracy score & 0.8319 & 0.8319 \\
\hline Roc_auc score & 0.7197 & 0.7197 \\
\hline F1 score & 0.5454 & 0.5454 \\
\hline
\end{tabular}

\section{Repeating the process by censoring and changing some attributes:}

To find out whether our model can detect and explain misclassified records, we repeat our methodology one time with removing one of the attributes and another time with changing its real value. Based on the important features of the original dataset from Phase 1, we found that the attribute "goout" has a key role in our prediction results. So, we remove this attribute and repeat all the steps. Interestingly, the model still has predicted the record "A" incorrectly as "nondrinker". This time the model says because " $\mathrm{A}$ " is a "Female" with a lot of "freetime" after school and not too many absences, she should be "nondrinker" which is an incorrect prediction. However, Phase 2 reveals, because she has not gone to the nursery school and has a father as her guardian, she definitely is a "drinker". 
Another instance from data records that were predicted as "drinker" incorrectly is "B'3" who is a "Male" with a low grade in "G2" (second period exam) and not having any extra-curricular activities. So the model predicts him incorrectly as "drinker" in Phase 1, while Phase 2 shows he should be a "nondrinker" because of his high "studytime".

The next step is changing the value of the attribute "goout" and repeating the explorations. We change all the records that have high "goout" (with rank 5 and 4 ) to the ones with less "goout". Again, "A" and "B" have been predicted incorrectly and our model is still able to explain this misclassification. According to the decision tree paths from Phase 1, "A" is "nondrinker" because she does not go out a lot with friends (this value has been reversed by us in this step). But Phase 2 indicates that because she spends a long time going from school to home, she should be a "drinker" which is true. For "B" also, changing its "goout" value from a person who goes out a lot to one who does not, does not prevent our model from detecting and revealing the reasons behind its incorrect prediction.

In summary, removing or changing the attributes does not affect our model in finding and interpreting the incorrect prediction results. It uses other attributes or changes the logic for choosing and splitting the decision areas of the decision tree classifier to detect and explain incorrect predictions.

\subsubsection{Case study 2}

\subsubsection{German credit dataset}

This dataset classifies people by a set of attributes as "good" for customers with low risk in loan repayment and "bad" for those who have high risk for late or incomplete 
loan repayment. Each row represents a previous customer, with each column representing an attribute, such as age or employment status, and a final column in which the customer's credit risk has been labeled (either 1 for "Good", or 2 for "Bad"). (Tables 4.42-43)

Table 4. 42 German Credit dataset attributes

\begin{tabular}{|c|c|c|c|}
\hline & Attributes & Definition & \\
\hline \multirow[t]{4}{*}{1} & \multirow[t]{4}{*}{ Status of existing checking account } & A11 & $\ldots<0 \mathrm{DM}$ \\
\hline & & A12 & $0<=\ldots<200 \mathrm{DM}$ \\
\hline & & A13 & $\begin{array}{l}\ldots>=200 \mathrm{DM} / \text { salary assignments for at least } 1 \\
\text { year }\end{array}$ \\
\hline & & A14 & no checking account \\
\hline 2 & \multicolumn{2}{|l|}{ Duration } & in month \\
\hline \multirow[t]{5}{*}{3} & \multirow[t]{5}{*}{ Credit history } & $\mathrm{A} 30$ & no credits taken/ all credits paid back duly \\
\hline & & $\mathrm{A} 31$ & all credits at this bank paid back duly \\
\hline & & A32 & existing credits paid back duly till now \\
\hline & & A33 & delay in paying off in the pas \\
\hline & & A34 & $\begin{array}{l}\text { critical account/ other credits existing (not at this } \\
\text { bank) }\end{array}$ \\
\hline \multirow[t]{11}{*}{4} & \multirow[t]{11}{*}{ Purpose } & $\mathrm{A} 40$ & car (new) \\
\hline & & A41 & car (used) \\
\hline & & A42 & furniture/equipment \\
\hline & & A43 & radio/television \\
\hline & & A44 & domestic appliances \\
\hline & & A45 & repairs \\
\hline & & A46 & education \\
\hline & & A47 & (vacation - does not exist?) \\
\hline & & A48 & retraining \\
\hline & & A49 & business \\
\hline & & A410 & others \\
\hline 5 & Credit amount & & \\
\hline \multirow[t]{5}{*}{6} & \multirow[t]{5}{*}{ Savings account/bonds } & A61 & $\ldots<100 \mathrm{DM}$ \\
\hline & & A62 & $100<=\ldots<500 \mathrm{DM}$ \\
\hline & & A63 & $500<=\ldots<1000 \mathrm{DM}$ \\
\hline & & A64 & $\ldots>=1000 \mathrm{DM}$ \\
\hline & & A65 & unknown/ no savings account \\
\hline \multirow[t]{5}{*}{7} & \multirow[t]{5}{*}{ Present employment since } & A71 & unemployed \\
\hline & & A72 & $\ldots<1$ year \\
\hline & & A73 & $1<=\ldots<4$ years \\
\hline & & A74 & $4<=\ldots<7$ years \\
\hline & & A75 & $\ldots>=7$ years \\
\hline 8 & \multicolumn{3}{|l|}{ Installment rate in percentage of } \\
\hline
\end{tabular}




\begin{tabular}{|c|c|c|c|}
\hline & disposable income & & \\
\hline \multirow[t]{5}{*}{9} & \multirow{5}{*}{ Personal status and sex } & A91 & male : divorced/separated \\
\hline & & A92 & female : divorced/separated/married \\
\hline & & A93 & male : single \\
\hline & & A94 & male : married/widowed \\
\hline & & A95 & female : single \\
\hline \multirow[t]{3}{*}{10} & \multirow[t]{3}{*}{ Other debtors / guarantors } & A101 & none \\
\hline & & A102 & co-applicant \\
\hline & & A103 & guarantor \\
\hline 11 & Present residence since & & \\
\hline \multirow[t]{4}{*}{12} & \multirow{4}{*}{ Property } & A121 & real estate \\
\hline & & A122 & $\begin{array}{l}\text { if not A121 : building society savings } \\
\text { agreement/ life insurance }\end{array}$ \\
\hline & & A123 & if not A121/A122: car or other, not in attribute 6 \\
\hline & & A124 & unknown / no property \\
\hline 13 & \multicolumn{2}{|l|}{ Age } & in years \\
\hline \multirow[t]{3}{*}{14} & \multirow[t]{3}{*}{ Other installment plans } & A141 & bank \\
\hline & & A142 & stores \\
\hline & & A143 & none \\
\hline \multirow[t]{3}{*}{15} & \multirow[t]{3}{*}{ Housing } & A151 & rent \\
\hline & & A152 & own \\
\hline & & A153 & for free \\
\hline 16 & \multicolumn{3}{|l|}{$\begin{array}{l}\text { Number of existing credits at this } \\
\text { bank }\end{array}$} \\
\hline \multirow[t]{4}{*}{17} & \multirow[t]{4}{*}{ Job } & A171 & unemployed/ unskilled - non-resident \\
\hline & & A172 & unskilled - resident \\
\hline & & A173 & skilled employee / official \\
\hline & & A174 & $\begin{array}{l}\text { management/ self-employed/ } \\
\text { highly qualified employee/ officer }\end{array}$ \\
\hline 18 & \multicolumn{2}{|l|}{ Dependents } & $\begin{array}{l}\text { Number of people being liable to provide } \\
\text { maintenance for }\end{array}$ \\
\hline \multirow[t]{2}{*}{19} & \multirow[t]{2}{*}{ Telephone } & A191 & none \\
\hline & & A192 & yes, registered under the customer's name \\
\hline \multirow[t]{2}{*}{20} & \multirow[t]{2}{*}{ Foreign worker } & A201 & yes \\
\hline & & A202 & no \\
\hline \multirow[t]{2}{*}{21} & \multirow[t]{2}{*}{ Creditability (Class label) } & good & 0 \\
\hline & & bad & 1 \\
\hline
\end{tabular}

Table 4. 43 German Credit dataset information

\begin{tabular}{|c|c|c|c|c|c|}
\hline & Instances & Attributes & Missing values & $\begin{array}{c}\text { Default label } \\
\text { good }\end{array}$ & $\begin{array}{c}\text { Default label } \\
\text { bad }\end{array}$ \\
\hline Data & 1000 & 20 & 0 & 700 & 300 \\
\hline
\end{tabular}




\subsection{Phase 1}

After applying the decision tree classifier to the divided datasets with ratio of 0.7 for training and 0.3 for testing, the best accuracy score will be reached by building the decision trees with depth=3 but it makes the F1 score of the subsets of data in Phase 2 to zero (Table 4.44). So, to avoid this situation and to have a better and deeper view, we choose depth $=5$ to continue our work. After learning the decision trees, the confusion matrix results is calculated and presented in Table 4.45 .

Table 4. 44 Phase 1's D.T. for German credit data, Finding the Optimal Depth and Best Accuracy Score

\begin{tabular}{|l|l|}
\hline D.T depth & Accuracy score \\
\hline 1 & 0.70 \\
\hline 2 & 0.70 \\
\hline 3 & 0.72 \\
\hline 4 & 0.71 \\
\hline 5 & 0.70 \\
\hline 6 & 0.69 \\
\hline 7 & 0.69 \\
\hline
\end{tabular}

Table 4. 45 Phase 1's D.T. Classifier's Confusion matrix with max_depth=5 for German credit dataset

\begin{tabular}{|l|l|l|l|}
\hline & accuracy_score & Roc_auc_score & $\begin{array}{l}\text { F1 } \\
\text { score }\end{array}$ \\
\hline $\begin{array}{l}\text { D.T. Classifier with } \\
\text { Max_depth=5 }\end{array}$ & 0.69 & 0.66 & 0.35 \\
\hline
\end{tabular}




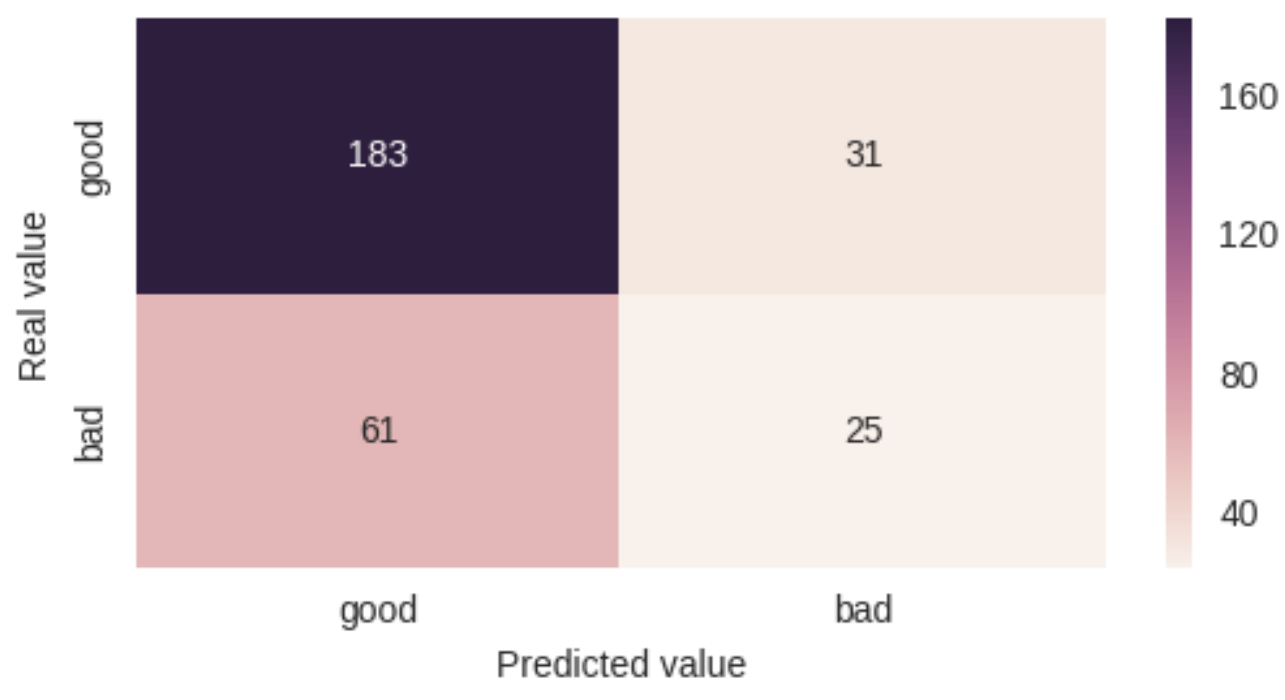

Figure 4. 10 Phase 1's D.T. Classifier's Confusion matrix with max_depth=5 for German credit dataset

Table 4. 46 Phase 1's D.T's top important features for German credit dataset

\begin{tabular}{|l|l|}
\hline features & Degree of importance \\
\hline checkin_acc_A14 & 0.259394 \\
\hline credit_amount & 0.145334 \\
\hline duration & 0.136960 \\
\hline other_parties_A101 & 0.079646 \\
\hline credit_history_A34 & 0.068615 \\
\hline age & 0.044485 \\
\hline saving_acc_A61 & 0.041987 \\
\hline
\end{tabular}




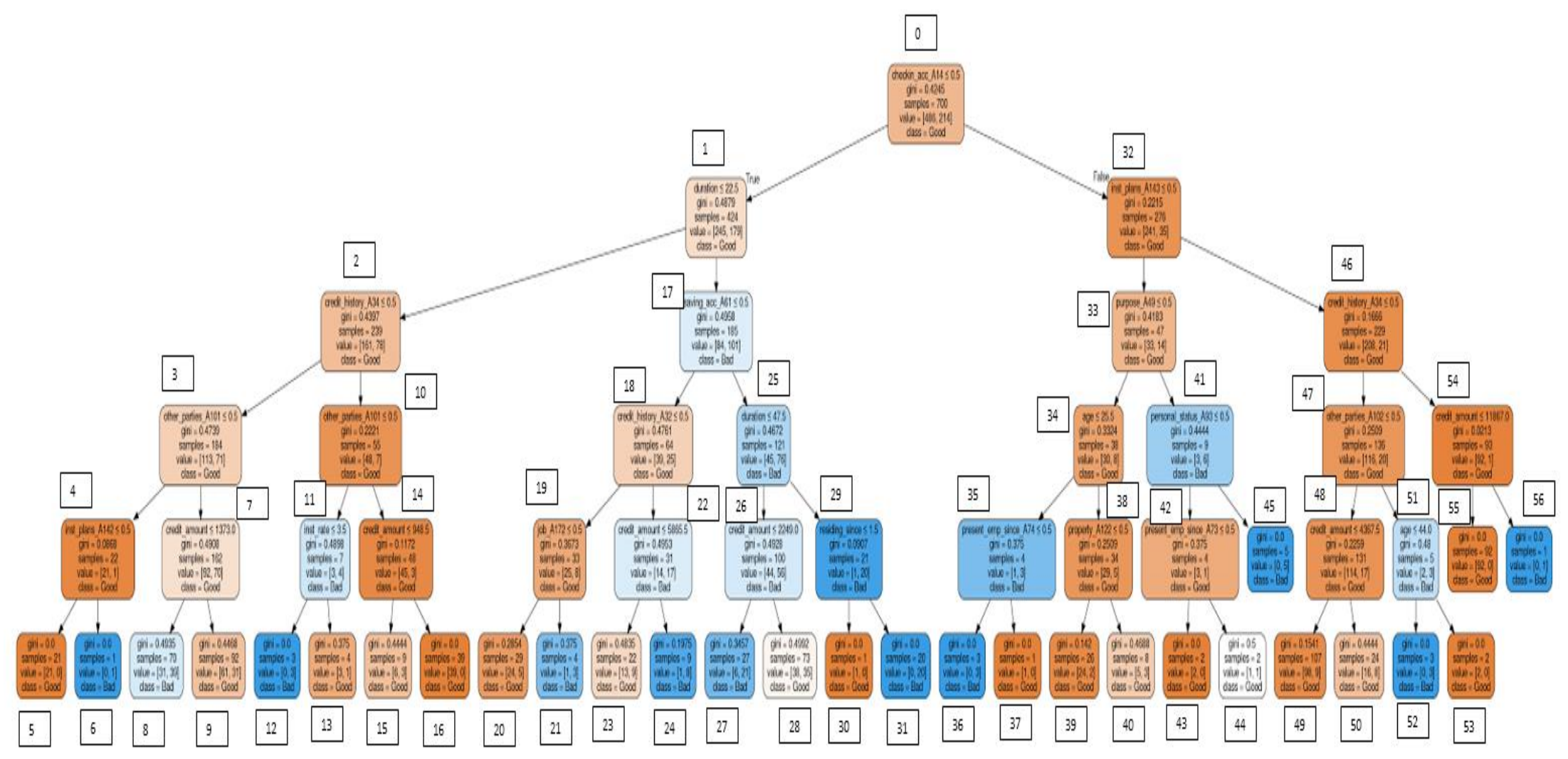

Figure 4. 11 Phase 1's D.T's diagram for German credit dataset with max depth=5 


\subsection{Phase 2}

In this Phase, all the steps such as the ratio of splitting the testing data from Phase 1 (0.7 for training dataset and 0.3 for testing dataset) into two subsets, "Predicted as good" and "Predicted as bad", choosing a new label, learning the decision tree classifier by considering the best accuracy score and sufficient depth to extract meaningful rules, has been repeated for the German credit dataset. The results are shown in the following tables and figures.

\section{Building the D.T. Classifier for the subset of data that was predicted as "bad":}

According to Table 4.47, the best accuracy score will reach by building the decision trees with depth $=1$ but to have a better and deeper view, we choose depth=5 to continue our work.

Table 4. 47 Phase 2's D.T. Classifier, Finding the Optimal Depth and Best Accuracy Score for the subset of data that was predicted as "bad" in Phase 1 for German credit data

\begin{tabular}{|l|l|}
\hline D.T depth & Accuracy score \\
\hline 1 & 0.69 \\
\hline 2 & 0.55 \\
\hline 3 & 0.57 \\
\hline 4 & 0.60 \\
\hline 5 & 0.64 \\
\hline 6 & 0.67 \\
\hline
\end{tabular}

Table 4. 48 Phase 2's D.T. Confusion matrix report for the subset of data that was predicted as "bad" in Phase 1 for German Credit data

\begin{tabular}{|l|l|l|l|}
\hline & accuracy_score & Roc_auc_score & $\begin{array}{l}\text { F1 } \\
\text { score }\end{array}$ \\
\hline $\begin{array}{l}\text { D.T. Classifier with max- } \\
\text { depth=5 }\end{array}$ & 0.5882 & 0.7307 & 0.6315 \\
\hline
\end{tabular}




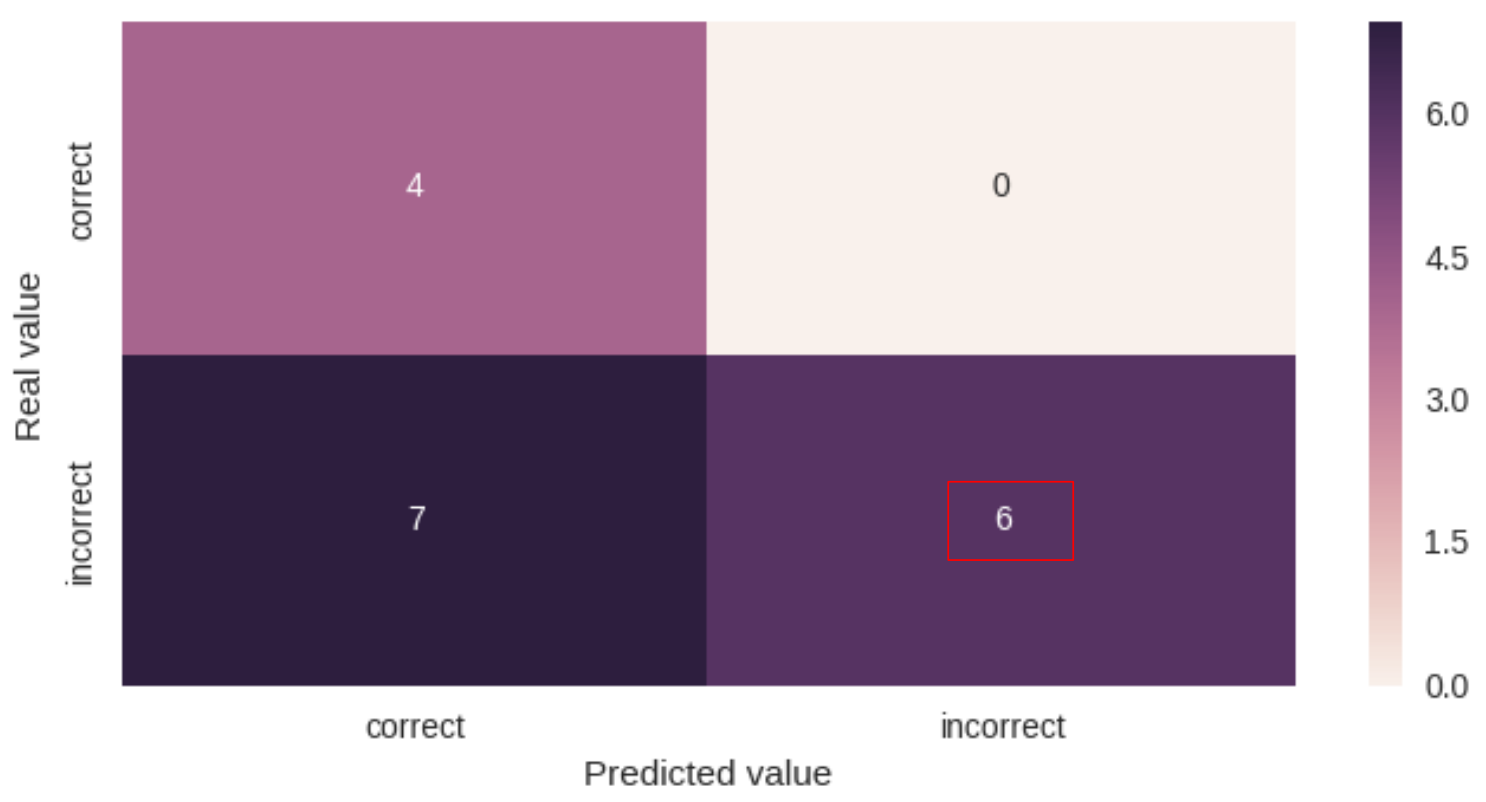

Figure 4. 12 Phase 2's D.T. Confusion matrix report for the subset that was predicted as "bad" in Phase 1 for German credit data

Table 4. 49 Important features for the subset of data that was predicted as "bad" in Phase 1 for German credit data

\begin{tabular}{|l|l|}
\hline features & Degree of importance \\
\hline credit_amount & 0.2721 \\
\hline property_A124 & 0.2211 \\
\hline age & 0.1404 \\
\hline personal_status_A91 & 0.1168 \\
\hline duration & 0.1031 \\
\hline purpose_A40 & 0.0773 \\
\hline saving_acc_A64 & 0.0687 \\
\hline
\end{tabular}

\section{Building the D.T. Classifier for the subset of data that was predicted as "good":}

Table 4.50 shows that the best accuracy score will reach by building the decision trees with depth $=2$ but to have a better and deeper view, we choose depth $=5$ to continue our work. 
Table 4. 50 Phase 2's D.T. Classifier, Finding the Optimal Depth and Best Accuracy Score for the subset of data that was predicted as "good" in Phase 1 for German credit data

\begin{tabular}{|l|l|}
\hline D.T depth & Accuracy score \\
\hline 1 & 0.75 \\
\hline 2 & 0.77 \\
\hline 3 & 0.75 \\
\hline 4 & 0.75 \\
\hline 5 & 0.73 \\
\hline 6 & 0.73 \\
\hline
\end{tabular}

Table 4. 51 Phase 2's D.T. Confusion matrix report for the subset of data that was predicted as "good" in Phase 1 for German Credit data

\begin{tabular}{|l|l|l|l|}
\hline & accuracy_score & Roc_auc_score & $\begin{array}{l}\text { F1 } \\
\text { score }\end{array}$ \\
\hline $\begin{array}{l}\text { D.T. Classifier with max- } \\
\text { depth=5 }\end{array}$ & 0.6351 & 0.6608 & 0.40 \\
\hline
\end{tabular}

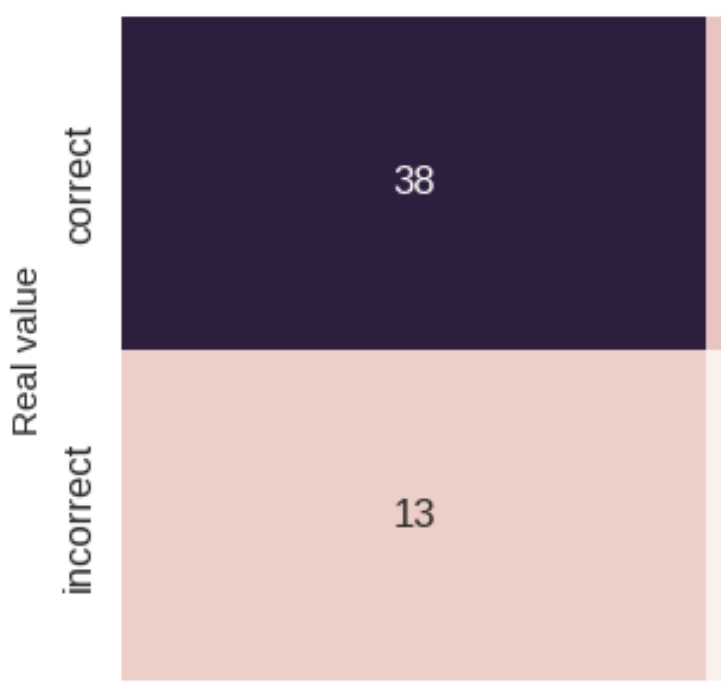

correct

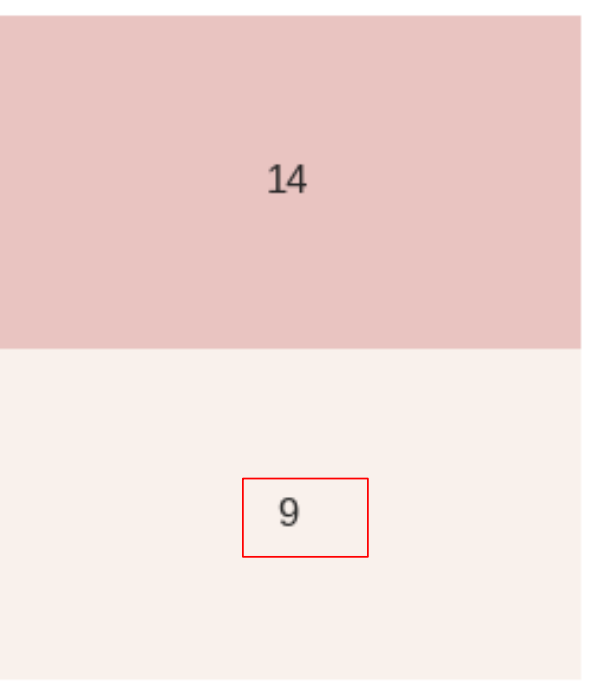

incorrect

Predicted value

Figure 4. 13 Phase 2's D.T. Confusion matrix report for the subset of data that was predicted as "good" in Phase 1 for German Credit data

Table 4. 52 Important features for the subset of data that was predicted as "good" in Phase 1 for German credit data

\begin{tabular}{|l|l|}
\hline features & Degree of importance \\
\hline checkin_acc_A14 & 0.1986 \\
\hline age & 0.1880 \\
\hline
\end{tabular}




\begin{tabular}{|l|l|}
\hline credit_amount & 0.1564 \\
\hline duration & 0.1285 \\
\hline personal_status_A93 & 0.0870 \\
\hline inst_rate & 0.0711 \\
\hline purpose_A43 & 0.0649 \\
\hline
\end{tabular}

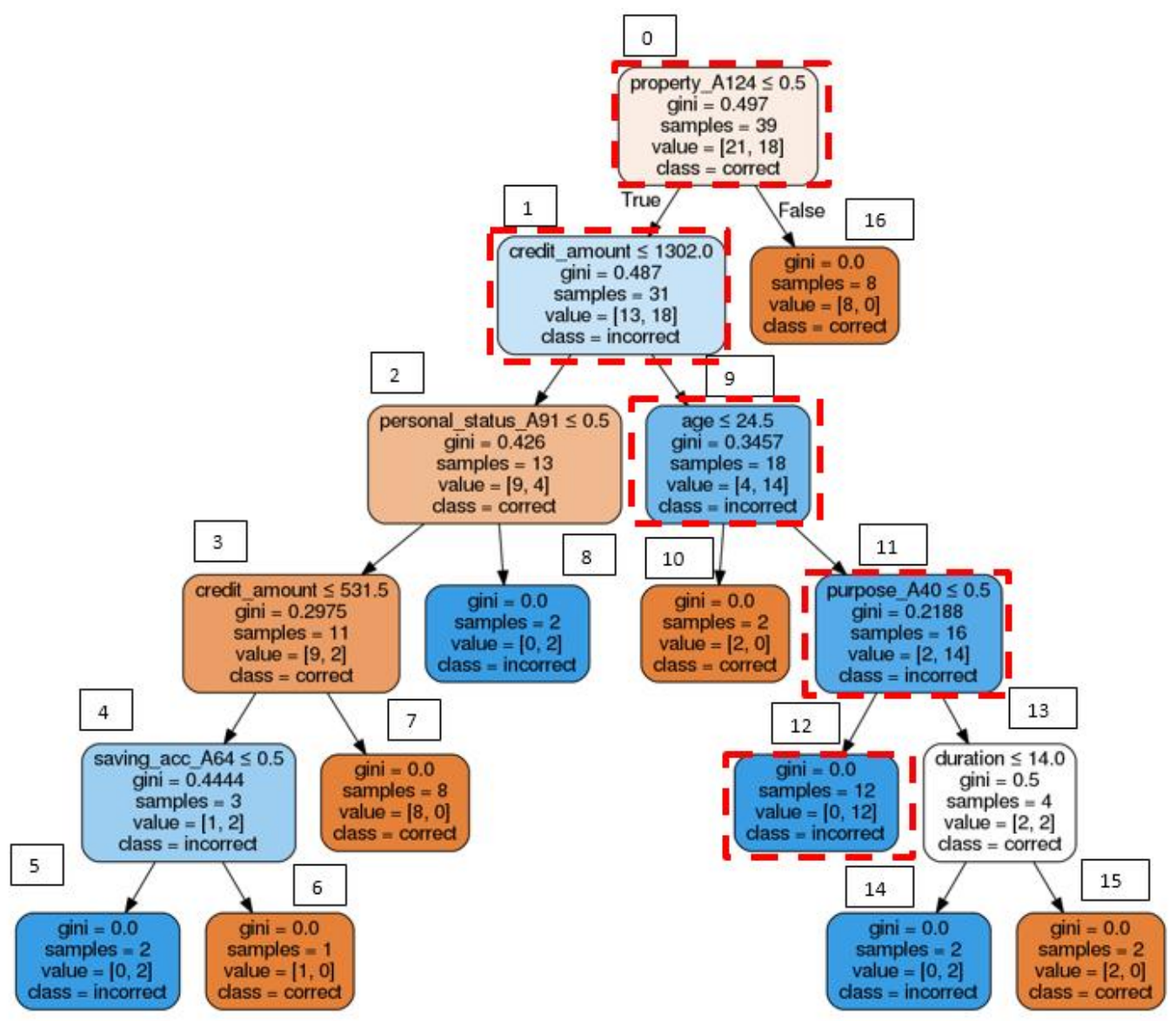

Figure 4. 14 Phase 2's D.T's path for data record H 


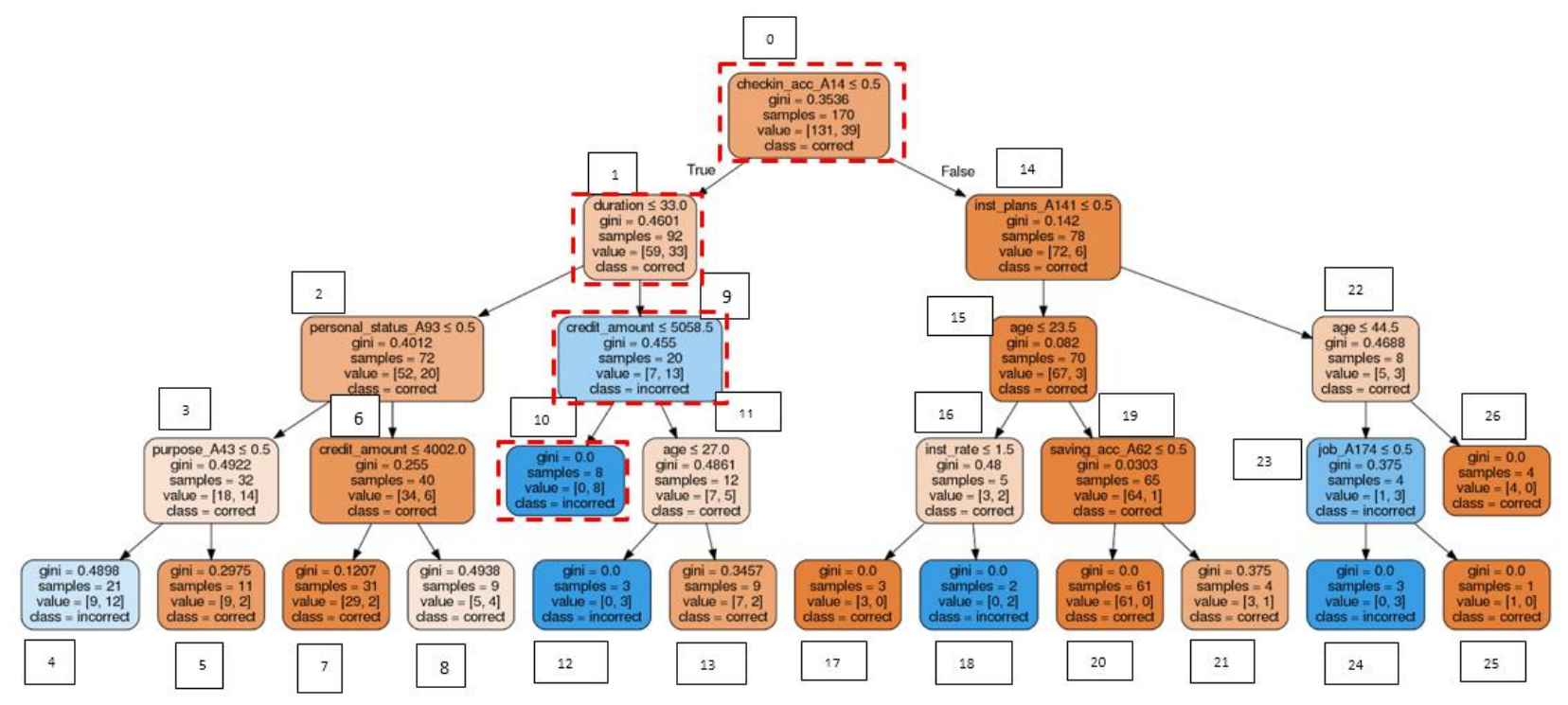

Figure 4. 15 Phase 2's D.T's path for data record D

\subsection{Analyzing the results}

Table 4.53 summarizes the reasons behind the incorrect predictions for data records D and H. For example data record D, with true class "bad", has been classified as "good" loan payer in Phase 1, because he has a checking account and his credit amount is more than 2249. Phase 2 reveals that it took a long time for him to pay off his previous loans. He had a loan to buy a radio or television but he has paid it in 42 months. Also, the amount of his credit should be more to be considered as "good" payer. Therefore, to decide about granting a loan to the applicants that have some credit amounts but which not very high, we need to pay attention to their previous loan's history and how long it took for them to repay the loan completely.

Another misclassified data record is $\mathrm{H}$ with true class "good" but which has been classified as "bad" customer. Phase 1 says that because this person does not have a 
checking account and an installment plan such as bank or store, and has a co-applicant, he is more likely to be a "bad" payer. Although, Phase 2 explains that because he is older than 24 years and has a real estate as his property, the prediction in Phase 2 was incorrect.

Table 4. 53 Summary of the results for German Credit dataset

\begin{tabular}{|c|c|c|c|c|}
\hline $\begin{array}{l}\text { Misclassified } \\
\text { data record }\end{array}$ & $\begin{array}{l}\text { Real } \\
\text { Label in } \\
\text { phase } 1\end{array}$ & $\begin{array}{l}\text { Predicted } \\
\text { Label in } \\
\text { phase } 1\end{array}$ & $\begin{array}{l}\text { Reasons for } \\
\text { prediction in } \\
\text { Phase } 1\end{array}$ & $\begin{array}{l}\text { Reasons which } \\
\text { can explain } \\
\text { incorrect } \\
\text { prediction in } \\
\text { Phase } 1 \\
\end{array}$ \\
\hline $\bar{D}$ & bad & good & $\begin{array}{l}\text { Having a } \\
\text { checking } \\
\text { account } \\
\text { Having } \\
\text { credit } \\
\text { amount } \\
\text { more than } \\
2249 \\
\end{array}$ & $\begin{array}{ll}- & \begin{array}{l}\text { Long pay } \\
\text { off }\end{array} \\
- & \text { Having } \\
\text { credit } \\
\text { amount } \\
\text { less than } \\
\mathbf{5 0 5 8}\end{array}$ \\
\hline $\mathbf{H}$ & good & bad & $\begin{array}{ll}\text { - } & \begin{array}{l}\text { Having no } \\
\text { checking }\end{array} \\
\text { account } \\
\text { - Having no } \\
\text { installmen } \\
\text { t plan } \\
\text { - Having co- } \\
\text { applicant }\end{array}$ & $\begin{array}{ll}- & \text { Having } \\
\text { real estate } \\
\text { as } \\
\text { property } \\
\text { - Is older } \\
\text { than } 24\end{array}$ \\
\hline
\end{tabular}

For more investigations, we look at the neighbors for data records D and H. Table 4.54 shows that there are more records, with the same true class, near data record D that have the same attributes and have been classified incorrectly. Also, based on the information in Table 4.55 we can see that considering the purpose of loan and critical credit history can lead to correct predictions even for those customers who do not have a checking account or any installment plan such as bank or store. Another point is to be more careful about the definition of attribute checking account= A14 (having no checking 
account) because it does not specify whether it talks about having no checking account only at this bank or others.

Table 4. 54 Nearest Neighbors of data record D, in training data set, from true class "bad" and predicted as "good" in Phase 1

\begin{tabular}{|c|c|c|c|c|c|c|c|c|c|c|}
\hline $\begin{array}{c}\text { Index } \\
\text { of } \\
\text { data } \\
\text { recor } \\
\text { ds }\end{array}$ & $\begin{array}{c}\text { Tempor } \\
\text { ary } \\
\text { name }\end{array}$ & $\begin{array}{c}\text { Distan } \\
\text { ce } \\
\text { from } \\
\text { A }\end{array}$ & $\begin{array}{c}\text { Rea } \\
1 \\
\text { Lab } \\
\text { el in } \\
\text { pha } \\
\text { se } 1 \\
\end{array}$ & $\begin{array}{c}\text { Predict } \\
\text { ed } \\
\text { Label } \\
\text { in } \\
\text { phase } 1\end{array}$ & $\begin{array}{c}\text { Probabili } \\
\text { ty to be } \\
\text { in class } \\
\text { nondrink } \\
\text { er, phase } \\
1\end{array}$ & $\begin{array}{l}\text { Probabil } \\
\text { ity to be } \\
\text { in class } \\
\text { drinker, } \\
\text { phase } 1\end{array}$ & $\begin{array}{l}\text { Path from } \\
\text { phase } 1\end{array}$ & $\begin{array}{c}\text { Real } \\
\text { Label } \\
\text { in } \\
\text { phase } \\
2\end{array}$ & $\begin{array}{c}\text { Predict } \\
\text { ed } \\
\text { Label } \\
\text { in } \\
\text { phase } 2\end{array}$ & $\begin{array}{c}\text { Path } \\
\text { in } \\
\text { phase } \\
2\end{array}$ \\
\hline 639 & D & 0 & bad & good & 0.53 & 0.47 & $\begin{array}{c}0,1,17,25,2 \\
6,28\end{array}$ & $\begin{array}{c}\text { incorr } \\
\text { ect }\end{array}$ & $\begin{array}{c}\text { incorre } \\
\text { ct }\end{array}$ & $\begin{array}{c}0,1,9 \\
10\end{array}$ \\
\hline 35 & D'1 & 85 & bad & good & 0.52 & 0.47 & $\begin{array}{c}0,1,17,25,2 \\
6,28 \\
\end{array}$ & $\begin{array}{c}\text { incorr } \\
\text { ect }\end{array}$ & $\begin{array}{c}\text { incorre } \\
\text { ct }\end{array}$ & $\begin{array}{c}0,1,9 \\
10\end{array}$ \\
\hline 181 & D'2 & 121 & bad & good & 0.52 & 0.47 & $\begin{array}{c}0,1,17,25,2 \\
6,28\end{array}$ & $\begin{array}{c}\text { incorr } \\
\text { ect }\end{array}$ & $\begin{array}{c}\text { incorre } \\
\text { ct }\end{array}$ & $\begin{array}{c}0,1,9 \\
10\end{array}$ \\
\hline 320 & D'3 & 376 & bad & good & 0.52 & 0.47 & $\begin{array}{c}0,1,17,25,2 \\
6,28 \\
\end{array}$ & $\begin{array}{c}\text { incorr } \\
\text { ect }\end{array}$ & $\begin{array}{c}\text { incorre } \\
\text { ct }\end{array}$ & $\begin{array}{c}0,1,2, \\
3,4 \\
\end{array}$ \\
\hline
\end{tabular}

Table 4. 55 Nearest Neighbors of data record D, in training data set, from true class "good" and predicted as "good" in Phase 1

\begin{tabular}{|c|c|c|c|c|c|c|c|c|c|c|}
\hline $\begin{array}{c}\text { Index } \\
\text { of } \\
\text { data } \\
\text { recor } \\
\text { ds }\end{array}$ & $\begin{array}{c}\text { Tempo } \\
\text { rary } \\
\text { name }\end{array}$ & $\begin{array}{l}\text { Distance } \\
\text { from A }\end{array}$ & $\begin{array}{c}\text { Real } \\
\text { Label in } \\
\text { Phase } 1\end{array}$ & $\begin{array}{c}\text { Predicte } \\
\text { d Label } \\
\text { in Phase } \\
1\end{array}$ & $\begin{array}{c}\text { Probabili } \\
\text { ty to be } \\
\text { in class } \\
\text { nondrink } \\
\text { er, } \\
\text { (Phase 1) }\end{array}$ & $\begin{array}{c}\text { Probabil } \\
\text { ity to be } \\
\text { in class } \\
\text { drinker, } \\
\text { (Phase } \\
\text { 1) }\end{array}$ & $\begin{array}{c}\text { D.T } \\
\text { Path } \\
\text { fro } \\
\text { m } \\
\text { Pha } \\
\text { se 1 }\end{array}$ & $\begin{array}{c}\text { Real } \\
\text { Label } \\
\text { in } \\
\text { Phase } \\
2\end{array}$ & $\begin{array}{c}\text { Predict } \\
\text { ed } \\
\text { Label } \\
\text { in } \\
\text { Phase 2 }\end{array}$ & $\begin{array}{c}\text { D.T } \\
\text { Path } \\
\text { in } \\
\text { Pha } \\
\text { se } 2\end{array}$ \\
\hline 639 & D & 0 & bad & good & 0.53 & 0.47 & $\begin{array}{r}0,1,1 \\
7,25, \\
26,2\end{array}$ & $\begin{array}{c}\text { incorre } \\
\text { ct }\end{array}$ & $\begin{array}{c}\text { incorre } \\
\text { ct }\end{array}$ & $\begin{array}{r}\mathbf{0 , 1 , 9} \\
, \mathbf{1 0}\end{array}$ \\
\hline 910 & D1 & 84 & good & good & 0.67 & 0.33 & $\begin{array}{c}0,32, \\
46,4 \\
7,48, \\
50\end{array}$ & correct & correct & $\begin{array}{l}0,14, \\
15,1 \\
9,20\end{array}$ \\
\hline 459 & D2 & 225 & good & good & 0.67 & 0.33 & $\begin{array}{c}0,32, \\
46,4 \\
7,48, \\
50\end{array}$ & correct & correct & $\begin{array}{l}0,14, \\
15,1 \\
9,20\end{array}$ \\
\hline 306 & D3 & 441 & good & good & 1.00 & 0.00 & $\begin{array}{c}0,32, \\
33,3 \\
4,35, \\
37\end{array}$ & correct & correct & $\begin{array}{l}0,14, \\
15,1 \\
9,20\end{array}$ \\
\hline
\end{tabular}




\begin{tabular}{|c|c|c|c|}
\hline $\begin{array}{l}\text { Record } \\
\text { names }\end{array}$ & Phase/predicted class & Path & Rules \\
\hline $\begin{array}{c}\text { D, D'1, } \\
\text { D'2, D'3 }\end{array}$ & $1 /$ predicted as good & $0,1,17,25,26,28$ & $\begin{array}{l}\text { if ( checkin_acc_A14 <= } 0.5 \text { ) } \\
\text { if }(\text { duration }>22.5) \\
\text { if }(\text { saving_acc_A61 > 0.5) } \\
\text { if }(\text { duration }<=47.5) \\
\text { if }(\text { credit_amount }>2249.0 \text { ) } \\
\text { return good }\end{array}$ \\
\hline D1, D2 & & $0,32,46,47,48,50$ & $\begin{array}{l}\text { if }(\text { checkin_acc_A14 }>0.5) \\
\text { if }(\text { inst_plans_A143 }>0.5) \\
\text { if }(\text { credit_history_A34 < }<0.5) \\
\text { if }(\text { other_parties_A102 }<=0.5) \\
\text { if }(\text { credit_amount }>4367.5) \\
\text { return good }\end{array}$ \\
\hline D3 & & $\mathbf{0 , 3 2 , 3 3 , 3 4 , 3 5 , 3 7}$ & $\begin{array}{l}\text { if ( checkin_acc_A14 }>0.5 \text { ) } \\
\text { if ( inst_plans_A143 }<=0.5 \text { ) } \\
\text { if ( purpose_A49 }<=0.5 \text { ) } \\
\text { if }(\text { age }<=25.5 \text { ) } \\
\text { if(present_emp_since_A74>0.5) } \\
\text { return good }\end{array}$ \\
\hline $\begin{array}{l}\text { D, D'1, } \\
\text { D'2 }\end{array}$ & $2 /$ predicted as good & $0,1,9,10$ & $\begin{array}{l}\text { if }(\text { checkin_acc_A14 }<=0.5) \\
\text { if }(\text { duration }>33) \\
\text { if }(\text { credit_amount }<=5058.5) \\
\text { return incorrect }\end{array}$ \\
\hline D’3 & & $0, \mathbf{1 , 2 , 3 , 4}$ & $\begin{array}{l}\text { if }(\text { checkin_acc_A14 }<=0.5 \text { ) } \\
\text { if }(\text { duration }<=33.0) \\
\text { if(personal_status_A93<=0.5) } \\
\text { if }(\text { purpose_A43 }<=0.5) \\
\text { return incorrect }\end{array}$ \\
\hline $\begin{array}{c}\text { D1, D2, } \\
\text { D3 }\end{array}$ & & $0,14,15,19,20$ & $\begin{array}{l}\text { if }(\text { checkin_acc_A14 }>0.5) \\
\text { if }(\text { inst_plans_A141<=0.5) } \\
\text { if }(\text { age }>23.5) \\
\text { if }(\text { saving_acc_A62 <= } 0.5) \\
\text { return correct }\end{array}$ \\
\hline
\end{tabular}

Table 4. 56 Rules and Paths for Tables 4.54 and 4.55 
The information for data record $\mathrm{H}$ and its neighbors has been shown in Tables 4.57 and 4.58. Looking at its neighbors with the same true class, the data record H'1 has same characteristics and followed the same path. Another interesting point is about data records $\mathrm{H} 3$ and H'2. Despite their different true classes, they both has been predicted to the same label; H3 correctly and H'2 incorrectly. It explains because the data record H'2 has the same attributes as real "bad" customers the decision tree classifier in Phase 1, has predicted it incorrectly to the opposite class.

Table 4.57 Nearest Neighbors of data record H, in training data set, from true class "bad" and predicted as "bad" in Phase 1

\begin{tabular}{|c|c|c|c|c|c|c|c|c|c|c|}
\hline $\begin{array}{c}\text { Inde } \\
x \text { of } \\
\text { data } \\
\text { recor } \\
\text { ds }\end{array}$ & $\begin{array}{c}\text { Tempor } \\
\text { ary } \\
\text { name }\end{array}$ & $\begin{array}{c}\text { Dista } \\
\text { nce } \\
\text { from } \\
\text { A }\end{array}$ & $\begin{array}{c}\text { Rea } \\
\text { l } \\
\text { Lab } \\
\text { el } \\
\text { in } \\
\text { Pha } \\
\text { se } 1\end{array}$ & $\begin{array}{c}\text { Predic } \\
\text { ted } \\
\text { Label } \\
\text { in } \\
\text { Phase } \\
1\end{array}$ & $\begin{array}{c}\text { Probabi } \\
\text { lity to } \\
\text { be in } \\
\text { class } \\
\text { nondrin } \\
\text { ker, } \\
\text { (Phase } \\
\text { 1) }\end{array}$ & $\begin{array}{c}\text { Probabi } \\
\text { lity to } \\
\text { be in } \\
\text { class } \\
\text { drinker } \\
\text {, (Phase } \\
\text { 1) }\end{array}$ & $\begin{array}{l}\text { D.T Path } \\
\text { from phase } \\
\quad 1\end{array}$ & $\begin{array}{c}\text { Real } \\
\text { Label } \\
\text { in } \\
\text { Phase } \\
2\end{array}$ & $\begin{array}{c}\text { Predic } \\
\text { ted } \\
\text { Label } \\
\text { in } \\
\text { Phase } \\
2\end{array}$ & $\begin{array}{c}\text { D.T Path } \\
\text { in Phase } \\
\quad 2\end{array}$ \\
\hline 916 & $\mathbf{H}$ & 0 & $\begin{array}{c}\text { goo } \\
\text { d }\end{array}$ & bad & 0.00 & 1.00 & $\begin{array}{c}\mathbf{0 , 3 2 , 4 6 , 4 7}, \\
51,52\end{array}$ & $\begin{array}{c}\text { incorr } \\
\text { ect }\end{array}$ & $\begin{array}{c}\text { incorr } \\
\text { ect }\end{array}$ & $\begin{array}{c}0,1,9,11,1 \\
2\end{array}$ \\
\hline 900 & H1 & 223 & bad & bad & 0.00 & 1.00 & $\begin{array}{c}0,1,2,10,11 \\
12\end{array}$ & $\begin{array}{c}\text { correc } \\
t\end{array}$ & $\begin{array}{c}\text { correc } \\
t\end{array}$ & $\begin{array}{c}0,1,9,11,1 \\
3,15\end{array}$ \\
\hline 951 & H2 & 703 & bad & bad & 0.23 & 0.77 & $\begin{array}{c}0,1,17,25,2 \\
6,27 \\
\end{array}$ & $\begin{array}{c}\text { correc } \\
t\end{array}$ & $\begin{array}{c}\text { correc } \\
t\end{array}$ & $\mathbf{0 , 1 , 9 , 1 0}$ \\
\hline 191 & H3 & 996 & bad & bad & 0.25 & 0.75 & $\begin{array}{c}0,1,17,18,1 \\
9,21\end{array}$ & $\begin{array}{c}\text { correc } \\
t\end{array}$ & $\begin{array}{c}\text { correc } \\
t\end{array}$ & 0,16 \\
\hline
\end{tabular}

Table 4. 58 Nearest Neighbors of data record H, in training data set, from true class "good" and predicted as "bad" in Phase 1

\begin{tabular}{|c|c|c|c|c|c|c|c|c|c|c|}
\hline $\begin{array}{l}\text { Inde } \\
x \text { of } \\
\text { data } \\
\text { recor } \\
\text { ds }\end{array}$ & $\begin{array}{l}\text { Tempor } \\
\text { ary } \\
\text { name }\end{array}$ & $\begin{array}{l}\text { Dista } \\
\text { nce } \\
\text { from } \\
\text { A }\end{array}$ & $\begin{array}{l}\text { Rea } \\
\text { l } \\
\text { Lab } \\
\text { el in } \\
\text { Pha } \\
\text { se } 1\end{array}$ & $\begin{array}{l}\text { Predic } \\
\text { ted } \\
\text { Label } \\
\text { in } \\
\text { Phase } \\
1\end{array}$ & $\begin{array}{l}\text { Probabil } \\
\text { ity to be } \\
\text { in class } \\
\text { nondrin } \\
\text { ker, } \\
\text { (Phase } \\
\text { 1) }\end{array}$ & $\begin{array}{l}\text { Probabi } \\
\text { lity to } \\
\text { be in } \\
\text { class } \\
\text { drinker, } \\
\text { (Phase } \\
\text { 1) }\end{array}$ & $\begin{array}{l}\text { D.T Path } \\
\text { from Phase } \\
1\end{array}$ & $\begin{array}{l}\text { Real } \\
\text { Label } \\
\text { in } \\
\text { Phase } \\
2\end{array}$ & $\begin{array}{l}\text { Predic } \\
\text { ted } \\
\text { Label } \\
\text { in } \\
\text { Phase } \\
2\end{array}$ & $\begin{array}{l}\text { D.T } \\
\text { Path in } \\
\text { Phase 2 }\end{array}$ \\
\hline 916 & H & 0 & $\begin{array}{l}\text { goo } \\
\text { d }\end{array}$ & bad & 0.00 & 1.00 & $\begin{array}{l}0,32,46,47, \\
51,52\end{array}$ & $\begin{array}{l}\text { incorr } \\
\text { ect }\end{array}$ & $\begin{array}{l}\text { incorr } \\
\text { ect }\end{array}$ & $\begin{array}{l}0,1,9,11 \\
, 12 \\
\end{array}$ \\
\hline 688 & H'1 & 95 & $\begin{array}{l}\text { goo } \\
\text { d }\end{array}$ & bad & 0.00 & 1.00 & $\begin{array}{l}0,32,46,47, \\
51,52\end{array}$ & $\begin{array}{l}\text { incorr } \\
\text { ect }\end{array}$ & $\begin{array}{l}\text { incorr } \\
\text { ect }\end{array}$ & $\begin{array}{l}0,1,9,11 \\
, 12 \\
\end{array}$ \\
\hline 50 & H'2 & 515 & $\begin{array}{l}\text { goo } \\
\text { d }\end{array}$ & bad & 0.25 & 0.75 & $\begin{array}{l}0,1,17,18,1 \\
9,21\end{array}$ & $\begin{array}{l}\text { incorr } \\
\text { ect }\end{array}$ & $\begin{array}{l}\text { incorr } \\
\text { ect }\end{array}$ & $\begin{array}{l}0,1,9,11 \\
, 12\end{array}$ \\
\hline
\end{tabular}




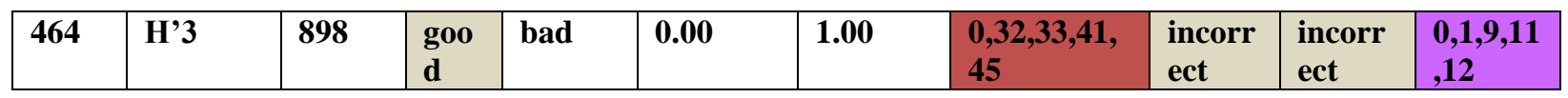

Table 4. 59 Rules and Paths for Tables 4.57 and 4.58

\begin{tabular}{|c|c|c|c|}
\hline Records name & Phase/class & Path & Rules \\
\hline H, H'1 & 1/predicted as bad & $0,32,46,47,51,52$ & $\begin{array}{l}\text { if ( checkin_acc_A14 >0.5) } \\
\text { if ( inst_plans_A143>0.5) } \\
\text { if }(\text { credit_history_A34 }<=0.5 \text { ) } \\
\text { if }(\text { other_parties_A102 >0.5) } \\
\text { if }(\text { age }<=44) \\
\text { return bad }\end{array}$ \\
\hline H'2,H3 & & $0,1,17,18,19,21$ & $\begin{array}{l}\text { if }(\text { checkin_acc_A14<=0.5) } \\
\text { if }(\text { duration }>22.5) \\
\text { if(saving_acc_A61<=0.5) } \\
\text { if }(\text { credit_history_A32<=0.5) } \\
\text { if }(\text { job_A172 >0.5 ) } \\
\text { return bad }\end{array}$ \\
\hline H'3 & & $0,32,33,41,45$ & $\begin{array}{l}\text { if }(\text { checkin_acc_A14 }>0.5) \\
\text { if }(\text { inst_plans_A143<=0.5) } \\
\text { if }(\text { purpose_A49 }>0.5 \text { ) } \\
\text { if }(\text { personal_status_A93 }>0.5 \text { ) } \\
\text { return bad }\end{array}$ \\
\hline H1 & & $0,1,2,10,11,12$ & $\begin{array}{l}\text { if ( checkin_acc_A14<=0.5) } \\
\text { if ( duration }<=22.5 \text { ) } \\
\text { if(credit_history_A34>0.5) } \\
\text { if(other_parties_A101<=0.5) } \\
\text { if (inst_rate }<=3.5 \text { ) } \\
\text { return bad }\end{array}$ \\
\hline H2 & & $0,1,17,25,26,27$ & $\begin{array}{l}\text { if ( checkin_acc_A14 <= } 0.5 \text { ) } \\
\text { if }(\text { duration }>22.5) \\
\text { if }(\text { saving_acc_A61 >0.5) } \\
\text { if }(\text { duration }<=47.5) \\
\text { if }(\text { credit_amount }<=2249.0) \\
\text { return bad }\end{array}$ \\
\hline $\begin{array}{l}\text { H, H'1, H'2, } \\
\text { H’3 }\end{array}$ & 2/predicted as bad & $0,1,9,11,12$ & $\begin{array}{l}\text { if ( property_A124 <=0.5) } \\
\text { if }(\text { credit_amount }>1302.0) \\
\text { if }(\text { age }>24.5) \\
\text { if }(\text { purpose_A40 < }<=0.5) \\
\text { return incorrect }\end{array}$ \\
\hline H1 & & $0,1,9,11,13,15$ & $\begin{array}{l}\text { if }(\text { property_A124 <= } 0.5) \\
\text { if }(\text { credit_amount }>1302.0) \\
\text { if }(\text { age }>24.5) \\
\text { if }(\text { purpose_A40 }>0.5) \\
\text { if }(\text { duration }>14) \\
\text { return correct }\end{array}$ \\
\hline H2 & & $0,1,9,10$ & $\begin{array}{l}\text { if ( property_A124 }<=0.5 \text { ) } \\
\text { if ( credit_amount }>1302.0 \text { ) } \\
\text { if }(\text { age }<=24.5 \text { ) } \\
\text { return correct }\end{array}$ \\
\hline $\mathbf{H 3}$ & & 0,16 & $\begin{array}{l}\text { if }(\text { property_A124 > } 0.5) \\
\text { return correct }\end{array}$ \\
\hline
\end{tabular}




\section{CHAPTER 5}

\section{CONCLUSION}

Interpretable models provide brief and convincing prediction results and play an important role in communicating with experts. They also help make the complex machine learning algorithms more trustable for the users. Many classification models have been evaluated for their comprehensibility and interpretability such as Decision Tables, Naïve Bayes, and Nearest Neighbors but decision trees have special characteristics that make them more popular interpretable and understandable models. In this thesis, we tried to use the interpretability of decision tree models to investigate the common rules that can lead to wrong predictions. These rules exemplify stereotypes that can be learned by classifiers.

Our methodology to investigate some reasons behind the incorrect predictions, was conducted in two Phases. Phase 1 produced the initial prediction results and the important features, while Phase 2 revealed which attributes are more responsible for incorrect predictions. We used the decision tree classifier to find incorrectly predicted data records and to analyze the features by following the tree paths for data that have been classified incorrectly. Then we analyzed the k-nearest neighbors of a misclassified sample, to find which attributes are the same among incorrectly predicted records and their neighbors. 
In the experimental part, in Chapter 4, we applied the presented methodology to two datasets from UCI machine learning repository, the Student Alcohol Consumption and the German credit dataset, to explore the predictive rules after applying the decision tree classifier and then analyzing the neighborhood of misclassifies samples. In the first case study with the Student Alcohol Consumption dataset, we explored which attributes are more important in predicting some students incorrectly as "drinker" or "nondrinker", and hence, finding some stereotypes that can lead to wrong predictions. These incorrect stereotypical predictions could be corrected in the second phase; in our example, by considering the parents' education for students who have been incorrectly predicted as "drinker" and the time they spent getting home from school for students who have been predicted as "nondrinker". Also, we found that removing or changing the attributes does not affect our methodology in finding and explaining the possible flaws in a data set. In the second case study, after applying our methodology we found that to decide whether to a loan to the applicants that have some credit amounts but that are not very high, we need to pay attention to their previous loan history and how long it took for them to repay the loan completely. Also, if a customer does not have a checking account and an installment plan such as bank or store, and has a co-applicant, which are the typical attributes for a "bad" payer, we should look at her/his age and properties.

For future work, we will apply our methodology to bigger datasets and with different interpretable algorithms to further incorrect algorithmic decisions. Also, we plan to extend our work to detect potential automatic discriminating decisions against certain groups such as minorities which can happen in data analysis. 


\section{REFERENCES}

1. Baesens, B., Developing Intelligence System For Credit Scoring Using Machine Learning Techniques.

2. Bibal, A. and B. Frénay. Interpretability of machine learning models and representations: an introduction.

3. Ribeiro, M.T., S. Singh, and C. Guestrin. Why Should I Trust You?: Explaining the Predictions of Any Classifier. in Proceedings of the 22nd ACM SIGKDD International Conference on Knowledge Discovery and Data Mining. 2016. ACM.

4. Japkowicz, N. and M. Shah, Evaluating learning algorithms: a classification perspective. 2011: Cambridge University Press.

5. $\quad$ Rokach, L., Pattern classification using ensemble methods. Vol. 75. 2010: World Scientific.

6. Ding, L. and B.-h. Sheng. Error analysis of classifiers in machine learning. in Image and Signal Processing (CISP), 2010 3rd International Congress on. 2010. IEEE.

7. Cristianini, N. and J. Shawe-Taylor, An introduction to support vector machines and other kernel-based learning methods. 2000: Cambridge university press.

8. Ferri, C., J. Hernández-Orallo, and M.J. Ramírez-Quintana. From ensemble methods to comprehensible models. in International Conference on Discovery Science. 2002. Springer.

9. Freitas, A.A., D.C. Wieser, and R. Apweiler, On the importance of comprehensible classification models for protein function prediction. IEEE/ACM Transactions on Computational Biology and Bioinformatics, 2010. 7(1): p. 172182.

10. Fürnkranz, J., Separate-and-conquer rule learning. Artificial Intelligence Review, 1999. 13(1): p. 3-54.

11. Quinlan, J.R. Some elements of machine learning. in International Conference on Inductive Logic Programming. 1999. Springer.

12. Carmichael, L., S. Stalla-Bourdillon, and S. Staab, Data Mining and Automated Discrimination: A Mixed Legal/Technical Perspective. IEEE Intelligent Systems, 2016. 31(6): p. 51-55.

13. Hajian, S., J. Domingo-Ferrer, and A. Martinez-Balleste. Discrimination prevention in data mining for intrusion and crime detection. in Computational Intelligence in Cyber Security (CICS), 2011 IEEE Symposium on. 2011. IEEE.

14. Datta, A., S. Sen, and Y. Zick. Algorithmic transparency via quantitative input influence: Theory and experiments with learning systems. in Security and Privacy (SP), 2016 IEEE Symposium on. 2016. IEEE. 
15. Boyd, D. Be Careful What You Code For. 2016; Available from: https://points.datasociety.net/be-careful-what-you-code-for-c8e9f3f6f55e.

16. Caruana, R., et al. Intelligible models for healthcare: Predicting pneumonia risk and hospital 30-day readmission. in Proceedings of the 21th ACM SIGKDD International Conference on Knowledge Discovery and Data Mining. 2015. ACM.

17. Allahyari, H. and N. Lavesson. User-oriented assessment of classification model understandability. in 11th scandinavian conference on Artificial intelligence. 2011. IOS Press.

18. Vellido, A., J.D. Martín-Guerrero, and P.J. Lisboa. Making machine learning models interpretable. in ESANN. 2012. Citeseer.

19. Giraud-Carrier, C. Beyond predictive accuracy: what in Proceedings of the ECML-98 Workshop on Upgrading Learning to Meta-Level: Model Selection and Data Transformation. 1998.

20. Pazzani, M.J., Knowledge discovery from data? IEEE intelligent systems and their applications, 2000. 15(2): p. 10-12.

21. Rüping, S., Learning interpretable models. 2006, Universität Dortmund.

22. Nakhaeizadeh, G. and A. Schnabl. Development of Multi-Criteria Metrics for Evaluation of Data Mining Algorithms. in KDD. 1997.

23. Andrzejak, A., F. Langner, and S. Zabala. Interpretable models from distributed data via merging of decision trees. in Computational Intelligence and Data Mining (CIDM), 2013 IEEE Symposium on. 2013. IEEE.

24. Askira-Gelman, I. Knowledge discovery: comprehensibility of the results. in System Sciences, 1998., Proceedings of the Thirty-First Hawaii International Conference on. 1998. IEEE.

25. Feng, C. and D. Michie, Machine learning of rules and trees. Machine Learning, Neural and Statistical Classification. Ellis Horwood, Hemel Hempstead, 1994.

26. Ustun, B. and C. Rudin, Methods and models for interpretable linear classification. arXiv preprint arXiv:1405.4047, 2014.

27. Mitchell, T.M., Machine learning. WCB. 1997, McGraw-Hill Boston, MA:

28. Quinlan, J.R., C4. 5: Programming for machine learning. Morgan Kauffmann, 1993: p. 38.

29. Breiman, L., et al., Classification and regression trees. 1984: CRC press.

30. Maimon, O. and L. Rokach, Data mining and knowledge discovery handbook. Vol. 2. 2005: Springer.

31. Kotsiantis, S.B., I. Zaharakis, and P. Pintelas, Supervised machine learning: A review of classification techniques. 2007.

32. Huysmans, J., et al., An empirical evaluation of the comprehensibility of decision table, tree and rule based predictive models, in Decision Support Systems. 2011. p. 141-154.

33. Friedman, J., T. Hastie, and R. Tibshirani, The elements of statistical learning. Vol. 1. 2001: Springer series in statistics Springer, Berlin.

34. Baehrens, D., et al., How to explain individual classification decisions. Journal of Machine Learning Research, 2010. 11(Jun): p. 1803-1831.

35. Alex Smola , S.V.N.V., Introduction to Machine Learning. 2008. 
36. Baesens, B., et al., Building intelligent credit scoring systems using decision tables, in Enterprise Information Systems V. 2004, Springer. p. 131-137.

37. Bellazzi, R. and B. Zupan, Predictive data mining in clinical medicine: current issues and guidelines. International journal of medical informatics, 2008. 77(2): p. 81-97.

38. Fox, J. and S. Das, Safe and sound: artificial intelligence in hazardous applications. 2000: MIT press.

39. Elazmeh, W., Matwin, W., O’Sullivan, D., Michalowski, W., and W. and Farion, Insights from predicting pediatric asthma exacerbations from retrospective clinical data. Evaluation

Methods for Machine Learning II, 2007.

40. Johansson, U. and L. Niklasson. Evolving decision trees using oracle guides. in Computational Intelligence and Data Mining, 2009. CIDM'09. IEEE Symposium on. 2009. IEEE.

41. Lavrač, N., Selected techniques for data mining in medicine. Artificial intelligence in medicine, 1999. 16(1): p. 3-23.

42. Pappa, G.L., A.J. Baines, and A.A. Freitas, Predicting post-synaptic activity in proteins with data mining. Bioinformatics, 2005. 21(suppl 2): p. ii19-ii25.

43. Dhar, V., D. Chou, and F. Provost, Discovering Interesting Patterns for Investment Decision Making with GLOWER - A Genetic Learner Overlaid with Entropy Reduction. Data Mining and Knowledge Discovery, 2000. 4(4): p. 251280.

44. Holehouse, A.S. Machine Learning System Design by University of Stanford. [cited 2011; Available from: http://www.holehouse.org/mlclass/11_Machine_Learning_System_Design.html.

45. Banerjee, B. and J.K. Dutta. Efficient learning from explanation of prediction errors in streaming data. in Big Data, 2013 IEEE International Conference on. 2013. IEEE.

46. Zhang, J., L. Gruenwald, and M. Gertz, VDM-RS: A visual data mining system for exploring and classifying remotely sensed images. Computers \& Geosciences, 2009. 35(9): p. 1827-1836.

47. Ruggieri, S., D. Pedreschi, and F. Turini, Data mining for discrimination discovery. ACM Transactions on Knowledge Discovery from Data (TKDD), 2010. 4(2): p. 9.

48. Lowry, S., Student selection. BMJ: British Medical Journal, 1992. 305(6865): p. 1352.

49. NehaVinod, C. and U.M. Patil. Antidiscrimination using direct and indirect methods in data mining. in Colossal Data Analysis and Networking (CDAN), Symposium on. 2016. IEEE.

50. Hajian, S., et al., Discrimination-and privacy-aware patterns. Data Mining and Knowledge Discovery, 2015. 29(6): p. 1733-1782.

51. Bickel, P.J., E.A. Hammel, and J.W. O'Connell, Sex bias in graduate admissions: Data from Berkeley. Science, 1975. 187(4175): p. 398-404.

52. Hajian, S. and J. Domingo-Ferrer, A methodology for direct and indirect discrimination prevention in data mining. IEEE Transactions on knowledge and data engineering, 2013. 25(7): p. 1445-1459. 
53. Phil Asaro, E.E., Erik Rowlett, Jen Trokey. A TOOL FOR ASSIGNING INTEREST RATE ON THE BASIS OF RISK FROM THE GERMAN CREDIT DATASET. Available from: http://meru.cs.missouri.edu/courses/cecs401_data_mining/projects/group3/Germa nCreditWeb.htm.

54. Lichman, M. UCI Machine Learning Repository. 2013; Available from: http://archive.ics.uci.edu/ml.

55. Pagnotta, F. and H. Amran, Using data mining to predict secondary school student alcohol consumption. Department of Computer Science, University of Camerino. 


\section{CURRICULUM VITAE}

NAME: $\quad$ Aneseh Alvanpour

ADDRESS: Department of Computer Engineering and Computer Science

University of Louisville

Louisville, KY 40292

\section{EDUCATION:}

M.S. Computer Science

University of Louisville, KY

2017

B.S. Information and Communication Technology Engineering (ICT)

Sadra University, Tehran, Iran

2010

AWARDS:

Graduate Dean's Citation Award, University of Louisville, KY

2017

International Student Tuition Support Scholarship

University of Louisville, KY

2015,2016

Non-Resident Differential Tuition Award

University of Louisville, KY

2015

PROFESSIONAL EXPERIENCE

Graduate Teaching Assistant

CECS Department, University of Louisville, KY

2015-2016 
Graduate Student Assistant

REACH (Resources for Academic Achievement) Computer Center, University of Louisville, KY

2016-2017 